Illinois State University

ISU ReD: Research and eData

Theses and Dissertations

9-7-2016

\title{
Exploring Student Interaction and Reflection Through the Use of Digital Backchannel Discussions
}

Heather J. Donnelly

Illinois State University, hjdonne@gmail.com

Follow this and additional works at: https://ir.library.illinoisstate.edu/etd

Part of the Instructional Media Design Commons, and the Teacher Education and Professional

Development Commons

\section{Recommended Citation}

Donnelly, Heather J., "Exploring Student Interaction and Reflection Through the Use of Digital Backchannel Discussions" (2016). Theses and Dissertations. 612.

https://ir.library.illinoisstate.edu/etd/612

This Dissertation is brought to you for free and open access by ISU ReD: Research and eData. It has been accepted for inclusion in Theses and Dissertations by an authorized administrator of ISU ReD: Research and eData. For more information, please contact ISUReD@ilstu.edu. 


\title{
EXPLORING STUDENT INTERACTION AND REFLECTION \\ THROUGH THE USE OF DIGITAL
}

\section{BACKCHANNEL DISCUSSIONS}

\author{
Heather J. Donnelly
}

\section{Pages}

A qualitative multicase study utilizing content analysis and qualitative coding techniques was conducted to explore the influence of the use of digital backchannels on student interaction and reflection during an in-class discussion. Data were collected from six front channel transcripts and 20 backchannel transcripts, which resulted from six backchannel discussions that were conducted in three different teacher education courses. Additional data were gathered from participant interviews of seven students who were enrolled in the participating courses. The outcome of the research indicates two main themes developed in regards to the influence of digital backchannels on student interactivity: (1) The content chosen for backchannel discussions influenced student content and student - student interaction and (2) The design of the backchannel activity affected all three types of interaction. The content analysis indicated there was limited variation in the amount of dialogue dedicated to discussing content. Interaction with content was apparent in all six class sessions, and the nature of the digital backchannel activity encouraged interaction with content at a relatively high level, with evidence of 
students building knowledge, drawing conclusions, and asking additional questions throughout the activity. The structure of the backchannel design also influenced student interactivity. Three factors were instrumental in determining how interaction was affected: (1) Whether or not the separate backchannel groups were connected digitally to the front channel group, (2) The role the instructor took throughout the activity, and (3) The seating arrangement and number of group members in the backchannel groups.

The following primary theme emerged in relation to the second research question, which considered the influence of digital backchanneling on reflection: (1) Student reflective thinking was present and supported throughout the activity. All 26 front and backchannel transcripts displayed evidence of reflective thinking as measured by Rodgers (2002) criteria for reflection in an educational setting. The seven students interviewed agreed this type of thinking took place during the activity, and the technique gave them the opportunity to reflect more as compared to a verbal in-class discussion. Additionally, all seven students felt they would utilize the educational technology in their future classrooms, directly connecting their experience with current situations and new ideas.

Lastly, the third research question was designed to explore the overall learning experience associated with backchannel discussions. Two primary themes resulted in relation to the third research question (1) Digital backchanneling resulted in a meaningful, positive, and focused learning experience, and (2) Millennials/Net Generation students seem to be less comfortable with technology and multi-tasking when used in an educational environment.

KEYWORDS: Digital Backchannels, Educational Technology, Interactivity, Reflection, Teacher Education 


\title{
EXPLORING STUDENT INTERACTION AND REFLECTION THROUGH THE USE OF DIGITAL BACKCHANNEL DISCUSSIONS
}

\author{
HEATHER J. DONNELLY
}

A Dissertation Submitted in Partial Fulfillment of the Requirements for the Degree of

DOCTOR OF EDUCATION

School of Teaching and Learning ILLINOIS STATE UNIVERSITY 
Copyright 2016 Heather J. Donnelly 


\title{
EXPLORING STUDENT INTERACTION AND REFLECTION THROUGH THE USE OF DIGITAL BACKCHANNEL DISCUSSIONS
}

\author{
HEATHER J. DONNELLY
}

COMMITTEE MEMBERS:

Linda Haling, Chair

Robyn Seglem

Lydia Kyei-Blankson 


\section{CONTENTS}

Page

$\begin{array}{ll}\text { CONTENTS } & \text { i }\end{array}$

TABLES

CHAPTER

I. THE PROBLEM AND ITS BACKGROUND 1

Statement of the Problem 1

Purpose of the Study 5

$\begin{array}{ll}\text { Background and Need for the Study } & 7\end{array}$

$\begin{array}{ll}\text { Theoretical Framework } & 10\end{array}$

The Perspective of a Student, a Teacher, and a Teacher Educator $\quad 20$

Research Questions 22

Definitions of Terms 24

$\begin{array}{ll}\text { Assumptions } & 24\end{array}$

II. REVIEW OF RELATED LITERATURE 26

The Current State of Educational Technology in Teacher Education 27

The Changing Landscape of In-Class Discussion in Higher Education 31

Asynchronous Online Discussions - Interaction, Presence, and Community 35

Digital Backchannels - Trends and Uses 40

Summary of Related Literature 49

III. RESEARCH DESIGN 51

Restatement of Problem and Questions 51

Research Design $\quad 53$

Underlying Philosophy $\quad 56$

$\begin{array}{ll}\text { Participants } & 59\end{array}$

Data Collection Approach $\quad 63$

$\begin{array}{ll}\text { Observations } & 64\end{array}$ 
Backchannel Technology, Structure, and Content $\quad 73$

$\begin{array}{ll}\text { Methods of Analysis } & 78\end{array}$

Content Analysis Classifications $\quad 80$

Summary of Methodology $\quad 89$

IV. ANALYSIS OF THE DATA 90

$\begin{array}{ll}\text { Question } 1 & 90\end{array}$

The Influence of Content 93

Backchannel Design 104

Summary of the Results for Question 1

Question 2

The Presence of Reflective Thinking 119

Summary of the Results for Question 2 125

Question $3 \quad 126$

Positive Overall Learning Experience 126

Tech Savviness May Not Translate to an Educational Setting

Summary of the Results for Question 3

V. OVERVIEW, DISCUSSION OF RESULTS, RECOMMENDATIONS, AND FUTURE RESEARCH

Overview of the Study

Discussion of the Results

Recommendations

Future Research

Final Thoughts

Limitations of Study 
APPENDIX D: Original List of In Vivo Codes 186

APPENDIX E: Meaning, Focused Learning 192

APPENDIX F: Connection to Peers 195

APPENDIX G: Use of Educational Technology 198

APPENDIX H: Participation Engagement 200

APPENDIX I: Instructor Moderated 203

APPENDIX J: Reflective Thinking 205

APPENDIX K: Structure, Design, and Instructor Role 207

APPENDIX L: Connection to Prior Learning and/or Lived Experiences 210

APPENDIX M: Multi-tasking Difficult $\quad 212$

APPENDIX N: Flexible Mode for Learning 215

$\begin{array}{ll}\text { APPENDIX O: Positive Learning Experience } & 217\end{array}$

APPENDIX P: Content Influences Interaction and Final Analysis 219 


\section{TABLES}

Table

Page

1. Sample Selection - Variation of Student Experience 62

2. Backchanneling Structure $\quad 74$

3. Content Chosen for Backchannel Activity 76

4. Framework for Analysis (adapted and modified from Henri, 1992

5. Content Related Cognitive Processing 97

6. Examples of Higher Order Thinking in Student Dialogue

- Applying/Analyzing

7. Examples of Higher Order thinking in Student Dialogue

- Evaluating/Creating

8. Examples of Reflective Thinking in Student Dialogue with Digital Backchanneling 


\section{CHAPTER 1}

\section{THE PROBLEM AND ITS BACKGROUND}

\section{Statement of the Problem}

Classroom discussions in a face-to-face learning environment often are utilized with good intentions (full participation, increased interactivity, pensive reflection), and have been shown in previous research to be an effective learning strategy (Ellis \& Calvo, 2004; Hung, Tan, \& Chen, 2005), but sometimes the results are debatable. Research has shown that students who are timid and less confident for a variety of reasons, are not as willing to fully participate and engage in classroom dialogue, therefore limiting the potential benefits associated with face-to-face communication (Belcher 1999; Bordia, 1997; Kern, 1995; Lee 2009). With an abundance of previous literature connecting the importance of interactivity to student success in general (Beauchamp \& Kennewell, 2010; Slavin, 1999; Wenger, McDermott, \& Snyder, 2002), face-to-face discussions may not live up to their potential if only a minority of students are participating and interacting with their peers, the instructor, and the content.

Furthermore, the act of reflection has been studied at length by other researchers (Boud, Keogh, \& Walker, 2013; Fernsten \& Fernsten, 2005; Moon, 2013) and has been shown to enhance the teaching and learning process, by allowing students to make connections to content and transform an ordinary learning activity into a growth experience (Dewey, 1916; Schubert, 2014). Reflection has been shown to be vital to the 
learning process, giving students the opportunity to "affirm the value of one's own experience," while broadening the platform for understanding and acquiring the ability to "engage in the process of inquiry" (Rodgers, 2002, p. 857). In some cases, face-to-face classroom discussions may be extremely fast paced and impulsive, leaving little time for contemplation and reflection, contributing to more "off the cuff" remarks and a diversion towards unrelated dialogue (Card \& Horton, 2000; Kern, 1995; Walther, 1996).

Educational technology may be a way to turn an unengaged and ineffectual faceto-face discussion into a highly effective, participatory learning experience, and as institutions of higher education adjust to changes brought about by the information age, continual efforts are being made to utilize educational technology to solve problems and to enhance the learning process (Garrison \& Kanuka, 2004). The shifting demographics of current college students and a demand for "technology based practices in the curriculum" (Hicks, Reid, and George, 2001, p. 143) to ensure preparation for an increasingly digital society, is forcing leaders in higher education to think differently regarding curriculum content and delivery.

The literature supporting the use of internet based, asynchronous communication tools to enhance learning and to contribute to more significant educational experiences has been well documented (Garrison, Anderson, \& Archer, 2001; Marjanovic, 1999; and Williams, 2002). For instance, online discussion forums in particular, within a fully online or blended learning environment, have been shown to support communities of inquiry, increased interactivity and participation, and more in-depth student reflection (Fisher \& Baird, 2005; Ke \& Kwak, 2013; Morgan, 2011; Schwier \& Seatin, 2013; 
Shackelford \& Maxwell, 2012; Song \& McNary, 2011; Vercellone-Smith, Jablokow, \& Friedel, 2012). With past research tending to focus heavily on asynchronous communication tools, there is a lack of knowledge on the analysis of utilizing synchronous, computer-mediated communication to enhance learning and support student interactivity and reflection.

Digital backchanneling is a type of synchronous communication that may be used simultaneously during an in-class discussion to support participation, engagement, interaction, and reflection. Historically, the phrase "backchannel" has generally referred to the verbal utterances and nonverbal body language that supplement the primary conversation or dialogue. This traditional concept of a "backchannel" has proven to provide additional cues to speakers and listeners, improving the communication process by augmenting the primary channel of the exchange of information with various mannerisms, actions, gestures, and verbal expressions (Harry, Green, \& Donath, 2009).

Building on the meaning of the original use of the term "backchannel," digital backchanneling is also considered a secondary line of communication that supplements the primary discourse. However, digital backchanneling utilizes computer mediated communication technology to enable the user to provide a public or private short message that supports "a dialog between people who are co-present in a real world space having some sort of shared experience" (Harry, Green, \& Donath, 2009, p.1). Previous educational research has tended to center around the use of backchanneling in sizable survey course structures (Aagard, Bowen \& Olesova, 2010; Gehlen-Baum, Pohl, and Bry, 2011), as well as academic and other industry conferences (Jacobs \& McFarlane, 2005; Harry, Green, \& Donath, 2009; McCarthey \& Boyd, 2005; Saunders et al., 2009). 
Limited research has been conducted on the use of digital backchannels in smaller class sizes (Jarrett \& Devine, 2010; Markett, Arnedillo Sanchez, Weber, \& Tangney, 2006; Poleon \& Krishnan, 2013) and even less scholarship has been devoted to specifically looking at how backchannels influence learning in a teacher education classroom. Furthermore, there is a lack of knowledge on the analysis of interaction and reflection with the use of backchannels to conduct live classroom discussions in order to enhance and enrich the overall learning experience.

Today's learners are exposed to a plethora of social communication and connectivity in their everyday lives, simply due to the advancement of technology and the ever-increasing reliance on social media and the internet to work, live, and communicate effectively. Classrooms in higher education should consider taking advantage of students' increased aptitude for using technology to foster more in-depth and timely communication, making the most of valuable face-to-face interactions. Additionally, increased interactivity and more comprehensive in-class discussions may positively influence subject matter reflection, thereby contributing to a more comprehensive and beneficial learning experience.

As the landscape in higher education continues to evolve, college level educators are feeling the pressure to provide students with a "value added" experience when their students are participating and committing to a face-to-face course, rather than choosing the increasingly widespread option of online learning. Face-to-face course design is essentially competing with online formats and the popularity of online courses in U.S. colleges and universities continues to expand according to a recent report tracking online education in the United States over the last ten years (Allen \& Seaman, 2013). The 
increased availability of online courses in higher education has been made possible through technological advancements and the need for universities to respond to market trends by offering more flexible options to a variety of learners at various stages of their lives (Garrison \& Kanuka, 2004; Picciano, Seaman, \& Allen, 2010). Similarly, Teacher Education departments have followed this trend, offering more courses online, thereby allowing students to make choices regarding course delivery (Bigum \& Rowan, 2008).

Teacher educators who are instructing in a face-to-face setting need to find creative ways to engage and stimulate students during in-class discussions. As the use of instructional technology increases and new genres of communication are emerging (Williams, 2000), teacher education faculty are presented with a vast array of decisions regarding the structure and layout of the courses they facilitate. By utilizing familiar technology that is readily available, student interactivity with their peers, instructors, and content may be enhanced, along with the depth and breadth of in and post class reflection.

\section{Purpose of the Study}

The purpose of this study was to explore the influence of digital backchanneling as a complement to live discussions within a teacher preparation program. Specifically, this study considered the effectiveness of backchannels in promoting in-class interactivity and student reflection within undergraduate teacher education courses. As the review of the literature in Chapter II demonstrates, research has shown the need for innovative and effective practices within teacher preparation classrooms. In addition, past literature has solidified the importance of interactivity and reflection in the learning process and the 
need for shifts in pedagogical practices to harness the known benefits of increased interactivity and quality reflection.

This study not only contributes to the general knowledge in the area of instructional technology research, but also provides numerous stakeholders with information regarding the effectiveness of digital backchanneling within an in-class discussion. More specifically, this research is useful for teacher preparation faculty who are trying to better meet the needs of their students by adjusting their pedagogic practices to enhance delivery of content and model technology use by teachers. In addition, teacher education administrators, faculty, and students are made aware of the advantages and disadvantages, as well as the general characteristics associated with the implementation of a synchronous computer-mediated communication technique such as backchanneling. This study addressed the concerns and challenges associated with a synchronous digital communication technique from the student's viewpoint, particularly evaluating the influence of digital backchanneling on student interactivity and reflection, as well as provided insight on the overall learning experience. Lastly, faculty in higher education may find the results of this study useful when making strategic decisions concerning how they will go about conducting in-class discussions and utilizing instructional technology.

This study was an effort to fill the existing gap in the research relative to the utilization of digital backchannels within teacher education classrooms, which generally avoid large survey courses and possess smaller numbers compared to sizable conferences or lecture classes. Additionally, the research undertaken with this study provided some 
insight on the influence of digital backchannels on two highly recognized learning processes associated with student success: interactivity and reflection.

\section{Background and Need for the Study}

By utilizing multiple mediums to elicit student participation within an in-class discussion, digital backchannels may enhance face-to-face teaching by offering the instructor and discussion participants additional opportunities to express feedback and exchange cues. Past research has shown rich medium educational environments (utilization of numerous mediums or modes of instruction) include both asynchronous and synchronous communications (Volery and Lord, 2000) and tend to cultivate a more effective learning environment and can increase levels of interaction amongst students (Balaji and Chakrabarti, 2010; Dennis and Valacich, 1999).

Computer-mediated communication, such as digital backchannels, may be just the tool to encourage students who are generally introverted and in most cases have an abundance to say, but do not have the self-efficacy to verbalize it. Volery and Lord (2000) contribute to this idea by arguing that in many cases the lack of visual attachment during computer-mediated communication frees participants to openly contribute and strips away the social hierarchy that may occur in face-to-face communication. For some students, the anonymity associated with digital communication allows them to participate without the added worry over whether they supplied the 'right' or 'wrong' answer (Davis, 2003). Likewise, Draper \& Brown (2004) found that using technology to communicate in class encourages participation from the normally shy, self-conscious student and increases learner-content interaction. 
According to Cain (2013), the culture in which we live tends to idolize extroverts and the qualities that are oftentimes associated with this personality type (confident, risktakers, gregarious, controlled, and outspoken). At the expense of ignoring the "quiet competence" of a person who more closely identifies with the personality characteristics of an introvert (shyness, soft-spoken, and sensitive), our society tends to push the "Extrovert Ideal” that Cain (2013) discusses in her latest book Quiet (p. 4). This author argues that modern Western culture misinterprets and underutilizes the qualities and talents of introverted people and makes the case that people with strong personalities are not the only ones flourishing and making a difference in our society.

The education sector has followed this trend by emphasizing group work, oftentimes requiring in-class presentations, and putting a high value on in-class participation during discussion and collaborative work. These type of student-centered, project-based classrooms are "buzzing with activity" and have been supported in past literature as being highly conducive to knowledge construction and student success (McCarthey \& Anderson, 2000), but the non-participatory, introverted student is clearly at a disadvantage. It is understandable why many teacher educators are structuring their classrooms to make use of active learning techniques, such as collaborative role-playing and simulations. These learning techniques can produce as good, if not better student results on subsequent essay assessments, indicating successful learning and knowledge construction (McCarthy \& Anderson, 2000). As cooperative, active learning practices have become more mainstream since their introduction in 1960s and 70s (Camp, 1996), the increase of in-class discussions and content related conversations have naturally followed suit. 
With this in mind, using technology to help bridge the gap between lackluster and high levels of engagement during in-class discussion, and more thoughtful reflection, may be reason enough to investigate the use of backchannels as a discussion technique in a face-to-face educational setting. By adding an additional level of communication to an in-class discussion, students of varying abilities and personality types may have a more equitable platform to interact with the instructor, content, and their fellow students. Digital backchannels may also contribute to more in-depth reflective practices for teacher education students during the actual discussion, as well as, once they leave the classroom and have the chance to further contemplate the discussion content.

Furthermore, one of the imperative components of the teacher education accreditation process deals with how to best prepare future educators to teach to students in a $21^{\text {st }}$ century educational environment. In fact, the Council for the Accreditation of Educator Preparation (CAEP) devotes numerous sections to educational technology preparation within their five primary accreditation standards. The organization specifically highlights its importance within the organization's first standard titled: Content and Pedagogical Knowledge. This standard requires accredited educator preparation institutions to ensure that "candidates model and apply technology standards as they design, implement, and assess learning experiences to engage students and improve learning" (Council for the Accreditation, 2015, p. 3). Teacher preparation programs may benefit, as well as comply with accreditation requirements by using digital tools such as backchannels to effectively engage all students, using a medium that corresponds with $21^{\text {st }}$ century standards. By integrating digital backchannels, teacher educators would have the opportunity to model educational technology in their higher 
education classrooms (Allsopp, McHatton, \& Cranston-Gingras, 2009). Future teachers would be given an example to support their decisions regarding technology integration into their own teaching practices.

\section{Theoretical Framework}

This study was guided by an overall or grand theory consisting of "loosely interrelated sets of assumptions, concepts, and propositions, that make up an overall worldview," (Goetz \& LeCompte, 1984, p. 36) as well as several substantive theories which have "tightly interrelated propositions" (Goetz \& LeCompte, 1984, p. 37) that explain phenomena and function as guideposts to the teaching and learning process.

The conceptual framework of constructivism/interpretism served as the epistemological position for this study, directing the course of the research and providing a background for an exposition of the data (Creswell, 2013; Merriam, 2009). As noted by Driscoll (2005), "there is no single constructivist theory of instruction" (p. 386). On the contrary, constructivist thinking comes in many shapes and sizes, while revealing various shared characteristics such as the assumption that knowledge is constructed rather than a fixed reality that is to be learned. To add to this line of thought, multiple realities do exist which are ever changing according to history and context; self-regulation and mindful reflection are required for learning and growing (Creswell, 2013; Driscoll, 2005; Merriam, 2009).

An example of the varied aspect of constructivism can be seen with the theory of situated cognition's knowledge of lived practices concept, whereas "knowledge accrues through the lived practices of the people in a society," rather than simply internalized by the learner after an experience, a discovery, or transmission of knowledge (Driscoll, 
2005, p.158). The nature of situated cognition suggests that the focus for learning needs to be shifted from the individual to the society, where cultural factors and social interactions within a community are the means to acquiring knowledge. This theory holds that learners should essentially construct concepts, paradigms, and ideas in a sociocultural setting, where there is the flexibility to forge relationships and build ties with people and organizations that are purposeful and critical to their world. Selfefficacy, motivation, effort, and outcomes as described by Bandura (2001) are mediators of performance and achievement and "positive expectations serve as incentives" for learners to engage in the task at hand (as cited in Driscoll, 2005, p. 316-317). Students generally come into a social setting with various levels of self-efficacy, which in turn can influence how they think, perceive, and develop in a fundamentally social context. Bandura (2001) and Driscoll (2005) lay the foundation for supporting the idea of using technology such as backchannels in a sociocultural setting (teacher education classroom) to influence effort, participation, and confidence within a student or instructor led in-class discussion.

The learning theory of social constructivism (Burr, 1995; Vygotsky, 1978; Wertsch, 1985), which is grounded in and derived from the constructivism/interpretism epistemological perspective, will provide a more refined lens to view a student's involvement with digital backchanneling in a teacher preparation course. This worldview emphasizes that knowledge is constructed according to environmental, cultural, and historical factors, and the same knowledge can be construed and perceived differently by different people, situations, and backgrounds (Willig, 2013). This study attempted to explore the influence of backchannels during a variety of classroom discussions in 
various teacher education classrooms, concurring with Willig (2013) on how fixed knowledge can be perceived differently depending on the setting and the people involved.

Social constructivism will function as the grand theory guiding the research and contributing to the concepts, deductions and arguments associated with the following three substantive theories, which will be described below: 1.) Conversational Framework for Learning Theory 2.) Theory of Transactional Distance, and 3.) Philosophy of the use of reflection in education. This collection of philosophies served as an inspiration for the study and will allow the author to further refine the inquiry and guide the explication of the data (Edmonson \& Irby, 2008). Overall, this research was based on the fundamental viewpoint that learning phenomenon can be described by "multiple realities, or interpretations of a single event," where "reality is socially constructed" (Merriam, 2009). Each of the teacher education courses/classrooms that were used to collect data, provided a variation of students, discussed topics, and environmental factors.

Laurillard's (2002) Conversational Framework for Learning theory was developed as a pedagogical model to capitalize on the genuine benefits offered through the use of educational technologies by closely evaluating teachers' and learners' needs. According to Laurillard (2002), the teaching and learning process requires various critical exchanges between three different groups of participants: the instructor, the learner, and the learners' peers. The exchanges between involved teachers and learners are classified into two categories: discursive and experiential, with both being a necessary component of the educational process. Discursive levels of teaching and learning primarily consist of the articulation of ideas, concepts, and theories and the experiential levels are geared more towards application in a real world setting and the practicing of specific tasks 
associated with learned knowledge and skills. In order to link the two levels of exchanges, there should be continual iteration between instructors and learners, contributing to the adaptation of actions by learners in light of feedback and reflection on performance that is associated with task completion (Laurillard, 2009).

As explained by Laurillard (2008), oftentimes technology is brought into the classroom as a trendy gadget that accomplishes nothing more than a convenient way to deliver information from the instructor to the student. Podcasting is given as an example of this phenomenon, describing this activity as students simply listening to an audio recording of a lecture or a text, with no real consideration of advancing pedagogy through the use of this technology (Laurillard, 2008). By evaluating digital technologies with a critical eye, Laurillard (2008) believes decision-makers will be more apt to "harness technology to the needs of education, rather than simply search for the problems to which the latest technology is a solution (p. 139).

Sharples, Taylor, and Vavoula (2005) concur with Laurillard (2008) in that educational technology has the potential to enhance traditional learning methods and techniques by extending the learning process through the incorporation of context-aware technology that promotes exploration, communication, and relevant interactions through an iterative process (Laurillard, 2002). Again, the process of advocating the tactical and meaningful integration of educational technology in the learning process seems to be the missing piece when instructors are making decisions on how best to utilize digital tools.

The Conversational Framework for Learning theory (Laurillard, 2002) structure is derived from already existing philosophies associated with teaching and learning best practices. Past research focusing on pedagogical principles points out what has already 
been revealed about what it takes to learn and the process associated with acquiring knowledge. By grouping past pedagogical theories into four main categories: instructionism (Merrill, 2002; Reigeluth, 1983), constructionism (Papert \& Harel, 1991), socio-cultural learning (Wertsch, 1980; Wertsch, 1985), and collaborative learning (Dillenbourg, Järvelä, \& Fischer, 2009; Scardamalia and Bereiter, 2006), and realizing each set of ideas contributes to different aspects of the learning process, the Conversational Framework for Learning theory synthesizes past educational research to focus on numerous core conditions of what it takes to learn (Laurillard, 2008).

The Conversational Framework for Learning theory guides this research on two levels: (1) Providing a protocol for evaluating instructional technology and (2) Providing a breakdown of the educational process into two levels of learning with the critical requirement of social exchanges. This study will explore the level and quality of student interaction and reflection as computer-mediated communication (backchannels) are used to supplement an in-class discussion. Rather than just using technology (above podcast example) to deliver information innovatively, digital backchannels will be integrated during class in order to potentially aid in knowledge construction by increasing interactivity and personal reflection amongst students. The second level of the theory in essence, supports the idea of using backchannel technology to support required functions within the learning process (discursive, adaptive, interactive, and reflective iterative dialogue). The question then becomes how do digital backchannels influence learning in a teacher education classroom in the context of the Conversational Framework for Learning theory (Laurillard, 2009)? 
As the purpose and research questions of this study began to evolve, the Transactional Distance theory proposed by Moore (1993), and Dewey’s (1916/1980) philosophies regarding reflection in the teaching and learning process, naturally augmented, supported and further developed the initial phases of the investigation. It was at this point, the decision was made to focus on the influence of backchannels on student interactivity and reflection. Although there is adequate research on the level of interactivity and reflection within traditional in-class and small group discussions, little research has been devoted to the analysis of interaction and reflection using backchannels as a method for conducting live classroom discussions.

According to Moore $(1993,2007)$, the term transaction refers to the interplay between teachers, learners, and the environment. In a distance education situation, the environment is drastically influenced simply because of the innate separation of teacher and learner. Even outside of a distance education situation, the interplay between these three educational participants is never the same and cannot be characterized as absolute in any way. Rather, the variables take on a continuous, fluid nature, falling on a spectrum, where there are many different degrees of transactional distance. Moore (1993) generalizes about the extent of transactional distance in any educational process, whether that is face-to-face or from a distance, and postulates that the degree of transactional distance is determined by three groups of variables: dialogue, structure, and learner autonomy (Falloon, 2011).

Dialogue is referred to as more than just two-way verbal communication between educational participants. Rather, dialogue takes into account all two-way constructive interaction between participating parties, whether that is through the mail, computer- 
mediated sources, or in person. The level of interactivity, the number of conversation participants, the academic level and content area, and the teacher and learner personality are all contributors to the characteristics of dialogue (Moore, 1993).

The second factor contributing to Moore's $(1993,2007)$ degree of transactional distance concerning educational programs, refers to the arrangement of the course structure. Pedagogical philosophy, scope and sequence of material, nature of information dissemination, and accommodations and flexibility of requirements all play into the structure of a particular class.

Learner autonomy is described as the third factor of Moore's model and is dependent on the two aspects previously described. The sense of autonomy experienced by the learner relates to the extent of independence, control, and self-determination in an educational situation (Falloon, 2011). As noted by Giossos et al. (2009), the "extent to which the learner exerts control over learning procedures" is contingent on course dialogue, structure, and design, which in turn connects to the degree of transactional distance (p. 2).

Furthermore, Moore (2007) expounds on his discussion concerning transactional distance in distance education and distinguishes between three types of interactions found in learning contexts: learner-instructor communication, learner-learner collaboration, and learner-content interaction (Bernard et el, 2009). Overall, Transactional Distance theory proposes that online learning is most effective when the perceived pedagogical distance between the instructor and students in the course is minimized with increased interaction; Interaction occurs through learner-instructor communication, learner-learner collaboration, and learner-content interaction. The key point to consider here is that all 
three levels of interaction have important implications for effective online learning and therefore, can be extrapolated to face-to-face environments, where increased interaction is seen to be positive for learning (Kennedy \& Cavanaugh, 2008; Moore 2007).

The second element that was explored through this research study in relation to digital backchannels is the concept of reflection. The use of reflection in education has grown in popularity, while simultaneously suffering from a lack of clarity and refinement. In many cases, the concept overlaps and is used interchangeably with other terms such as metacognition, inquiry, and self-examination, contributing to the general "fogginess" of the strategy (Rodgers, 2002). Borrowing from Rodgers' (2002) insightful classification of Dewey's (1929) perception of reflection, the following four criteria are identified revealing a descriptive, in-depth definition of reflection:

1.) Reflection is a process where learners are engaged in meaning-making and are making continual connections between what they have learned to other experiences and ideas.

2.) Reflection is purposeful, systematic, and disciplined, finding its roots in scientific inquiry.

3.) Reflection needs to happen in a social environment, where connection and interaction is happening with others.

4.) Reflection requires a set of dispositions that value life-long learning of oneself and others.

With the above articulation of reflection in mind, where does the function of reflection fit into the learning process? Laurillard $(2002,2008,2009)$ contends reflection is an integral piece of the iterative process, linking the two levels of exchanges between 
the teachers and learners and contributing to the adaptation of the learning environment to respond to feedback and reflective thinking. According to Laurillard (2008), this goalaction-feedback-reflection-adaptation cycle is the determinant of what constitutes a reflective practitioner. This learning process builds on Dewey's belief that reflection is that activity that reconstructs and organizes experience to make meaning of knowledge, involvement, and practice (Rodgers, 2002).

In addition to Dewey's thoughts on reflection, his views on the concept of application in the educative process tends to harmonize with Laurillard's (2002) line of thought, and most likely provided a backdrop for the aspect of the Conversational Framework for Learning theory that directly correlates to the importance of experimentation and practice (Laurillard, 2009). Dewey explicitly outlines his feelings on too much content without enough application in the statement that follows:

There is the standing danger that the material of formal instruction will be merely the subject matter of the schools, isolated from the subject matter of life-experience. The permanent social interests are likely to be lost from view. Those which have not been carried over into the structure of social life, but which remain largely matters of technical information expressed in symbols, are made conspicuous in schools (as cited in Breault \& Breault, 2013, p. 11). Dewey, as early as 1916, expressed this critical point concerning America's schooling system and had the foresight to mention how education, school, and life-experience cannot be so drastically separated from one another, for fear of teaching information that is useless and immaterial.

Dewey's (1929) continual emphasis on linking education to the social experience draws attention to his view on how important he believes this is to learning and 
schooling. Considering a society constitutes many elements, (culture, economy, community, leadership, religion), Dewey was stressing the importance of connecting education to life. He elaborates on the idea that school is not necessarily in place to just prepare students for jobs, but it was a place to provide students with some of the necessary attributes to contribute positively to society and experience happiness and contentment as a member of a community. In the Creed's first Article, where Dewey answers the question: "What is Education?" he uses phrases such as, "impossible to prepare for any precise set of conditions," and "to prepare him for the future life...he will have the full and ready use of all his capacities" (Dewey, 1929, p. 292). These phrases reinforce the belief that a child's education should be broad, holistic, complex and in a way, ever changing, which is quite frankly, a pretty good description of life.

This study focused on students within a teacher preparation degree/certification program, with the majority of the participants transferring the knowledge they gain in class to a "real situation" through novice teaching and/or student teaching. The teacher preparation classroom was chosen for this study based on the emphasized importance of "learning by doing" in any educational situation (Dewey, 1916, 1929; Laurillard, 2002).

As a final point, Hatt (2008) discusses how theory can sometimes be a "fuzzy concept" and suggests that, "theory can be very useful but only when we humble it," which requires the researcher to begin to use theory to personalize their project, to a certain degree, while trying to simplify the constructs of their aligned philosophy in order for it to relate to the understanding of the issue being researched (p. 31). As scholars begin to understand how theory provides a foundation for their research, a study can start to take shape by making why and how decisions relating to the research topic, approach, 
design, and questions. Silverman (1993) contends, there is a distinct purpose of theory in research, and without it, data would not be able to be analyzed and/or interpreted. The decision by the researcher in deciding what the data represents is grounded in all levels of theory, and depending on the particular view the researcher adopts, will determine how the data is expressed (Willig, 2001).

\section{The Perspective of a Student, a Teacher, and a Teacher Educator}

I have used theory as Hatt (2008) has suggested as a place to start and a way to add a personal perspective to any project that is in front of me. As the subtitle indicates, so far in my educational career, I have had the privilege to fulfill the role of a "student" a “teacher" and a "teacher educator" at numerous levels and at various life stages.

I became interested in the proposed topic during my time as a past teacher education student, and as I moved on and experienced my first year of teaching at the K12 level, my interest level intensified. I began my teaching career under a new principal at the school at which I was hired, who had high expectations regarding the use of technology as part of the educational process. With me being the "new person on the block," fresh out of a relatively progressive teacher education institution, I felt the need and desire to meet the principal's expectations. Additionally, I figured education was heading in a digital direction anyway, and it would be wise of me to start off on the right foot and try to get acclimated with has much instructional technology as possible, trying to make it a part of my teaching paradigm right from the beginning.

The questions I continued to ask myself were: Was I prepared to do this? Did my instructors in teacher education do a sufficient job of modeling technology use, allowing me to have quality technology tools in my teaching repertoire? Was I given the necessary 
tools to successfully integrate technology into history education as part of my pedagogic strategy, or, had I been prepared to just insert technology because it was the trendy thing to do? As a first year teacher, would I be able to satisfy the National Education Technology Standards (NETS) put forth by the International Society for Technology in Education?

As I reflected on that initial year, I pondered these inquiries and realized answering them was not going to be as straightforward as I thought. For instance, compared to some of my colleagues at the time, I would say my implementation of technology into my teaching practices was at a fairly high level. On the contrary, when I compared myself to other tech savvy, novice instructors, who worked for other schools, I felt completely under prepared and intimidated by educational technology.

As I continued my studies and began my pursuit of a doctorate in education, I began thinking about postsecondary students' perceptions of technology use by higher education faculty, specifically contemplating my experience as a college student, as well as an adjunct faculty member. For instance, as a teacher educator, was I incorporating the best use of technology in the courses I taught, or was I simply interjecting it into the curriculum to make use of the college's substantial investment in iPads, video equipment, wireless capability, and state of the art projection equipment. What were my students' views on technology use in teacher education and did they feel prepared to incorporate effective, meaningful technology into their lessons?

As I mulled over these questions, I became more cognizant and even inquisitive about other factors that may have an additional effect on this issue. For example, can technology actually change the way students interact, participate, apply their skills and 
knowledge? Are certain courses and content information enhanced by the use of instructional technology? Are students better able to reflect on the issues and topics that are being presented to them if communication technology is integrated into the discussion process? Lastly, by using a tool such as digital backchanneling in a teacher education classroom, are students better able to move through the iterative process of learning as described by Laurillard (2002)?

This study attempted to explore the student viewpoint of digital backchannel communication within a teacher preparation course, as well as expose some of the issues that surround using computer-mediated communication during the in-class segment of a college level course.

\section{Research Questions}

The theories described above influenced numerous aspects of this study and adequately provided the groundwork for the purpose of the research and the focus of inquiry. Laurillard $(2008,2009)$ explains the motivation behind the development of the Conversational Framework for Learning theory was this particular researcher's experience with seeing and using numerous elements of educational technology that were in place without a thorough, evidence-based evaluation process to support decisions to utilize the technology. Much of the technology being used today in education is simply there to provide a novel way of approaching a task, rather than truly transforming pedagogy in the hopes of advancing the teaching and learning process. Laurillard's (2002) approach takes what we already know regarding how people learn and breaks the process down to consider technology decisions in education in a purposeful, efficient manner. Laurillard's (2002) framework for the effective use of learning technologies 
highlights the component of conversations between teacher and learner, and later the conversations that are integral during the experimental or application stage of process. The theory uses a model that is intended to be universal to all learning processes and includes the elements of interactivity and reflection in the conversational cycle that occurs between instructors and learners.

Examining these two elements in relation to digital backchanneling enabled the researcher to explore why, how, and to what extent backchanneling contributed to inclass discussions relating to the discursive nature of learning and the practice of reflecting on the experimental aspect of the learning process. The following research questions were developed in light of Laurillard's (2002) framework and the current trends in higher education regarding instructional technology, as well as a personal/professional motivation by the researcher to understand the influence of a particular technology on student interactivity and reflection:

1. In what way does digital backchanneling contribute to student interactivity during in-class discussions by teacher education students?

2. In what way does digital backchanneling contribute to student reflection in a teacher education course?

3. How does digital backchanneling influence the overall learning experience associated with in-class discussions in a face-to-face educational setting?

The research questions this study was seeking to address were answered from the perspective of undergraduate students enrolled in three distinct teacher preparation courses taught by three different instructors at a Midwestern university. As the above questions were contemplated, this study strived to 
illuminate the procedures, developments, and perceptions that were associated with using digital backchannels while participating in face-to-face discussions during the in-class portion of each course.

\section{Definition of Terms}

1. Digital Backchannel - Text based chat or instant messaging systems that support a dialog between people who are co-present in a real world space having some sort of shared experience (Harry, Jones, \& Donath, 2009).

2. Student Interactivity - Three types of interaction in an educational environment: student - student, any interface from one student to another student; student - content, interaction between the student and the subject of study resulting in changes in one's perspectives, beliefs, and ideas; student - instructor, interaction between the student and the person who prepared the curriculum and is facilitating the instruction (Moore, 1989).

3. Student Reflection - Purposeful, systematic thinking that involves the process of meaning-making while making connections to what has been learned to other experiences and ideas (Rodgers, 2002).

\section{Assumptions}

1. This study assumed that for a variety of reasons, not all students generally participate in in-class discussions and quality interaction usually takes place for a minority of participants.

2. This study assumed that student participants have familiarity with computer-mediated communication techniques such as web-based chat rooms and texting through Multimedia Messaging Service (MMS). 
3. This study assumed interactivity and reflection are an integral part of the learning process and may be influenced in a variety of ways in different educational contexts. 


\section{CHAPTER II}

\section{REVIEW OF RELATED LITERATURE}

This study explored the use of digital backchannels in teacher preparation, specifically looking at this type of communication technology and its influence on inclass interactivity and student reflection during a classroom discussion. Digital backchannels are defined as "text based chat or instant messaging systems" that supplement a dialog between individuals who share a physical or "real world" space (Harry, Green \& Donath, 2009). Digital backchannels are a type of computer-mediated communication that are specifically in place to support the front channel, which is in essence, the primary or live communication happening in present time, whether that is in the form of a lecture, presentation, discussion, etc. (Pohl, Gehlen-Baum, \& Bry, 2011). By analyzing the content of backchannel and front channel in-class discussions, as well as the interplay between the two levels of communication, all three types of student interaction as described by Moore $(1993,2007)$ were effectively evaluated. In addition, by utilizing Rodgers (2002) four parameters for reflective thinking, student reflection on the discussed topic during the in-class dialogue, was able to be assessed and later interpreted to draw conclusions.

After reviewing the literature, numerous categories emerged contributing to and aligning with the structure and purpose of this study: (1) The Current State of Educational Technology in Teacher Education, (2) The Changing Landscape of In-Class Discussion 
in Higher Education, (3) Asynchronous Online Discussions - Interaction, Presence, \& Community, and (4) Digital Backchannels - Trends and Uses.

\section{The Current State of Educational Technology in Teacher Preparation}

Over the last two decades, teacher preparation programs have had to incorporate technology courses into their curriculum in order to keep up with the demands of the frequently changing learning environment. As society continues to move in a high-tech, fast paced direction, k-12 educators are challenged to make the material they are teaching relevant, exciting, and applicable. Technology courses within teacher education are typically taught separate from subject area methods classes and have focused primarily on the development of digital skills and knowledge. Most often, new teachers enter the classroom with a general aptitude for computers and other technological devices such as LCD projectors, digital cameras, and scanners, but they lack the required expertise to effectively integrate technological practices into their teaching models (Chen \& Chang, 2010).

Waring (2010) explains that teachers need to seamlessly integrate digital activities into their lessons and use technology as a tool, rather than the "driving force behind instruction." Teacher preparation has taken the approach of offering a stand alone course to incorporate technology, typically requiring students to take one educational technology course throughout their program (Betrus, 2012; Brown \& Warschauer, 2006; Goetze \& Stransberry, 2012). The brief, direct instruction style of this method reinforces the idea that future teachers will walk away from a one or two-hour educational technology course with limited subject or grade specific application knowledge to use technology as a teaching tool as Waring (2010) suggested. As a result, new teachers would normally 
have the skills and knowledge to perform administrative duties such as attendance, lunch count, and email communications, but lack the ability to consistently implement digital instruments into their classroom practices (Chen \& Chang, 2010).

Although teacher candidates may show gains in technology comfort levels, this does not necessarily translate into effective technology use within lesson plans (Mayo \& Kais, 2005). Furthermore, research indicates that teacher preparation programs have struggled with connecting educational theory to practical application and are continually trying to find best practice solutions for closing this gap (Darling-Hammond, 2005; O'Connor, 2006-2007). This phenomenon consistently holds true in regards to the use of instructional technology in teacher education programs.

In 2006, Kay conducted a literature review of 68 journal articles concerning the effectiveness of technology integration into pre-service teacher education programs. In this instance, the reviewed studies integrated at least one of ten teaching methods to incorporate technology, including integrating technology in all courses; using a variety of multimedia; focusing on education faculty; delivering a single technology course; modeling how to use technology; collaboration among pre-service teachers, mentor teachers, and faculty; practicing technology in the field; offering mini-workshops; improving access to software, hardware, and/or support; and focusing on mentor teachers (Kay, 2006). Weaving technology throughout the entire program was the approach used most frequently compared to the other nine strategies. The tactic that was employed the least, involved putting the responsibility of technology teaching on a mentor instructor, who would work with the pre-service teacher on a one-on-one basis to educate the future teacher on the use of technology in the classroom. Subsequently, the author does point 
out when at least one method was used, there were statistically significant gains made in the areas of computer attitudes, ability, and use, and the gains in regards to classroom use increased the most when several strategies were used in combination. In fact, out of the 68 studies evaluated, the three that incorporated four or more learning strategies reported sizable gains in pre-service teacher computer use (Kay, 2006). Although Kay (2006) does not deliberately specify which combination supports the greatest gains, it was noted that standout colleges of education use the amalgamation approach including separate technology courses, technology embedded within subject specific methods courses, and the incorporation of digital tools in field experiences.

These findings are consistent with research indicating the benefits of selecting teaching materials and educational strategies to meet the learning needs of individual students, appealing to the How People Learn (HPL) framework discussed in Preparing Teachers For a Changing World (Darling-Hammond \& Bransford, 2005). It can be safely concluded the advantages of using a variety of learning strategies for different learners applies to people of all ages, including post-secondary students. Using a combination of learning strategies may positively impact teacher education students when trying to successfully incorporate technology into their lesson plans. As a variety of strategies are employed, future teachers will grasp different elements of each, thereby reinforcing the multiple uses of technology in the k-12 classroom.

Darling-Hammond \& Bransford (2005) report that reforms have been made in teacher education program design, addressing the need for a stronger connection between formal coursework and practical application. This concept also holds true in the area of education technology and lends support to the idea of using computer- mediated 
communication to supplement an in-class dialogue in a real world classroom space. By using an additional channel of communication through a web based backchannel system, teacher educators may have the opportunity to model instructional technology that can be transposed to a variety of educational settings, giving pre-service teachers real, practical tools to take into their classrooms.

Allsopp, McHatton, \& Cranston-Gingras (2009) studied 13 undergraduate special education majors who were involved in an inaugural "laptop" cohort within a College of Education (p. 342). The authors looked at teacher attitudes and perceptions toward classroom technology use after students were involved in a teacher education curriculum that embedded technology applications over three semesters of methods courses. The study applied a systematic approach where higher education faculty not only revised the content of their methods courses to include technology, but were also required to model technology use in their instruction. This research measured pre-service teachers' attitudes toward instructing with technology, their competence in using technology in the classroom, and their views on the modeling of technology by university faculty during the three-semester period. The results indicated that pre-service students perceived themselves as more proficient at using technology as a teaching tool after the study period, while having a consistently positive attitude toward the integration of technology throughout the course of the experiment (Allsopp, McHatton, \& Cranston-Gingras, 2009). Additionally, the research indicates that Colleges of Education will need to fully embrace technology as a teaching tool used in higher education classrooms. After education faculty were required to model the use of instructional technology, teacher 
education students changed their perceptions and attitudes about the use of technology in the classroom.

Research has shown the logic behind offering distance learning courses and integrating educational technology within teacher education programs is largely due to Colleges of Education trying to keep pace with the rest of society (Bigum \& Rowan, 2008). According to Bigum \& Rowan (2008), "keeping pace has been important, if not the main logic that has supported the practices of acquiring, deploying and using computing and communication technologies in teacher education and schools for almost thirty years" (p. 245). The question then becomes: Is just "keeping up" good enough as teacher preparation programs in the $21^{\text {st }}$ century are challenged to provide future teachers with the technological skills, knowledge, applications, and dispositions in order to effectively utilize technology in their teaching practices?

\section{The Changing Landscape of In-Class Discussion in Higher Education}

The physical and virtual spaces in higher education are undergoing rapid changes in how information is presented, learned, and applied due to the influence of ubiquitous technology on how people communicate, live, and work in our society (Leu, Kinzer, Coiro, and Cammack, 2004). These scholars argue the most influential of technologies influencing the school environment are the wide variety of information and communication technologies (ICTs) that have emerged over the years and have become a part of society in the information age. ICTs such as blogs, email, and the handful of major social networking sites (Twitter, Facebook, Snapchat, Instagram, and Pinterest), with more developing as this research is being written, are, according to Leu, Kinzer, Coiro, and Cammack (2004), greatly impacting how educators teach and how students 
learn. In a well developed literature review, which focuses in on how this field of research is moving toward a theory of new literacies, these authors acknowledge and support the idea that the "nature of reading, writing, and communication is being fundamentally transformed" (p. 26). In their review of the current literature, it was found that the concept of "new literacies" lacks a clear definition, and there seems to be a absence of a consensus amongst scholars in the field. With this in mind, Leu, Kinzer, Coiro, and Cammack (2004) outlined a "New Literacies Perspective," which in their view provides a "useful starting point to inquiry," in this ever expanding space of knowledge (p. 26). A list of ten principals were developed that inform this new perspective. Although it is too soon to articulate a comprehensive theory, these authors argue, the following factors should be considered when the time comes to expand on the concept of a theory associated with new literacies (Leu, Kinzer, Coiro, and Cammack, 2004, p. 14):

1. The Internet and other ICTs are central technologies for literacy within a global community in an information age.

2. The Internet and other ICTs require new literacies to fully access their potential.

3. New literacies are deictic.

4. The relationship between literacy and technology is transactional.

5. New literacies are multiple in nature.

6. Critical literacies are central to the new literacies.

7. New forms of strategic knowledge are central to the new literacies.

8. Speed counts in important ways within the new literacies.

9. Learning often is socially constructed within the new literacies.

10. Teachers become more important, though their role changes, within new literacy classrooms. 
As Crystal (2001) argues, the impact of new technologies on language development and the norms of conversation must be considered in instructional environments. For instance, Crystal (2001) has coined the term "netspeak" which refers to a "type of language displaying features that are unique to the Internet," and represents a speaking and writing "medium which is electronic, global, and interactive" (p. 18).

As institutions of higher education are scrambling to try to keep up with the pace of the information era, digital socially distributed information will change the way students learn and instructors teach in postsecondary institutions. Hanford's (2011) audio podcast on American Public Media titled, "Don't Lecture Me," reports on the inefficiencies and ineffectiveness of the sole use of in-class lectures in a college classroom. The program emphasizes that a select few universities may be shifting the learning paradigm in higher education by creating programs of study that are studentcentered and technology based, relying less on the professor as the all knowing expert, and more on social network resources and collaboration among faculty and peers. As the metaphor of a moving freight train is continuing to be used to describe the momentum of technology advancements in our society, educational institutions will need to reformulate the way they present teaching and learning in the schools (Christensen, Horn, \& Johnson, 2008).

According to Kukulska-Hulme (2012), the higher education workforce needs to adapt to an environment that is pervasive with technological change and an increasingly diverse student population. In her recent paper, this author evaluates professional development opportunities that are offered through The Open University, which is one of the largest universities in the United Kingdom and is primarily a distance education 
institution. The Mobile Learning Guide, which is given to the faculty at The Open University as part of their technology training program, was evaluated by obtaining information through interviews conducted with University staff who had been sent the guide. Twenty-four course instructors who were sent the guide, were randomly selected to be interviewed by the researcher. Although The Open University is considered to be a public distance and research university, there were many faculty members at the time of the study that were not using a full range of mobile technologies in their courses. The interview results indicated there was a general sense of skepticism on the use of mobile devices in course delivery and faculty were apprehensive about the time and resources required to learn about such technologies. However, attitudes did begin to shift when the obvious benefits of incorporating mobile technologies were presented to faculty in the interview process (Kukulska-Hulme, 2012).

Not only are higher education institutions having to adjust to a changing landscape as a result of rapid technological changes in our society, but as Staley and Trinkle (2011) point out, there are many other societal forces contributing to a transformation on how colleges and universities do business. In their recent report, Staley and Trinkle (2011) bring up a collection of issues that colleges and universities are currently facing, such as an increasingly diverse study body, a reevaluated general educational curriculum, and the continuing skepticism over the economic value of a college degree. These factors certainly have technological implications, but as these authors suggest, careful consideration must be given to these movements and trends in order to not miss out on other important "environmental factors that are drivers for change in higher education" (Staley and Trinkle, 2011, p. 30). 


\section{Asynchronous Online Discussions - Interaction, Presence, and Community}

Presumably due to the upsurge in the availability of online classes in higher education (Bigum \& Rowan, 2008; Picciano, Seaman, \& Allen, 2010), numerous researchers have investigated the use of asynchronous, online discussions, commonly referred to as online discussion forums (ODFs) (Fisher \& Baird, 2005; Ke \& Kwak, 2013; Morgan, 2011; Redfern, \& Naughton, 2002; Schwier \& Seaton, 2013; Shackelford \& Maxwell, 2012; Song \& McNary, 2011; Vercellone-Smith, Jablokow, \& Friedel, 2012). Past research supports the use of this type of online communication to reach a variety of learners and to increase participation and build a sense of community among distance learners. Through the use of ODFs, students are given the opportunity to reflect and interact, with the instructional purpose of emulating an in-class discussion in a face-toface learning environment (Armstrong \& Thornton, 2012; Garrison, Anderson, \& Archer, 2001; Garrison, Cleveland-Innes, \& Fung, 2010; Jones, 2011; Redford \& Naughton, 2002; Shackelford \& Maxwell, 2012). As noted above, the majority of research as centered on asynchronous online discussions, rather than the utilization of synchronous, computer-mediated communication to augment the learning experience when students and teachers are meeting in a traditional, face-to-face classroom setting.

In fact, much of the recent literature concerned with interaction repeatedly stressed and analyzed student interaction in the context of participation in online group discussion activities, or ODFs (Ke \& Kwak, 2013; Schwier \& Seatin, 2013). Student participation is often interchangeable with the concept of interaction described by Moore $(1989,1993)$, simply due to the fact that participation in an educational setting is often 
seen as students cooperating, communicating, and interrelating with one another, their teachers, or with the content directly.

Providing a setting to foster emotional connections and making sure content is meaningful and relevant are two elements of course design worth noting when it comes to promoting participation in an online learning environment (Schwier \& Seatin, 2013). These authors conducted an exploratory study and made some preliminary conclusions about participation patterns of online learning environments, by investigating three types of online communication groups: formal, non-formal, and informal. Each category consisted of two groups (six total) and was differentiated by whether participation was required or optional. An informal discussion group was characterized by open conversations, voluntary participation, and if conversation or prompts were left completely up to the participants. In contrast, a formal discussion environment was described as the communication of students in classrooms being taught by teachers in coordinated, structured courses, which lead to programs of certificate or degree completion. Particularly in a formal online educational setting, participation seemed to increase if the instructor was flexible and evoked "casual, personal, and learner-directed conversations within the directed, formal discussion activity (Schwier \& Seatin, 2013, pg. 12).

Building on Moore's (1989, 1993) description of interaction in distance education as learner-content, learner-instruction, and learner-learner oriented, Song and McNary (2011) studied the learner-learner and learner-instruction aspect of interaction through the utilization of Soller's (2001) Collaborative Learning Conversation Skill Taxonomy (CLCST). The CLCST was the protocol chosen for analyzing asynchronous online 
discussion posts in a graduate level online course consisting of 18 students ( 2 doctoral and 16 master's level graduate students). The course was taught using Blackboard ${ }^{\circledR}$, an online course management system, which included seven modules that were made up of required topic related readings and discussion forums. This model displayed a detailed structure of conversational skills that are most often exhibited in collaborative learning. The CLCST is based off the idea that "inter-dependence, accountability, promotive interaction, social skill, and group processing are necessary ingredients of a successful learning group" (Johnson \& Johnson, 2005; Song \& McNary, 2011, p. 3). In particular, Song and McNary (2011) found that course design did influence the type and transformation of student posts over time. The particular course observed in the study required students to respond to a prompting question posed by the instructor to improve their understanding of various topics related to the class. Revealed through the CLCST coding system, the most common type of posts were "Inform-Suggest" and "ExplainClarify," which were consistent with the course design and instructor expectations. In contrast, this research determined an absence of a strong correlation between the quantity of posts and students' overall course grade. The nonappearance of a relationship between the two variables measured could have been due to several limitations in the study. For instance, the class used in the research showed very little grade variation simply due to it being a graduate level course (Song and McNary, 2011).

Not only does the type of online communication environment influence learner participation, but demographic qualities such as age, ethnicity, and education level determine participation and satisfaction levels (Ke \& Kwak, 2013). Ke and Kwak's (2013) investigation evaluated the transcripts of course required online discussions of 392 
students enrolled in 28 online classes at a well-known university in the United States. The courses were drawn from a collection of different disciplines and were made up of students of various ages, education levels, and ethnicities. According to this research, minority and highly educated learners tended to report positively on student-student interaction, as well as instructor-student contact, whereas their attitude regarding online distance education in general was unenthusiastic. Learners of a variety of ages appreciated and valued interaction within a multigenerational setting and minority groups reportedly felt included and accepted based on their cultural differences (Ke \& Kwak, 2013).

Building a sense of community within an online learning situation has also been firmly established in past research as a key element to online learning success (Armstrong \& Thorton, 2012; Garrison, Anderson, \& Archer, 2001; Garrison, ClevelandInnes, \& Fung, 2010; Jones, 2011; Redford \& Naughton, 2002; Shackelford \& Maxwell, 2012). Not only does interaction in online courses facilitate a sense of community (Shackelford \& Maxwell, 2012), but social, cognitive, and teaching presence generally leads to a more comprehensive, all-inclusive community of learners according to Garrison, Anderson, \& Archer (2001). Presence is been shown to be critical to student success in online courses (Yuen, Deng, \& Fox, 2009) and the reviewed literature is highly focused on teaching presence and its implications for online learning and its specific contribution toward developing a community of learners. In fact, Armstrong \& Thornton (2012) found by implementing the use of a synchronous discussion activity in an asynchronous graduate online degree program, all three types of presence were enhanced, contributing to a community of inquiry where students considered themselves 
"active participants in a cohesive community" (p. 6). Teacher presence was seen as significant to the development of a sense of community among participants and presence was boosted when instructors took on a welcoming and accepting attitude towards students with varying levels of content and technological knowledge. Moreover, teacher presence was affirmed when faculty authenticated and added new information to student conceptions (Armstrong \& Thornton, 2012).

Morgan (2011) goes further by determining that online learning, specifically online discussion spaces are not particularly standardized and instructors perceive and approach these communication spaces differently, which characterizes their teaching presence. With this particular research, Morgan (2011) emphasized the disconnect between online course designers and online course instructors when it comes to conceptions and uses of interactive discussion spaces and suggest exploring more alternative methods to unify their approach to online learning.

Jones (2011) adds to the importance of teaching presence in online learning by encouraging all three types of interaction as described by Moore (2007), by making sure instructors utilize a variety of teaching methods and materials. The design of the course studied included online discussions boards and group projects, which effectively engaged students and nurtured a learning community where students felt accepted and listened to (Jones, 2011).

Through the use of online class discussion activities, such as ODFs, students are given the opportunity to effectively engage in course content through interaction and active participation. Past literature on ODFs reinforces the importance of using this instructional technique as a way to develop a learning community in an online class, 
where students feel a sense of belonging and obligation to their peers, the instructor, and the course material itself. ODFs certainly have a place in today's online learning arena and continued research is needed in informing course designers and online learning instructors on best practice approaches in structuring ODFs to achieve optimal learning outcomes. Additionally, the adequate amount of research that has already been conducted in this area may inform scholarship associated with synchronous online communication techniques such as digital backchannels.

\section{Digital Backchannels - Trends and Use}

The previous literature associated explicitly with digital backchannels has typically been focused on using backchannels as a way to engage large audiences at industry or educational conferences, or students in a sizable lecture class format (Aagard, Bowen \& Olesova, 2010; Pohl, Gehlen-Baum, \& Bry, 2011; Jacobs \& McFarlane, 2005; Harry, Green, \& Donath, 2009; McCarthey \& Boyd, 2005; Saunders et al., 2009).

The majority of the literature describing digital backchannels in large settings leans toward the review and/or analysis of a particular computer-mediated communication platform (Backstage, backchan.nl, Hotseat, etc.) or looks at the use of networks or channels, such as Internet Relay Chat (IRC) to connect large groups of people through a global network of IRC servers. This research considers utilizing digital backchannels to connect synchronously in large venues in order to increase engagement, participation, and connectivity, as well as compensate for the lack of interactivity that occurs between presenters and audience members due to the scope and size of the event.

McCarthy and Boyd (2005) evaluated usage trends and patterns of a digital backchannel during a computer/technology industry conference that was made up of 
roughly 450 people over a 5-day period. The digital backchannel was made possible through a wireless Internet connection (Wifi) and four assigned Internet Relay Chat (IRC) channels, with three channels designated to three parallel sessions and one channel designated to the opening and closing conference wide sessions. McCarthey and Boyd (2005) used data from IRC backchannel logs, informal interviews from conference members, and comments gathered from other online forums to preliminarily explore and report on a relatively new communication medium at the time.

The study's authors were candid regarding their intention of the paper and used this research to gather general conclusions, rather than conducting an "exhaustive analysis" of the effects of digital backchannels in a large, same physical space setting (McCarthy and Boyd, 2005, p. 550). With the analysis taking place roughly ten years ago, it was not surprising to find the bulk of the concerns elicited from informal interview responses had to do with IRC awareness, access, and comfort levels. Conference participants indicated, "not everyone has a laptop, is capable of multi-tasking, or is comfortable chatting in this context" (McCarthy and Boyd, 2005, p. 550). Additionally, through the interviews and backchannel posts, conference speakers revealed their discomfort and irritation concerning the amount of listeners who seemed distracted and "attending to their laptops" during the presentation, giving the perception of disengagement (McCarthy and Boyd, 2005, p. 551). Although some degree of dissatisfaction was expressed by conference participants exposed to the front channel and backchannel (IRC) set-up, first-time conference attendees believed the practice to be helpful and valuable as they were acclimating to the norms and procedures of the event and getting acquainted with the conference attendees. 
More recently, research on backchannels during large events and/or venues tends to revolve around the analysis of a specific web-based system that is designed to give users easy to navigate, customized layouts in order to integrate digital backchanneling into their course. Backchan.nl (Harry, Green, and Donath, 2009), Hotseat (Aagard, Bowen, and Olesova, 2010), and Backstage (Pohl, Gehlen-Baum, and Bry, 2011) are all examples of proprietary online applications that enable participants easy access to the backchannel conversation, as long as an Internet connection is available.

Harry, Green, and Donath (2009) utilize backchan.nl, a particular type of web based backchannel system, in two large industry conferences, in order to analyze posts content, voting and posting patterns, and user responses to the system. As described by the study authors, backchan.nl is more than just a shared chat room. Rather, the system gives users the ability to not only pose questions and comments, but also allows users to rank questions and comments by voting either for or against them. The system uses a formula, giving preference to the quantity and most recent positive voting activity (Harry, Green, and Donath, 2009).

Similarily, Aagard, Bowen, and Olesova (2010), use the large venue format to describe the implementation and instructional use of a specific social networking tool called Hotseat. The Hotseat program was designed at Purdue University with all the commonly referred to disadvantages of large lecture teaching and learning environments in mind (impersonal, low levels of student engagement, and lack of student participation). Although large classes are cost effective and tend to give the majority of control of the content and delivery to the instructor, they leave little room for active and participatory learning by the student. Hotseat was designed to take advantage of the mobile devices 
students are already bringing to class (Smith, Salaway, and Caruso, 2009) and using them to create a "backchannel of collaborative discussion both in and out of the classroom" (Aagard, Bowen, and Olesova, 2010, p. 4). Unlike in the previously mentioned study, Hotseat allows the user to carry on the discussion outside of class by giving the student the ability to review marked or rated posts. In addition, this backchannel program interfaces with a large selection of devices including laptops, electronic notebooks, and common handheld devices such as iPhone and Android.

For this study, Hotseat was implemented in three large lecture classes over the fall 2009 semester and eight large classes over the spring 2010 semester. The total number of students exposed to Hotseat was roughly 2,700 and the data for the article was collected from a social presence survey, which was implemented in the spring. Overall, the majority of responders agreed or strongly agreed that Hotseat helped them understand what others in the class were thinking, which improved the class discussion and helped students feel less isolated (Aagard, Bowen, and Olesova, 2010). Furthermore, the study results indicated the anonymity of the backchannel program increased participation and reduced general student inhibition.

Much like Hotseat, Backstage is yet another digital backchannel program specifically designed to operate in large lecture classes (Gehlen-Baum, Pohl, and Bry, 2011). Backstage was tested in a large lecture class format using a preliminary user study to evaluate usability, the nature and type of questions posted, and how exactly the questions posed correlated with user's attitude about using a digital backchannel such as Backstage to ask questions in a learning environment. This experimental design research used a sample of nineteen participants randomly selected from different disciplines, with 
fourteen participants assigned to the experimental group and five participants assigned to the control group. Two content related subjects were presented to each group through a thirty-minute presentation, where the experimental group was logged in and informed of Backstage's features and were enabled to use the usable features of the current edition at the time. The control group listened to the lecture in a traditional way, asking questions by raising their hands and generally speaking only after the instructor had posed a question (Gehlen-Baum, Pohl, and Bry, 2011)

Based on this research, Gehlen-Baum, Pohl, and Bry (2011) made the following preliminary conclusions regarding the use of Backstage in a large lecture class format. In relation to usability, descriptive statistics gathered from surveys indicated the average time it took for users to get comfortable with Backstage was nine minutes, and $100 \%$ of participants posted at least one message on the system. Gathered from the open-ended questions on the survey, it was noted eight times how the participant appreciated the ability to directly communicate with the lecturer, and participants were also pleased to have their current knowledge checked by the quiz functionality of the program.

In relation to analyzing questioning specifically, the results from this study indicated the experimental group asked more questions and provided more feedback to the instructor compared to the control group. The type of questions asked in the experimental group were reported as being more "factual" and "comprehensive," compared to the questions in the control group being of an "integrative" nature, meaning more in-depth and relating to higher cognitive processes. The latter finding was not consistent with the authors' expectations, but may be explained by the level of schooling 
and field of study of three out of five of the control group participants (Gehlen-Baum, Pohl, and Bry, 2011)

Although the majority of the findings concerning Backstage were encouraging, data revealed from the survey open questions suggested that the addition of the lecture presentation slides being displayed on the program would be helpful. Additionally, participants noted there may be an issue with distraction, which can be supported by the Cognitive Load Theory (Sweller, 1994), and should be further addressed in future investigations of this digital backchannel program.

Markett, Arnedillo Sanchez, Weber, and Tangney (2006) looked at using short message service (SMS) in a smaller class size compared to the large lecture, using students' personal mobile phones to promote a "more active learning environment" ( $p$. 280). The study used short message service, commonly referred to as text messaging (Lai, 2004), to utilize technology to "support students and instructors in understanding and using an interactive message loop" (Markett et al., 2006, p. 283). The constraints of the interactive message loop were as follows: (1) communication between participants needed to be initiated by the student, (2) interactivity was able to occur during or after class, and (3) interactivity was able to transpire with or without technology (Markett et al., 2006.)

The study participants were made up of three different post secondary classes over a two-semester period with a total of forty-two students. The first class (Class A undergraduate students) met in person for lecture purposes, and the second and third classes (Class B and Class C - post-graduate students), which were primarily online courses, met in person to conduct group presentations only. All student participants had a 
mobile phone where they were encouraged to communicate by texting and the instructor used a laptop to receive and display text messages, which were only visible to him. The study literature failed to mention any specific parameters for students when sending messages, therefore it can be assumed the students were encouraged to text their thoughts regarding the lecture or presentation that was currently taking place. Data was collected from information that transpired in-class in the form of transcripts of text messages sent, timing of messages, sender of messages, as well as class observations. The after-class data came from postings made on the class website. Lastly, information was collected from pre- and post- student surveys, in addition to instructor feedback by way of interview responses or the voluntary submission of thoughts and reflections (Markett et al., 2006).

The findings of the above study were structured according to the initiating, acknowledging, responding to, and completing of the interactive loop. In total, $47 \%$ of students initiated text messages using SMS, 71\% of students felt the instructor acknowledged and responded to their text message, students commented on or responded to $28 \%$ of the text messages sent by other students, and $31 \%$ of students indicated on the class website that the message loop was completed (Markett et al., 2006).

Due to technological limitations at the time this study was conducted, students were only able to message one another after class through the project website and the instructor was the only individual who was able to see the text messages. Unfortunately, at this point in time, prepackaged backchanneling websites (as mentioned in earlier reviewed studies) with added controls and features were not available. 
More recently, educational scholars have added to the literature on digital backchannelings by analyzing the communication tool when used in smaller teaching and learning settings. Poleon and Krishnan (2013) used digital backchanneling as a tool to encourage participation and digital citizenship during a secondary level English class. The purpose of the study was to specifically measure students' engagement levels while reading the text of Shakespeare's Macbeth. Reading the text aloud (performing the play) or participating in the discussion feed constituted participation or engagement for the purposes of this study. Digital backchanneling was used to essentially supplement the previous performance-based structure of the unit, which required students to $\mathrm{read} /$ perform the text out loud in order to qualify as participation.

Student-created guidelines were established at the beginning of the class and were effectively monitored and regulated by the students themselves during the course of the investigation. The study authors facilitated a "text-based discussion by posting insights and making important connections" that enriched the learning experience for all students by creating an alternative space for "low-risk participation" (Poleon \& Krishnan, 2013, p. 44).

The methods used to measure student engagement were simple. The study authors noted whether a student participated in the reading of the text and/or commented using the digital backchanneling software, BackChannel Chat. Students were encouraged to add to the discussion by posting questions or supplying feedback. As opposed to the low engagement levels in prior classes where performance-based units were implemented, this particular English class displayed 100\% participation for all sections during the study 
period when BackChannel Chat was "utilized as a strategy for maximizing student engagement" (Poleon \& Krishnan, 2013, p. 43).

Similar to the research mentioned above, Jarrett and Devine (2010) reported their use of TodaysMeet.com, a specially designed, web-based backchanneling software, in a middle school social studies classroom. The authors concluded the overall experience was positive in that it gave "every student a voice" and took advantage of the heightened multi-tasking skills associated with being a part of the digital native generation.

Carpenter (2015) adds to the optimistic literature on digital backchanneling in small class sizes, by describing his observation of the discussion tool in three different secondary classrooms $\left(11^{\text {th }}\right.$ grade U.S. history, $9^{\text {th }}$ grade English, and $8^{\text {th }}$ grade science). In all three experiences, digital backchanneling expanded participation by allowing students who may not normally be active speakers during classroom discussions, a chance to contribute without the stress of articulating their thoughts out loud. Carpenter (2015) also points out the benefit of digital backchannels being able to provide a dedicated online space to add to conversations, complete an assessment or knowledge check or review the backchannel archive, after the face-to-face class has ended. Although most of what Carpenter (2015) reports concerning backchannels is positive, the article reminds readers that backchannels are "like any teaching strategy," and require careful planning and "thoughtful use" within the classroom (p. 57). In addition, access may still be an issue for some schools and students. As with many educational technology tools, distraction and proper use are oftentimes an issue. As suggested by Carpenter (2015), instructors need to integrate digital backchannels into the appropriate 
subject matter and make sure to not only facilitate the discussion, but manage the entire activity.

\section{Summary of Related Literature}

After reviewing the literature, four broad categories developed that support the structure of this study and reveal a gap in the research concerning digital backchannels:

(1) The Current State of Educational Technology in Teacher Education, (2) The

Changing Landscape of In-Class Discussion in Higher Education, (3) Asynchronous

Online Discussions - Interaction, Presence, \& Community, and (4) Digital Backchannels - Trends and Uses.

The first two categories point to several of the themes and trends concerning educational technology that are evolving in higher education and more specifically, in teacher education. As technology becomes an ever-increasing factor in our society, most educational scholars agree the field of teaching and learning must adapt and incorporate technology into schools, but the verdict is still out on how best to do that.

The next category looks at the current research and the resulting theories on distance education and asynchronous online communication, which tend to dominate the scholarship up to this point. With the growing popularity of online learning and hybrid coursework, many educational scholars have dedicated research to communication technologies that assist in creating a connected learning environment. Asynchronous communication technologies such as online discussion forums, course wikis, and/or group emails can give a distant learner the sense of a student community and teacher presence, attempting to make up for the lack of face-to-face contact which is obviously associated with a more traditional learning environment. 
The final category evaluates the related research associated with backchannel technology in an educational setting. The scholarship in this area seems to focus more on the use of backchannels in settings other than classrooms (large conferences or lectures) and there is a significant gap in the literature concerning the use of backchannels in a smaller context, especially looking at the influence of backchannels on recognized characteristics of the learning process such as interactivity and reflection. In other words, little research exists evaluating the use of synchronous digital communication to assist in the learning process while in a face-to-face college classroom. 


\section{CHAPTER III}

\section{RESEARCH DESIGN}

\section{Restatement of Problem and Questions}

Teacher preparation programs in the $21^{\text {st }}$ century are challenged to provide future teachers with the technological skills, knowledge, applications, and dispositions in order to effectively utilize technology in their teaching practices. As technology advances, its place in teacher education continually evolves from being just a required core course to being considered a tool for learning throughout the sequence of the program. The U.S. Department of Education presented the 2010 National Educational Technology Plan, which presents a transformation of our current educational system from simply using technology on an occasional basis to using it to fuel a $21^{\text {st }}$ century learning model, focusing on five areas of education: learning, assessment, teaching, infrastructure, and productivity (National Education Technology Plan, 2010).

Past research indicates that higher education administrators are struggling with making critical decisions regarding the integration of technology within a long-standing paradigm associated with postsecondary education (Archer, Anderson, \& Garrison, 1999; Garrison \& Kanuka, 2004; Goetze \& Stansberry, 2012; Weigel, 2002). Questions and concerns are building amongst higher education stakeholders on how to best manage the transformative potential of technology for teaching and learning at the college level (Garrison \& Kanuka, 2004; Sutherland-Smith \& Saltmarsh, 2010). Colleges of Education in particular, may be even more sensitive to the pressures of restructuring and 
modernization, simply due to the fact that pedagogic practices are deeply scrutinized and passed on, along with the content, to future educators (Saltmarsh \& Sutherland-Smith, 2010). As Colleges of Education continue to move through "uncharted waters" in regards to issues concerning online learning, blended learning, and effective technology integration within face-to-face classrooms, research based educational technology models, instructional technology teaching methods, and digital tools need to be readily available for college instructors to employ within their classrooms (Archer, Anderson, \& Garrison, 1999; Garrison \& Kanuka, 2004, Saltmarsh \& Sutherland-Smith, 2010; Sutherland-Smith \& Saltmarsh, 2010).

Interactivity (Kennedy \& Cavanaugh, 2008; Kyei-Blankson \& Donnelly, 2014; Moore, 1993, 2007; Schwier \& Seaton, 2013; Song \& McNary, 2011) and reflection (Boud, Keogh, \& Walker, 2013; Dewey, 1916; Fernsten \& Fernsten, 2005; Moon, 2013; Schubert, 2014) have been shown in past research to be vital components of the teaching and learning process. With that being said, digital backchanneling has the potential to influence teaching and learning by supporting in-class discussions and providing the necessary tool to encourage quality interaction and inspire meaningful reflection.

The purpose of this study is to explore the influence of digital backchanneling as a complement to live discussions in an educational setting. Specifically, this research will consider the effectiveness of backchannels in promoting in-class interactivity and overall student reflection within an undergraduate teacher education course.

Laurillard's (2002) approach takes what we already know regarding how people learn and breaks the process down to consider technology decisions in education in a purposeful, efficient manner. Laurillard's (2002) framework for the effective use of 
learning technologies highlights the component of conversations between teacher and learner, and later the conversations that are integral during the experimental or application stage of that process. This theory uses a model that is intended to be universal to all learning processes and includes the elements of interactivity and reflection in the conversational cycle that occurs between instructors and learners, as well as between learners and learners. Examining these two elements in relation to digital backchanneling enabled the researcher to explore why, how, and to what extent backchanneling contributes to in-class discussions relating to the discursive nature of learning and the practice of reflecting on the experimental aspect of the learning process. The following research questions were developed in light of Laurillard's (2002) framework:

1. In what way does digital backchanneling contribute to student interactivity during inclass discussions by teacher education students?

2. In what way does digital backchanneling contribute to pre-service teacher reflection in teacher education courses?

3. How does digital backchanneling influence the overall learning experience associated with in-class discussions in a face-to-face educational setting?

\section{Research Design}

The qualitative multicase study approach was the overall design chosen to respond to the research questions outlined above. Multicase study research is made up of a series of individual cases (in this instance, three teacher education classrooms), which belong to a compendium of cases that share common characteristics and serve as an example of the phenomenon being studied (Stake, 2013). The teacher education classroom will serve as the "single unit" or "bounded system" to be explored in this 
research (Merriam, 2009, p.81). Rather than looking at one single case, numerous teacher education classrooms were chosen that fit the study's relevant criteria, and provided the researcher with "reasonable coverage of the phenomenon given the purpose of the study" (Patton, 2002, p. 246). Furthermore, individual teacher education students were invited to be a part of the study who were enrolled in the participating teacher education courses. This study utilized Miles, Huberman, and Saldana's (2014) description of within-case sampling to provide guidance and support for the idea of looking deeper within the case and selecting individuals who are "nested" in the numerous classrooms that are involved in the research (p. 33). The above mentioned scholars also note the importance of withincase qualitative sampling being driven by theory and the selection of "participants, episodes, and interactions" should be motivated by attempting to conceptually understand the phenomenon in "different instances..., at different moments, in different places, with different people" (Miles, Huberman, \& Saldana, 2014, p. 33).

Overall, the qualitative case study method was chosen for this study in order to answer the proposed research questions in an inductive manner with the use of "rich, thick description" to understand the influence of digital backchanneling on student interactivity and reflection (Merriam, 2009, p. 43). In particular, qualitative case study, as described by Creswell (2007) and Yin (2003), is useful when a researcher explores a bounded system or multiple bounded systems over a period of time, capturing the researched phenomenon within its natural setting or real-world conditions.

In general, through qualitative research studies, reality or meaning is constructed from social contexts where human beings are interacting with one another, as well as the world around them (Bogdan \& Biklen, 2007; Crotty, 1998). Merriam (2009) 
characterizes the case study as one type of qualitative research and acknowledges different interpretations of how case studies are defined (the process of the investigation, the unit of analysis, or the end product). For the purposes of this study, the case study method served as the process of carrying out the research and further exploring the influence of backchannels from a student's perspective. In addition, this process of investigation allowed me to purposefully select which students to interview within the case or teacher education class. As Merriam (2009) suggests, "sample selection occurs first at the case level, followed by sample selection within the case" (p. 82). In both instances, explicit criteria needs to be spelled out and used to inform the process and to adhere to the purposes of the research (Merriam, 2009).

The influence of digital backchanneling on interaction and reflection in a face-toface learning environment were properly addressed by recognizing and exploring this issue from a specific person or group's perspective, which in this occasion, was the teacher education student (Merriam, 2009). In large part, the future success of educational technology as a whole and more specifically, computer-mediated communication techniques, depends on the views and opinions of higher education's primary customer: the student.

This study attempted to uncover the realities of the integration of digital backchanneling during in-class discussions, where topics and issues such as literacy instruction and educational technology are covered that are relevant to pre-service teachers. With the utilization of the case study approach, teacher education students within a teacher education classroom were able to be interviewed, giving an in-depth, thorough description of each participant's understanding of digital backchannels and their 
use in lecture/discussion. Prior to conducting participant interviews, the researcher was able to gain invaluable insight from observing digital backchanneling sessions during face-to-face discussions, as well as analyzing the front and backchannel transcripts associated with those sessions.

Inherent to the qualitative process is the element of discovery and the idea that multiple truths or realities can be uncovered, depending on the participant and the researcher in any given condition (Harwell, 2011). Therefore, the goal of replication and generalization is commonly not the case. Instead, understanding, not predicting, as Denzin \& Lincoln (2009), put it, is the overarching theme associated with qualitative research and this study, and therefore, this method of collecting data should have a different set of validating criteria, as compared to positivist quantitative inquiry. Overall, the qualitative process enabled me to become intimate with the data and to gain a better understanding of the expectations, perceptions, and issues associated with implementing an interactive technology such as backchanneling into the college classroom. As such, the results of this research will allow higher education institutions to be better prepared to offer students $21^{\text {st }}$ century learning experiences, optimizing achievement, growth, and career related skills and competencies.

\section{Underlying Philosophy}

The overall conceptual framework of social constructivism served as the fundamental philosophy for this study, directing the course of the research and providing a background for an exposition of the data (Edmonson \& Irby, 2008). Derived from Vygotsky and Bruner's developmental theories and Bandura's learning theory, social constructivism emphasizes that meaning results from individuals' experiences and 
interactions with other human beings and the world around them. With a social constructivist viewpoint, researchers would heavily rely on the subjective interpretations from the participants of the issue being studied (Creswell, 2003). In the case of this study, a student's experience with backchanneling can be described by "multiple realities, or interpretations of a single event," where "reality is socially constructed" (Merriam, 2009). A more explicit focus detailing Laurillard's (2002) Conversational Framework for Learning theory, Moore's (1993) Transactional Distance theory, and Dewey's (1916) eminent conclusions regarding the necessity of reflection in the learning process, were used to make decisions regarding data sources, participants, and methods of analysis.

The Conversational Framework for Learning theory was generated from already existing theories outlining the importance of instructionism (Merrill, 2002; Reigeluth, 1983), constructionism (Papert \& Harel, 1991), socio-cultural learning (Wertsch, 1980; Wertsch, 1985), and collaborative learning (Dillenbourg, Järvelä, \& Fischer, 2009; Scardamalia and Bereiter, 2006) in the overall teaching and learning process. Given this existing set of ideas, the theory purports there are critical exchanges between the instructor, learner, and the learners' peers that are necessary to the learning process. Some of these interactions take place at the discursive level (dissemination of information and articulation of ideas) and some occur at the experiential level (real world experience, applying what has been learned). For effective learning, Laurillard (2002) argues these critical exchanges on two levels of learning occur within an iterative process involving discursive, adaptive, interactive, and reflective dialogue. In Laurillard's subsequent research, the Conversational Framework is used to evaluate forms of educational media or educational technology. 
The second theory that contributed to decisions regarding the specifics of this study was Moore's (1993) Transactional Distance Theory. The premise behind the research lies in the argument that learning is supported by interactivity between the learner and instructor, the learner and the content, and the learner and the learner (Moore, 1989). Moore (1993) contends the "psychological and communication space is the transactional distance" and there are three specific elements in a distance education environment that contribute to this space (p. 22). These elements are related to the structure of the teaching and learning processes as determined by the instructor, the qualities of the dialogue between learners and learners and learners and instructors, and the level of learner autonomy or independence. All three types of interactivity have important implications to course structure, learner dialogue, and learner autonomy and the transactional distance is minimized in a course with less structure and more dialogue. In other words, the less distance or space in a course, in terms of psychologically and communicatively, the more advantageous it is for learning (Moore, 2013). Interactivity contributes to the minimization of transactional distance, which in turn leads to a better educational experience, especially in an online or distance learning scenario, where transactional distance is inherently high.

Lastly, Dewey's (1916) views on the importance of reflection in the learning process weigh heavily on the structure and focus of the study. Laid out by Dewey throughout his writings, and further articulated by Rodgers (2002), authentic reflective thinking is defined by learners participating in purposeful and organized meaning-making within a social environment, while making ongoing connections of new knowledge to past experiences and thought processes. In concurrence with Dewey, 
Laurillard $(2002,2008,2009)$ suggests reflection is a necessary step in the iterative process of learning. The act of reflection is utilized by students to adapt to the information being taught in light of their experience and by teachers to adapt instruction in light of students' actions and/or feedback.

\section{Participants}

For this study, purposeful sampling, as described by Patton (1990), was used to select higher education classrooms from a large Midwestern university, where teacher education faculty had agreed to partake in this research, and have had experience using digital backchanneling in their course as part of their pedagogical strategy prior to this research. As Patton (1990) suggests, the logic behind purposeful sampling is to intentionally select "information-rich cases whose study will illuminate the questions under study" (p. 169).

Teacher education classrooms were chosen based on two criteria: (1) Instructors had previously used digital backchanneling in their courses and have deliberately integrated the technology into their curriculum. (2) Instructors were willing to allow the researcher to observe backchanneling sessions and to solicit the enrolled students to participate in one-on-one interviews. Edmonson \& Irby (2008) suggests, "if you are seeking to learn more about a specific teaching method, you would purposefully select teachers who have used the technique" (p. 64).

Within each case, individual student participants were selected for interviews based on the logic associated with maximum variation sampling. I purposively selected teacher education students who displayed the "widest possible range of the characteristics of interest for the study," focusing attention on relatively high and low levels of 
interactivity, as well as considering the role the student played in the backchannel activity (Merriam, 2009, p. 79). First identified by Glaser and Strauss (1967), and later affirmed by Miles and Huberman (1994) and Patton (2002), maximum variation sampling enables the researcher to draw valuable information from common patterns that are revealed through extreme instances.

For the purposes of choosing study participants who consented to one-on-one interviews, I evaluated levels of participation and the student's role during the backchannel activity to determine a wide range of variation amongst potential participant interviewees. By simply looking at the number of comments made during backchanneling, the researcher was given a preliminary understanding of the students' experience with backchanneling and their level of interaction with other learners, as well as the course content. In regards to the backchannel sessions observed, the instructor's interaction with students varied, and usually once the activity started, there was limited interaction between student and instructor. For this reason, in regards to interactivity, students were evaluated on their interface with one another and to the class content alone, when determining maximum variation. The student participant's role was the second characteristic used to determine diversity amongst the selected sample. The student's role was decided by whether they participated in the backchannel only during the two sessions observed, or, had a chance to be in both the backchannel and the front channel during the in-class discussion.

A total of three teacher education instructors participated in the study, allowing me to observe two backchannel sessions per instructor/course. Out of the 62 students who agreed to participate in the overall study (observations of classes/digital backchannel 
transcripts), I identified within each course the students who voluntarily agreed to participate in the interview portion of the study by signing an informed consent form. The number of times the student commented during the first backchannel session was tallied and compared to the number of times that same student commented in the second session. The backchannel session with the highest number of comments for that student was recorded in Table 1. The decision to use one session compared to adding both sessions together was decided upon to account for the students who were only able to participate in a backchannel session once, due to their placement in the front channel or due to the student being absent from class on that day.

Based on the criteria listed in Table 1, the students with the lowest and highest number of comments within each role category (BC only and BC \& FC) were purposely selected to fulfill the requirements of choosing students who displayed the widest range of dissimilarity in their backchanneling experience. 
Table 1

Sample Selection - Variation of Student Experience

\begin{tabular}{|c|c|c|}
\hline Student Participant - Instructor A & $\begin{array}{l}\text { \# of BC } \\
\text { Comments }\end{array}$ & Role \\
\hline Tara & $26(\mathrm{BC} 1)$ & BC only \\
\hline Cara (Student D) & 12 (BC 1) & BC only \\
\hline Wilma (Student A) & 40 (BC 2) & BC only \\
\hline Dave & $28(\mathrm{BC} 2)$ & BC only \\
\hline Ed & $45(\mathrm{BC} 2)$ & $\mathrm{BC} \& \mathrm{FC}$ \\
\hline Kat (Student B) & 52 (BC 2) & BC \& FC \\
\hline Nan (Student C) & 25 (BC 1) & BC \& FC \\
\hline Student Participant - Instructor B & $\begin{array}{l}\text { \# of BC } \\
\text { Comments }\end{array}$ & Role \\
\hline Jim (Student F) & 28 & BC \& FC \\
\hline Sara (Student E) & 68 & BC only \\
\hline Molly & & FC only \\
\hline Jack & 32 & BC only \\
\hline Kris & 22 & $\mathrm{BC} \& \mathrm{FC}$ \\
\hline Mara (Student G) & 51 & $\mathbf{B C} \& \mathbf{F C}$ \\
\hline Kelly & 41 & BC only \\
\hline Claire & 49 & BC only \\
\hline Sam & 31 & BC only \\
\hline Melody & 9 & $\mathrm{BC} \& \mathrm{FC}$ \\
\hline Andy & 21 & BC only \\
\hline
\end{tabular}

Although the study participants may or may not have had a thorough understanding of backchannels, most of the students enrolled in the participating courses have had involvement in teacher preparation courses and were quite familiar with the idea of collaboration/interactivity in a classroom setting. Instructor $\mathrm{C} / \mathrm{Course} \mathrm{C}$ was not included in the sample selection process simply because there were no students who voluntarily agreed to be interviewed after the interview consent form was presented to them. Although there were no students interviewed from Instructor C's course, Instructor 
C's data was still included in the study for the purposes of capturing the front and backchannel conversations for content analysis and theme development. In total, six front channel transcripts and 20 backchannel transcripts from three different courses and six different class sessions, along with seven student participant interview transcripts, were examined to determine the influence of backchanneling on student interactivity, reflective thinking, and overall learning.

\section{Data Collection Approach}

Observations of in-class discussions with the use of digital backchanneling as a teaching technique, transcripts of front and backchannel communication, and interviews of student participants were the primary techniques used to collect data for this study. The data collection process was supplemented by an initial phase, which consisted of the document analysis of course syllabi, assignment descriptions, and the particular course texts that were associated with the backchanneling activity. These were examples of course related documents that helped reveal how, why, and when backchanneling was integrated into the course and to "provide background and context, additional questions to be asked, supplementary data, a means of tracking change and development, and verification of findings from other data sources" (Bowen, 2009, p. 30). Specifically, I became familiar with the class content by reading over the course readings that were used to base the backchannel sessions on. The readings provided information to aid in the development of coding categories when analyzing student-content interaction. Furthermore, the documents helped me become familiar with the course content, objectives, requirements, etc., enabling me to figure out how the method of digital backchanneling is situated in the overall class. 
I audio recorded and transcribed the front channel conversations, as well as each interview. To add to this data, the backchannel communication was printed off as an additional information source, utilizing the online communication software that was chosen by each instructor. Data was collected from three distinct sources (classroom observations, front and backchannel communication transcripts, and student interviews), in order to fully address the study's research questions and to gain several different perspectives on digital backchannel communication.

\section{Observations}

The method of observation was used to address research question number three of this study: How does digital backchanneling influence the overall learning experience associated with in-class discussions in a face-to-face educational setting? In addition, classroom observations of teacher education students using digital backchanneling chronologically fell first in the data collection process, which enabled the researcher to lay the groundwork for evaluating the types, level, quality, and to what extent interactivity and reflection were taking place. The observation process informed the direction of the study, as well as provided information to specifically address research question number three. As expressed by Becker and Geer (1970), observational datum gives "more information about the event under study than data gathered by any other sociological method" (p. 133). Copious field notes during the observation sessions were taken, including the front-channel verbal discussion of the participants, along with detailed information concerning their behaviors, non-verbal cues, gestures, and body language. Merriam (2009) also suggests including "direct quotations and researcher 
comments" within the field notes, helping to transport the "reader to the site" or experience (p. 131).

Furthermore, comprehensive field notes were taken of the teacher education students who were participating in the discussion by using the backchannel. Although these participants were not verbally contributing to the conversation, their subtle factors such as informal interactions between participants, facial expressions, and less obvious or unplanned behavior, provided a wealth of information (Patton, 2002). Highly descriptive field notes (Merriam, 2009) capturing the classroom, the in-class discussion, and the teacher education students and faculty involved, provided the researcher with data indicating the quality and value of the overall learning experience with the use of digital backchanneling as a method to conducting an in-class discussion.

According to Denzin and Lincoln (2005), all forms of observational research include three levels: (1) descriptive observation (2) focused observation, and (3) selective observation, as the observation process progresses. The researcher used the first in-class observation as a descriptive observation in order to gain a comprehensive, thick portrayal of the classroom setting and the people involved in the digital backchanneling sessions. "Open jottings" as noted by Emerson, Fretz, and Shaw (1998) as being the brief notes taken during the actual observation, were written down on occasion in order to jog the researcher's memory when writing up a longer account of the observation (fieldnotes) at a later time. The first observation of each course used in the study was utilized to gather information on the actual classroom details such as the placement of participants, the sights and sounds associated with the room itself, and general characteristics associated 
with the backchannel dialogue (chosen topic, timing of the remarks, placement of the activity within the class period).

As soon as each observation session concluded, full fieldnotes were written up at a different location other than the classroom where the backchanneling took place, giving careful attention to describing the scene as in much detail as possible. As suggested by Bogdan and Biklen (2007), the fieldnotes were recorded immediately following the observation, making sure to not allow for too much time in between observing and recording. Jottings were also used in this process to supplement the fieldnote narrative with the researcher's thoughts, concerns, and questions (Miles, Huberman, \& Saldana, 2014). This portion of the description was written in italics. Fieldnotes from observations not only reveal the situation in detail as it occurs, but discloses the perception and interpretation of the particular researcher (Emerson, Fretz, and Shaw, 1995).

Although Emerson, Fretz, and Shaw (1998) have argued, there is no correct or exact way to write about what one observes in a natural setting, the researcher made certain to expand the description, making sure to not just write down "facts" concerning the situation. Rather, considerable time was taken to use "active processes of interpretation and sense-making," and to note the significance and impact of cues, interactions, and scenarios (Emerson, Fretz, and Shaw, 1995, p. 4).

The second observation allowed for a more "focused observation," by concentrating on the instances and scenarios that were directly tied to digital backchanneling (Denzin and Lincoln, 2005, p.732). For example, I made certain to choose a position within the room to carefully observe the sights, sounds, and images associated within the backchanneling experience. Additionally, the second observation 
allowed me to video record the session, capturing the experience for later review and analysis. By video recording the second observation and creating a saved file, I was able to go back and review the scene once again, focusing more on student participants' gestures, facial expressions, body language, and demeanor. This type of "selective observation" compliments the above-mentioned forms and provides a final step to a standardized procedure, which is imperative to the success and efficacy of the observational process (Denzin and Lincoln, 2005, p. 732).

\section{Content Analysis Front and Backchannel Transcripts}

To primarily respond to research question number one of this study (In what way does digital backchanneling contribute to student interactivity during in-class discussions by teacher education students?), I audio recorded and transcribed the front channel live discussions to later analyze and interpret. The backchannel conversations were printed out and analyzed from two dissimilar in-class discussions within three different teacher education courses, instructed by three different professors. As the process unfolded, I realized by focusing in on the content of what was being said by the student participants (whether they were in the backchannel or in the front channel) in relation to the discussion topic, the levels and types of reflective thinking were also able to be explored. Therefore, both sets of transcripts were used to also address research question number two of this study: In what way does digital backchanneling contribute to student reflection in a teacher education course? Rogers' (2002) interpretation of Dewey's analysis of true reflective thinking was utilized to determine whether the student participant's backchannel or front channel comment could be classified as a legitimate reflective thought. 


\section{Participant Interviews}

Lastly, the method of gathering qualitative data by conducting participant interviews was used to answer research questions number one, two, and three of this study (In what way does digital backchanneling contribute to student interactivity during in-class discussions by teacher education students? In what way does digital backchanneling contribute to pre-service teacher reflection in teacher education courses? How does digital backchanneling influence the overall learning experience associated with in-class discussions in a face-to-face educational setting?). The interviews were conducted toward the end of the semester, after the observations had taken place and the front and backchannel conversations had been recorded and transcribed. The interviews were audio recorded and later transcribed by a third party transcription service.

During the first backchannel observation session, before the class started, I briefly introduced myself and defined the study purpose, value, and their role in the process. Prior to the initial observation, the course instructor passed out two consent forms to each student thoroughly explaining the purpose of the research and inviting each student to optionally participate in the study. The consent forms explicitly described the use of all of the involved data collection methods (observation, interviewing, and the use of front and backchannel transcripts), as well as the procedures, potential risks and benefits, and confidentiality issues associated with the research. Students who voluntarily agreed to partake were also given the opportunity to take part in a researcher led interview. Participants were asked to print, sign, and return the form stating their willingness to meet at a convenient date, time, and location to conduct the interview. 
Once I received the interview consent forms back, the willing participants were set aside and the researcher proceeded to complete the process of determining a sample with maximum variation as described above. Select students were then contacted via email and an interview location, day, and time was arranged. Eight students were originally selected for maximum variation, but one student did not return my correspondence after repetitive attempts. As a result, seven total students were interviewed for this study.

Prior to asking the student participant a series of questions, I (interviewer) reviewed with the interviewee the purpose of the study and outlined the specific research questions the study was seeking to address. The interview protocol consisted of seventeen total questions (see Appendix B), where nine questions specifically related to the three levels of student interaction (student-student, student-instructor, and student-content) previously outlined by Moore (1993) earlier in this paper. Three of the interview questions were designed to understand a student's reflective thinking as a result of the digital backchanneling activity. In total, the interview questions were intended to capture the student's perception of digital backchanneling as it relates to connectivity, engagement, attention levels, satisfaction, motivation, ease of use, and knowledge construction, hence, allowing me to gather insight on the overall learning experience in a college level course. The student participants' elaboration on these areas of the learning process allowed the researcher to draw conclusions and develop themes revealing best practice solutions for using digital backchannels in a teacher education classroom.

Data gathered from face-to-face interviews has the potential to reveal a wealth of insight and perspective regarding the issue being studied. As with any qualitative data 
collection method, participant interviews may be subject to interviewer/interviewee bias, as well as "normatively appropriate responses" by the study participant, meaning interviewees may feel the pressure to respond to questions the way they perceive the interviewer wants them to respond (Bean, 2011, p. 174). I made sure to reinforce with the interviewee the language of the interview consent form, which outlined their rights in declining to answer any question and how the answers they provide will not influence their grade or student status within the university. With that being said, participant interviews are an effective measurement tool for gathering information associated with people's "feelings, thoughts, and intentions" (Patton, 2002, p. 340-341).

Researchers are not able to acquire information relating to the affective domain by simply observing participants or by analyzing topic related documents. Interview data allows the researcher to come into "the other person's perspective" in regards to the particular topic of study (Patton, 2002, p. 340-341).

The interviews consisted of a semi-structured format, allowing participants to expand on their answers to open-ended questions. With the semi-structured format, I was able to "set the stage" for data collection by giving a brief introduction of their role in the study and a description of the overall purpose of the research. The initial two to three questions were designed to orient the participant to the situation and allow them to collect their thoughts and focus on the topic at hand. These questions were somewhat directed, allowing me to obtain the participant's educational background and inquire about their general experience with digital backchanneling. The remainder of the interview was less structured, but still guided by the issues to be explored, giving participants a chance to 
tell their account of the backchanneling experience, as well as elaborate on their opinions and views.

The open-ended nature of the questions helped alleviate pressured responses by giving interviewees the opportunity to share their opinions and feel comfortable straying from the intended direction of the question. I chose a less structured format in order to explore the issues involved and respond to the participant's answers as the interview unfolds (Merriam, 2009). The majority of the questions were used to guide the conversation and elicit unique viewpoints on the researched topic (Merriam, 2009) and how it relates to an in-class teacher education discussion, interactivity amongst their fellow classmates, and in and out of class reflection on the topic at hand. The interview sessions lasted anywhere from thirty minutes to one hour and were held in one of two private conference rooms on the second floor of the college of education building at the university from where the pool of students were solicited.

The technique of participant interviewing permitted the researcher to not only gather rich, descriptive information through verbal responses, but allowed for observations of body language, facial expressions, tone of voice, and other non-verbal cues (Opdenakker, 2006). These sometimes imperceptible clues can remain hidden with other data collection options, supporting the decision to use participant interviewing in this study to supplement the other two data collection methods.

As described by Johnson (1997), methods triangulation validates the research by using multiple data collection techniques that reinforce different aspects of the evidence, contributing to a more holistic view of the phenomenon. Observations, transcript analysis, and participant interviews are the variety of methods that were used to collect 
data for this study. Data triangulation as explained by Johnson (1997) is another strategy employed to validate the research. Interviews were conducted with a variety of participants, noting the variance in depth and richness of their different backchanneling experiences, the type of backchannel program used, the class where participation took place, and the grade level of the participant in the teacher preparation program. By using multiple data sources, different perspectives were gathered from people who have various levels of experience with digital backchanneling (Johnson, 1997). As proposed by Mathison (1988) as one of the four types of triangulation, gathering data from multiple sources can increase the validity and credibility of the researcher's findings, contributing to a more reliable study. Lastly, although theory triangulation has its limitations and is considered somewhat "problematic at best" as explained by Denzin (1978) in his comprehensive review of the concept, this study attempted to use theory triangulation to gain a varied perspective from which to view digital backchannels (Mathison, 1988, p. 14). Denzin (1978) goes on to explain that theory triangulation is almost impossible to achieve simply because most scholars are naturally committed to a given perspective. At the very least, triangulation of theory, according to Denzin (1978), assures the study is conducted with some type of theoretical perspective and forces researchers to commit to a theoretical framework to some degree. In this study, theory triangulation does indeed exist with a presentation of three different perspectives (social constructivism, conversational framework for learning theory, and transactional distance theory) from which to view backchannels, allowing the researcher to commit to a framework that is supported and complimented by previous research and seminal educational theory. 
In general, the goal of triangulation is to show how the information from multiple sources converges to reveal a consensus or validation of the issue or specific situation. In many cases, the method of triangulation reveals the opposite: contrasting information and opposing viewpoints. The worthiness of this technique is not necessarily defined by its ability to show consistent data, but rather its ability to shed light on the context as a whole and force the researcher to take a holistic, yet reasonable approach to understanding a situation or phenomenon in its entirety (Mathison, 1988).

As Coffey and Atkinson (1996) explain, "qualitative researchers employ a variety of strategies and methods to collect and analyze a variety of empirical data" (p. 4). Interviews, observations, naturally occurring interactions, and documents are more common situations in the collection of data, whereas portraiture, visual sociology, oral history, autoethnography, and an arts based approach are thought of as more unique methods. The important point to consider in concerning this research is that data comes in many shapes and sizes, and when it comes to collection and analysis, "there is no single way of approaching those materials" (Coffey and Atkinson, 1996, p. 4).

\section{Backchannel Technology, Structure, and Content}

The first instructor participant utilized Chatzy and the other two instructors utilized TodaysMeet to facilitate both of their backchanneling sessions. Both Chatzy and TodaysMeet are free private chat services that provide a simple, easy to access online venue to host a backchannel session. TodaysMeet has marketed itself as being geared more toward educational settings by including information/text on its home page that aligns with educators' goals and school environments. Regardless, both services fundamentally provide the same features: (1) free, private chatrooms for online 
discussion and (2) saved, permanent transcripts for later retrieval. After each observation of the class session, the corresponding instructors emailed the backchannel transcripts to the researcher and the front channel audio recordings were transcribed using a third party transcription service.

Depending on the participating class and instructor, the number of groups (transcripts) in each backchanneling session varied. Table 2 represents the instructors who participated in the study and the corresponding structure of their backchanneling sessions:

Table 2

Backchanneling Structure

\begin{tabular}{|c|c|c|}
\hline Instructor - Course & \# of BC's/\# of FC's & Design \\
\hline Instructor $\mathrm{A}-\mathrm{BC} 1$ & $4 \mathrm{BC}$ 's/1 FC & $\begin{array}{l}\text { Fish Bowl - FC in } \\
\text { front of class, BC's } \\
\text { dispersed amongst } \\
\text { tables, no guiding } \\
\text { questions, no link to } \\
\text { FC }\end{array}$ \\
\hline Instructor $\mathrm{A}-\mathrm{BC} 2$ & $4 \mathrm{BC}$ 's/1 FC & $\begin{array}{l}\text { Fish Bowl - FC in } \\
\text { front, BC's sitting } \\
\text { together at tables, } \\
\text { guiding questions } \\
\text { online \& posted on } \\
\text { overhead monitors, } \\
\text { each BC had link to } 1 \\
\text { FC student }\end{array}$ \\
\hline Instructor B - BC 1 & $3 \mathrm{BC}$ 's/1 FC & $\begin{array}{l}\text { Fish Bowl - FC in } \\
\text { front of class, BC's } \\
\text { were dispersed } \\
\text { throughout room }\end{array}$ \\
\hline
\end{tabular}




Instructor - Course \# of BC's/\# of FC's Design

\begin{tabular}{|c|c|c|}
\hline & & $\begin{array}{l}\text { sitting in traditional } \\
\text { style desks, no } \\
\text { guiding questions, no } \\
\text { link to FC }\end{array}$ \\
\hline Instructor B - BC 2 & $3 \mathrm{BC}$ 's/1 FC & $\begin{array}{l}\text { Fish Bowl - FC in } \\
\text { front of class, BC's } \\
\text { dispersed throughout } \\
\text { room sitting in } \\
\text { traditional style } \\
\text { desks, no guiding } \\
\text { questions, each BC } \\
\text { had link to } 1 \text { FC } \\
\text { student }\end{array}$ \\
\hline Instructor $\mathrm{C}-\mathrm{BC} 1$ & $\begin{array}{l}1 \mathrm{BC} / 1 \mathrm{FC} \\
\text { (students switched } \\
\text { half-way through) }\end{array}$ & $\begin{array}{l}\text { Socratic - FC formed } \\
\text { middle circle, BC } \\
\text { formed outer circle, } \\
\text { instructor contributed } \\
\text { to BC with prompting } \\
\text { questions throughout, } \\
\text { no link to FC }\end{array}$ \\
\hline Instructor $\mathrm{C}-\mathrm{BC} 2$ & $\begin{array}{l}3 \mathrm{BC} \text { 's/1 FC } \\
\text { (students rotated) }\end{array}$ & $\begin{array}{l}\text { Socratic - FC formed } \\
\text { inner circle, each BC } \\
\text { had link to } 1 \mathrm{FC} \\
\text { student, instructor } \\
\text { contributed to BC } \\
\text { with initial prompting } \\
\text { questions }\end{array}$ \\
\hline
\end{tabular}

The overall content for the three courses that participated in this study was related to middle/secondary level literacy, learning, and instruction within the teacher education discipline. All three courses were undergraduate level and were required within their corresponding program of study. All six discussions were based off of a course related 
text/texts chosen by the instructor varying in size, readability, and relevance. Table 3 represents each instructor and the respective backchanneling session aligned with the content that was chosen to base the in-class discussion on.

Table 3

Content Chosen for Backchannel Activity

\begin{tabular}{|c|c|c|}
\hline Backchannel Discussion & Class Content & Summary \\
\hline Instructor $\mathrm{A}-\mathrm{BC} 1$ & $\begin{array}{l}\text { 1 Book - } \\
\text { 1.Literacy with an } \\
\text { attitude: Educating } \\
\text { working-class } \\
\text { children } \\
\text { in their own self- } \\
\text { interest }\end{array}$ & $\begin{array}{l}\text { 1. History of literacy } \\
\text { education; issues } \\
\text { associated with } \\
\text { educating the } \\
\text { working class; } \\
\text { social reform vs. } \\
\text { accommodations; } \\
\text { rethinking schools; } \\
\text { empowerment }\end{array}$ \\
\hline Instructor $\mathrm{A}-\mathrm{BC} 2$ & $\begin{aligned} 3 \text { Articles - } \\
\text { 1. Learning to Listen } \\
\text { to Student Voices: } \\
\text { Teaching with Our } \\
\text { Mouths Shut } \\
\text { 2. Working Toward } \\
\text { Third Space in } \\
\text { Content Area } \\
\text { Literacy } \\
\text { 3. Decoding Symbolic } \\
\text { Language: From } \\
\text { Icon to Understand }\end{aligned}$ & $\begin{array}{l}\text { 1. Using observations, } \\
\text { assessments, \& } \\
\text { inquiry to listen to } \\
\text { student voices, } \\
\text { creating a } \\
\text { community of } \\
\text { learners classroom } \\
\text { environment } \\
\text { 2. Examination of the } \\
\text { overlap between } \\
\text { home and school } \\
\text { funds of knowledge } \\
\text { and Discourse; } \\
\text { Urban, Latino } \\
\text { community } \\
\text { 3. Decoding visual } \\
\text { icons to result in } \\
\text { language } \\
\text { (Table Continues) }\end{array}$ \\
\hline
\end{tabular}




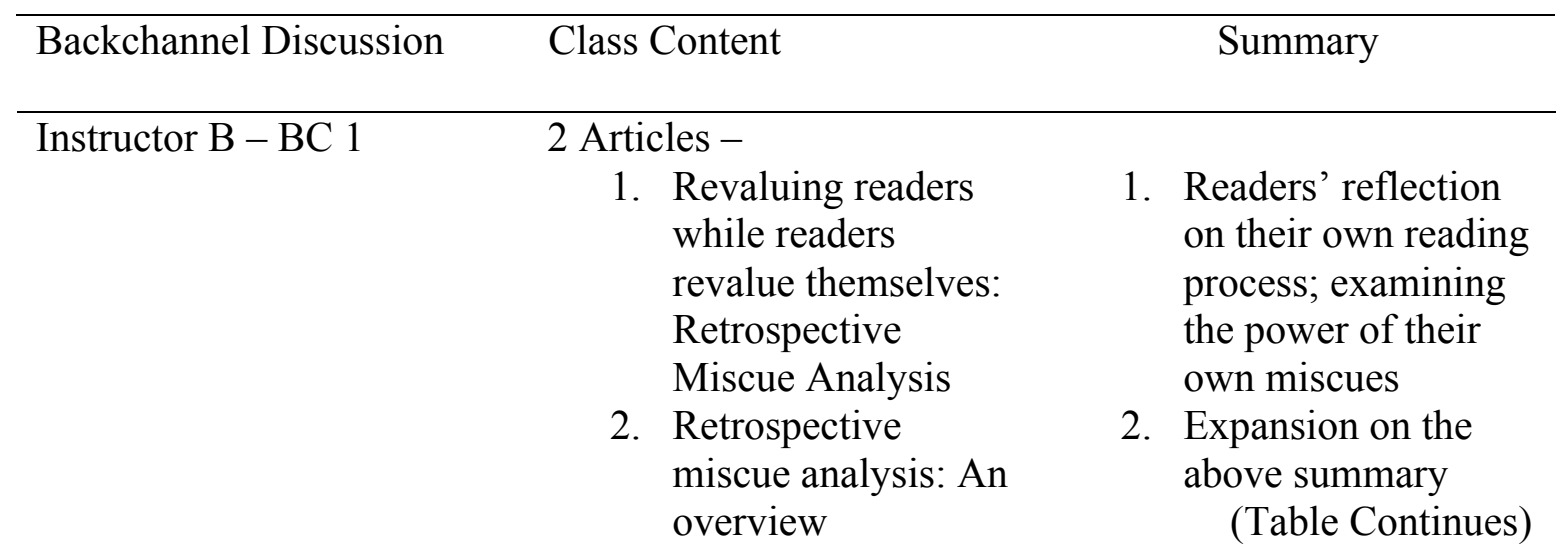

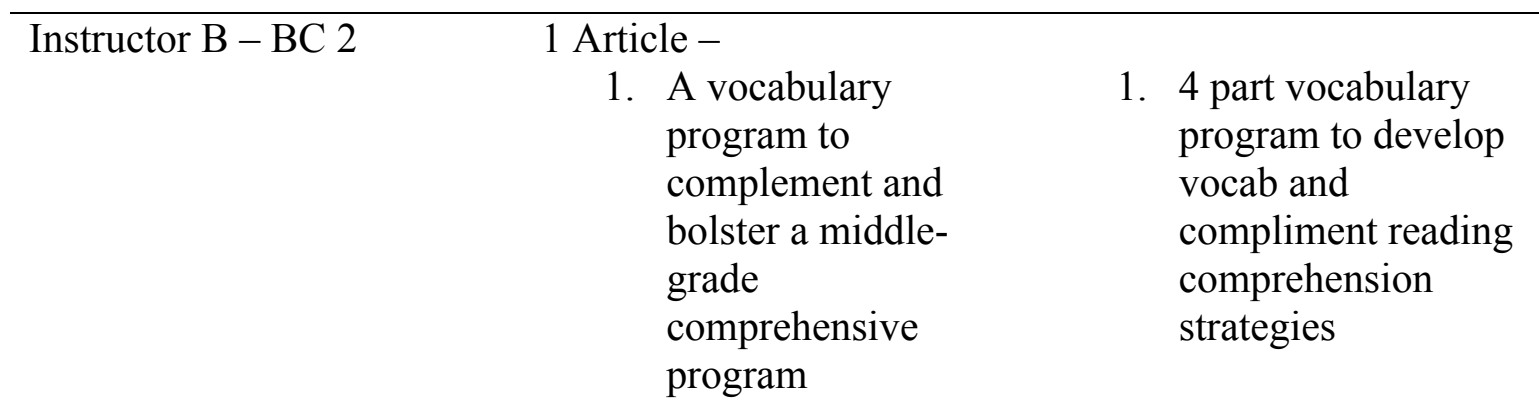

\begin{tabular}{l}
\hline Instructor $\mathrm{C}-\mathrm{BC} 1 \mathrm{Article}-$ \\
1. \\
Breathing Life into \\
Urban Ed with \\
Blended Learning
\end{tabular}

1. Carpe Diem blended learning curriculum model

\begin{tabular}{|c|c|c|}
\hline Instructor $\mathrm{C}-\mathrm{BC} 2$ & $\begin{array}{l}\text { 1 Article, } 1 \text { Youtube video - } \\
\text { 1. Stem \& visual } \\
\text { learning: A vital } \\
\text { combination } \\
\text { (article) } \\
\text { 2. } \begin{array}{l}\text { The surprising truth } \\
\text { about learning in } \\
\text { schools (video) }\end{array}\end{array}$ & $\begin{array}{l}\text { 1. Combining drawing } \\
\text { and visual } \\
\text { representation with } \\
\text { text to effectively } \\
\text { teach STEM } \\
\text { curriculum } \\
\text { 2. Schools aren't built } \\
\text { for learning; } \\
\text { argument for } \\
\text { personalized } \\
\text { learning plans to } \\
\text { increase engagement } \\
\text { and overall success }\end{array}$ \\
\hline
\end{tabular}




\section{Methods of Analysis}

This study utilized Wolcott's (1994) unique process of data analysis, which is more closely aligned with a transformation of the data, rather than simply an analysis. He argues that qualitative data can be transformed by following a procedure, which includes description, analysis, and interpretation. Wolcott (1994) suggests during the description stage to let the data speak for itself, meaning the researcher needs to be careful not to distort its original meaning by influencing it with their own interpretation. The act of observing in-class discussions and taking fieldnotes while students were engaged in the digital backchanneling discussion technique, interviewing student participants regarding the process and experience, and then transcribing verbatim all of the conversations that took place, allowed me to collect the data as it appeared in its "raw" form, by simply giving an account or description of the dialog that occurred.

Wolcott (1994) recommends using the analysis phase to find relationships, patterns, and different qualities from the data. Henri's (1992) method of content analysis was expended to provide an overall structure and protocol for the examination of the data and to explore this type of computer-mediated communication when used in teacher education courses (Kaye, 2012). Although the front channel transcripts were live discussions taking place during class time and were not considered computer-mediated communication, they were inherently connected to and inevitably influenced the backchannel discussion by design. Similarly, the participant interviews were conversations that took place after class time and were also not considered computermediated communication, but they were designed to explore digital backchannels from the student's perspective and evaluate their use within a teacher education setting. With 
that being said, I made the decision to analyze the front channel transcripts, as well as the participant interview transcripts using the same modified content analysis model derived from Henri's (1992) framework as a starting point in the analysis of these texts.

In general, content analysis is a qualitative research technique used to analyze text data, which may come in a variety of forms (verbal, print, or electronic) from numerous types of sources (interviews, electronic transcripts, open-ended survey questions). Over the years, this technique has evolved to allow for the modernization of communication through digital media and social messaging (Krippendorf, 2013). As early as 1992, Henri proposed a specific methodology to capture the content of computer-mediated communication, distinctly analyzing the "pedagogical characteristics" of the messages, focusing more on the "how" and "why" learning occurs through the use of this technology (Henri, 1992, p. 120). Henri (1992) points out that past research on computermediated learning processes use surface level variables (frequency of messages, number of participants, and number of conferences, etc.) that generally yield inconclusive results regarding its pedagogical significance. Whereas, Henri's (1992) version of content analysis focuses on learner identified processes and strategies that are associated with understanding the overall learning process, specifically looking at the influence and effect of the "interactive exchange in learning" (p. 122). By concentrating on the comprehensive process of learning, rather than simply looking at the end product, Henri (1992) decided on a model that is more in line with past and current research regarding learning progressions and the educational process in general.

This study utilized Henri's (1992) analytical framework as a model for data analysis, utilizing themes for investigation rather than strictly focusing on quantitative 
units of analysis (a straight tally of participant messages). As described by Donnelly and Gardner (2009), Henri’s content analysis approach utilizes the following five key areas for investigation: (1) participation, (2) social events, (3) cognitive effects, (4) interactivity, and (5) metacognitive events. Existing theory described in earlier portions of this study will compliment Henri's framework, specifically expounding on her ideas regarding interactivity and metacognition.

The key focus for this research was to analyze the influence of synchronous digital backchannels (type of computer-mediated conferencing) on student interactivity, reflection, and overall learning, by using Henri's model as a platform for analysis. For the purposes of this study, four dimensions (social events, interactivity, cognitive processing, and metacognition) were used to guide the analysis of the data (Table 4). The participative dimension, referenced by Henri (1992) as the quantitative compilation of the number of messages, was purposely left out of this study to direct more attention toward "what" was being said (content of the messages), rather than just the frequency of "what" was being said. Gunawardena, Lowe, and Anderson (1997) support this decision, stating the participative dimension should be "studied separately from the fundamentally qualitative analysis of message content because this type of analysis does not shed light on the quality of the learning experience" (p. 404).

\section{Content Analysis Classifications}

For the most part, the criteria used for this study mirrored Henri's (1992) suggestions for analysis of online communication. The transcripts from the front and backchannel discourse were divided according to "units of meaning," which inherently 
lended itself well to further analysis of those units along social, interactive, cognitive, and metacognitive dimensions (Henri, 1992, p. 134) (see Appendix A).

Concurring with Henri, past research has shown the importance of analyzing social events during online communication (Kuehn, 1994; Rice \& Love, 1987; Walther, 1996). Whether a statement relates to the course content or not, interaction, presence, and a sense of community are still being established and contribute to the overall learning experience (Conole, Galley \& Culver, 2010; Redfern \& Galway, 2002; Shackelford \& Maxwell, 2012; Song \& McNary, 2011). Social events would include such dialogue as “How is everyone?" or "See you later!" (Table 2).

Interactivity will be analyzed in terms of Moore's $(1993,2007)$ ideas concerning the degree of transactional distance in online educational settings, thereby distinguishing between interactivity between students and teachers, students and students, and students and content (Table 2). In relation to this study, Henri's (1992) categorization of interactivity into explicit, implicit, and independent does not necessarily give the researcher a measurement indicating in what way digital backchanneling influences who students are interacting with and what exactly students are interacting about. The author does concur with Henri (1992), in that capturing interactivity is a necessary component for analyzing computer-mediated communication. Whether or not the interaction is intentional or not intentional, is not entirely relevant to the purposes of this study. Rather, breaking down the content of front and backchanneling dialogue and categorizing according to Moore's $(1993,2007)$ definition of interactivity will illuminate in what way digital backchanneling is influencing the transactional distance of the educational 
experience between learners, content, and instructors, thus, according to Moore (1993, 2007), will influence the overall learning experience.

In terms of the concept of cognitive processing within Henri's (1992) model, this study used Bloom's (1956) Taxonomy of Educational Objectives to further guide the categorization of cognitive skills used during the discussions that took place within the digital backchanneling sessions. Bloom's (1956) seminal work on cognitive processing was recently expanded on by Anderson \& Krathwohl (2001) to produce a revised version of Bloom's original six categories to correspond more appropriately with $21^{\text {st }}$ century learning and working environments. Similar to Henri (1992), Anderson, Krathwohl, \& Bloom (2001) rate cognitive processes starting with more rudimentary abilities such as knowledge recall to a progression of higher order thinking skills, such as synthesis and evaluation, but tends to be more descriptive in the categorization of cognitive thinking skills. Building on Henri (1992) and further refining with Anderson, Krathwohl, and Bloom (2001), this research utilized the analysis of front and backchannel communication to reveal "student understanding, reasoning, and the development of critical thinking and problem solving skills," which in turn, indicated to what extent digital backchanneling influenced students' interactivity with content, as well as their overall learning experience (Hara, Bonk, \& Angeli 1998, p. 11).

With Henri's model, metacognition is broken down into two separate categories: metacognitive skills and metacognitive knowledge. These two areas of metacognition were further broken down into three subcategories (person, task, and strategies) under knowledge and four subcategories (evaluation, planning, regulation, and self-awareness) under skill. This study focused on the utilization of metacognitive skills, rather than 
knowledge, and extended on Henri's model by adding the concept of reflection as the fifth subcategory of metacognitive skills (Table 4), considering its vital importance in the overall learning process and the purpose of this study (Dewey, 1916; Fernsten \& Fernsten, 2005; Hara, Bonk, \& Angeli, 1998, Laurillard, 2002; Moon, 2013; Rodgers, 2002; Schubert, 2014). Borrowing from Rodgers (2002) breakdown of Dewey's (1929) perception of reflection, the digital backchannel communication constituted reflective thinking if: (1) Learners were engaged in meaning-making and were making continual connections between what they have learned to other experiences and ideas (2) Thoughts were purposeful, systematic, and disciplined, and (3) Connection and interaction were happening with others within a social environment. 
Table 4

Framework for Analysis (adapted and modified from Henri, 1992)

\begin{tabular}{|c|c|c|}
\hline Dimension & Definition & Measured By \\
\hline Social Events & $\begin{array}{l}\text { Dialogue unrelated to } \\
\text { discussion content }\end{array}$ & $\begin{array}{l}\text { Statements of expression, } \\
\text { emotion, feeling } \\
\text { Greeting/Closing } \\
\text { "How is everyone..." } \\
\text { Compliments } \\
\text { "Good job..." } \\
\text { Statements of humor }\end{array}$ \\
\hline Interactivity & $\begin{array}{l}\text { Connected messages } \\
\text { between } \\
\text { learner-learner, } \\
\text { learner-instructor, \& } \\
\text { learner-content }\end{array}$ & $\begin{array}{l}\text { Statements showing } \\
\text { connectivity } \\
\text { "In response to..." } \\
\text { "As we said earlier..." } \\
\text { "Similar to the last } \\
\text { statement..." }\end{array}$ \\
\hline Cognitive Processing & $\begin{array}{l}\text { Understanding, reasoning, } \\
\text { and development of } \\
\text { critical thinking and problem } \\
\text { solving skills }\end{array}$ & $\begin{array}{l}\text { Asking questions, } \\
\text { Identifying information, } \\
\text { Comprehending issues } \\
\text { and problems, } \\
\text { Inferring, } \\
\text { Judging, } \\
\text { Making decisions }\end{array}$ \\
\hline Metacognition & $\begin{array}{l}\text { Statements related to } \\
\text { declared knowledge of } \\
\text { oneself and others. } \\
\text { Statements related to } \\
\text { evaluation, self-awareness, } \\
\text { planning, and reflection }\end{array}$ & $\begin{array}{l}\text { Being aware of how } \\
\text { one approaches a task, } \\
\text { Evaluating one's } \\
\text { performance, } \\
\text { Interpreting one's } \\
\text { feelings and emotions } \\
\text { concerning a task }\end{array}$ \\
\hline
\end{tabular}

The content analysis using the dimensions from Table 4 lent itself well to a process of further breaking down the digital backchanneling dialogue by coding the content within the four dimensions to reveal more specific categories. Coding of front 
and backchannel transcripts and participant interview transcripts was conducted by using key concepts derived from existing theory (Hsieh and Shannon, 2005) that are associated with interactivity, reflection, and the concept of technology integration within an educational setting. Further, more in-depth coding or categorization took place to illuminate trends, patterns, and ideas and to connect with the questions this study was designed to answer. Saldana (2009) emphasizes the distinction between the two (coding and categorizing) and posits that coding is in essence, identifying the crux of what is being expressed and categorizing enables the researcher to develop a pattern of traceable regularity. In some cases, the general ideas that may emerge, will be contributing to more than one central theme/research question. This process insured that various patterns in the front and backchannel transcripts and the interview responses were identified and then linked to broader themes, which in turn were correlated with the research questions asked.

For this study, the transcripts that resulted from the front and backchanneling discussions were coded according to a first cycle coding method called structural coding (Saldana, 2013). This method is used as an initial categorization technique to separate large amounts of text according to the general concepts that have been recognized to address a specific research question or series of questions. In the case of this study, Miles, Huberman, Saldana's (2014) subcoding technique was also utilized to further analyze the data using the dimensions described by Henri's (1992) version of content analysis as a guideline. The initial act of content analysis enabled me to separate the backchannel and front channel transcripts into units of meaning, and assign each unit of meaning to a designated dimension or primary code (Social Events, Interactivity, 
Cognitive Processing, and Metacognition). Specifically, the entries from each transcript were reviewed in detail and I copied and pasted "units of meaning" or text segments into the appropriate category using the classification matrix displayed in Appendix A. Once the dialogue was split according to meaning, rather than simply looking at each message as a whole, each unit of meaning was color coded to signify a specific primary code. By color coding the text segments, I was given an easily accessible "snapshot" view of the front/backchannel conversations and how the text was broken down according to the designated primary codes (Social Events, Interactivity, Cognitive Processing, and Metacognition).

As the study progressed, I realized these four categories were too general and the data revealed more specific "qualities" and "interrelationships" within the four primary codes or dimensions (Miles, Huberman, Saldana, 2014, p. 80). Furthermore, in order to realize the purpose of the study and to answer the related research questions, the concept of interactivity and metacognition needed to be expanded upon to properly identify specific types of interactivity and to capture the component of student reflection within the metacognitive process. The color coding of the primary codes enabled the researcher to efficiently go back and further identify deeper, more in-depth meanings associated with the backchannel session dialogue, essentially revealing a set of subcodes assigned to the data. A "second-order tag" or subcode was designated to the primary code to produce a more nuanced account of the data and to reflect a deeper, more enriched description of the entries associated with the digital backchanneling sessions (Miles, Huberman, \& Saldana, 2014, p. 80) (see Appendix C). When reviewing all levels of interactivity (student-student, student-content, and student-instructor), the subcodes assisted me in 
identifying not only the type of interactivity that was transpiring, but illuminated the level of thinking or cognition and/or metacognition that occurred when students were interacting with content. Together with this, the researcher was also able to pinpoint comments associated with reflective thinking that were situated within the category of metacognition.

NVivo qualitative analysis software was utilized to organize and code the participant interviews and the instructor led debriefing sessions and to provide a digitalized approach to this portion of the coding process. A CAQDAS program was chosen for this area of the data analysis to effectively manage the labor-intensive process of utilizing In Vivo coding. In Vivo coding is a strategy that makes use of the participant's own words to sort data and to effectively grasp the genuine meaning or intention of a person's spoken expression (Saldana, 2013). This coding technique was chosen to "prioritize and honor the participant's voice" when gathering the thoughts, opinions, and views of the students who actually participated in the digital backchanneling sessions (Saldana, 2013, p. 91). The interview and debriefing transcripts were loaded into the NVivo program and each line of participant generated text was coded using actual words and/or phrases (quotes) of the student contributors. As a result of this process, 229 in vivo codes were generated (see Appendix D). In order to utilize the large numbers of initial in vivo codes and discover the most salient categories for the purpose of the research, a second cycle focused coding approach was used to illuminate main concepts and themes and to assist in the interpretation stage of the data analysis protocol. During this process, codes were condensed and eliminated if necessary. The resulting codes and categories are displayed in Appendices E-Q. 
The primary codes/sub codes that were developed from the content analysis of the front and back channel transcripts (see Appendix C) were then brought back in and were merged with the codes from the interview transcripts. By coding and understanding the conversations (verbal and online) that took place during the in-class backchanneling sessions and then integrating those codes with the codes that emerged from the participant interviews, twelve specific categories were developed (see Appendices E - P). From these categories, five main themes (see Appendix P) were established that corresponded to the intention of the study and were designed to answer the research questions presented: (1) The chosen content influenced interactivity and the overall learning experience, (2) The backchannel design influenced interactivity, (3) Digital backchanneling supported in-class reflective thinking, (4) Learning associated with digital backchannels was meaningful, focused, and positive, and (5) The multitasking related to the backchanneling activity presented a challenge.

Lastly, Wolcott includes interpretation as a possible final stage in the data transformation process. Wolcott (1994) does not limit the researcher to any particular order for these phases or even the necessary use of all three. Rather, he suggests using the combination that is most appropriate for the research being done and the questions being asked. Wolcott (1994) suggests to researchers to "think backward" in order to contemplate the "data they will need" and how exactly they will want to utilize it for their study (p. 387). Although this is true, it is important to note, the researcher was cognizant about adhering to the qualitative nature of this study by making sure to be open to what the data revealed regarding backchanneling, even though prior research/theory helped to pinpoint important learning variables such as interactivity and reflection. 


\section{Summary of Methodology}

The basic, qualitative method is a research design that caters to an exploratory focus, in which the researcher seeks to interpret an issue, a phenomena, or problem in its natural setting. This study is being framed by an interpretive/constructivist epistemological perspective, which aligns with the qualitative approach, allowing the researcher to take a questioning stance with respect to the overall project and enjoy the benefits of flexibility and ambiguity (Patton, 1990). The research questions presented require a technique that is more context oriented and necessitates a structure where meaning is not separated (Willig, 2001) from the setting, background, and circumstances of the students participating in this study. The multicase study approach allowed the me to gain perspective from a variety of teacher education classrooms, gathering data from classroom observations, the transcripts associated with the backchannel activity, and researcher led student participant interviews.

With the participant interviews taking place toward the end of the semester, the study utilized the class observations and document analyses at the beginning of the study to narrow down, mold, and refine the project. Through this process, questions were refined and purposes were reevaluated in order to properly gather the information necessary to answer the research questions and to follow the intention of the study. Essentially, the process of analyzing data was ongoing and was employed even while the data was being collected and analyzed (Bogdan and Biklen, 1998) and going along with what Rubin and Rubin (1995) argue; the data, the topic, and the researcher must continually be evaluated throughout the life of the project, in order to produce a "rich study" (p. 265). 


\section{CHAPTER IV}

\section{ANALYSIS OF THE DATA}

The purpose of this study was to evaluate the use of digital backchanneling as a complement to an in-class discussion within a teacher education course. By observing backchanneling sessions, analyzing both front and backchannel dialogue, and conducting interviews with students who participated in backchanneling, the researcher was able to explore the teacher education student's perspective in relation to the following research questions:

1. In what way does digital backchanneling contribute to student interactivity during in-class discussions by teacher education students?

2. In what way does digital backchanneling contribute to pre-service teacher reflection in a teacher education course?

3. How does digital backchanneling influence the overall learning experience associated with an in-class discussion in a face-to-face educational setting?

\section{Question 1:}

In what way does digital backchanneling contribute to student interactivity during inclass discussions by teacher education students?

Interactivity was assessed using transcripts of backchanneling sessions (whether students were in the front channel or the backchannel discussion) and student participant interview responses. Out of the 20 backchannel transcripts that were analyzed, there was $100 \%$ participation on some level by all students who participated in the study and were 
present on the particular class day backchanneling took place. Out of the six transcripts associated with the front channels, virtually every student participated at some point in time, with the exception of two students who were part of a front channel that rotated students in and out during the backchanneling discussion activity. Out of the seven students interviewed, all seven indicated their level of participation and engagement seemed higher compared to a normal classroom discussion, seemingly because they were given distinct roles, where they felt they were held accountable for participation, as well as given a platform to contribute to the discussion in a risk free manner (by typing rather than speaking). With that being said, past research has defined interactivity slightly different than participation. For instance, interactivity may take place between students in a class, without it necessarily constituting as class participation. On the other hand, class participation will usually not occur unless there is some form of interactivity that has taken place.

Although there are certain elements of participation and interactivity that overlap, the intent of this research was to explore the influence of digital backchannels on in-class interactivity, looking at the type, quality, and content of the interaction that took place, rather than just noting whether it took place at all. I made this decision based on the fact that participation, as well as interaction were somewhat inherent in the design of the digital backchannels that were used in the study, so it made sense to focus on the content of the interactivity itself, rather than simply the number of interactions that took place. For instance, in all but one class session, the backchannel and the front channel groups were made up of small numbers ( 3 to 4 students) and in all cases the front channel group was located in the middle or front of the room, effectively taking a "center stage" 
approach with the format of the activity. From the data gathered from the interview responses, most students indicated they felt the expectations to verbally contribute were high from the instructor, as well as the rest of the class, simply due to the layout of the front channel (small numbers placed in the middle or front of the room). Out of the sixtytwo students who participated in the study, each one participated in the backchannel at least one time if they were present on either of the class days the digital backchanneling discussion was being conducted, thereby giving even less vocal students a chance to contribute to the class discussion. Due to the backchanneling set-up, there was obviously some sort of interaction for the students involved during the tenure of the activity. Student $\mathrm{C}$ indicated the following when describing her backchanneling experience: I think that interaction kind of increases because you are constantly talking, and you were constantly responding. Compared to a different discussion, you're just kind of sitting there and either listening to the teacher or off... I mean, sometimes I sit during class and I raise my hand once just because it's just one of those days.

In order to articulate exactly how in-class interaction was influenced by digital backchanneling and what type of interaction took place, Moore's (1989) explanation was used, which differentiates between three types of interaction (student - content, student instructor, and student - student) that occur within an educational setting. Interaction is commonly referred to as "actions among individuals," but was added to by Moore (1989) to include actions between individuals and educational content (Bernard et al., 2009).

Student to student interaction is considered to be any interface from one student to another student, in a group or individual setting, with or without the simultaneous 
presence of the other students or the instructor (Moore, 1989). Student to content interaction is described as interaction between the student and the subject of study that results in changes in "the learner's understanding, the learner's perspective, or the cognitive structures of the leaner's mind" (Moore, 1989, p. 2). Lastly, student to instructor interaction is interaction between the student and the person who prepared the curriculum and is transmitting the content to the student, whether the mode of instruction is face-to-face, online, or a combination of both (Moore, 1989).

After coding the front and backchannel transcripts and the student participant interview transcripts, two main themes emerged in relation to interactivity: (1) The content chosen for backchannel discussions influenced two types of interactivity (student - content interaction and student - student interaction) and (2) The design of the backchannel activity affected all three types of interaction.

\section{The Influence of Content}

The overall content for the three courses that participated in this study was related to middle/secondary level literacy, learning, and instruction within the teacher education discipline. Each discussion was based off of a course related text/texts and varied in size, complexity, and relatability. Although the texts were all related to literacy instruction, with the subject matter essentially being the same or quite similar, the length, complexity, and relevance of the material to students' lived experiences played a key role in students' interactivity. In fact, these factors seemed to influence how students were interacting with the content throughout the backchannel activity, whether they were speaking from the perspective of the front channel or from the view of someone participating in the backchannel. Student $\mathrm{C}$ described how she interacted with the content before class in 
order to prepare for the first backchanneling session that was conducted for this particular course:

For the first back channeling I think it was a little bit hard because it was on an entire text so it was much larger thing. I wouldn't directly highlight some things, because on one page there'd be like more than one point that I wanted to discuss, so that was something to prepare for. And because we didn't really know what back channeling was I wasn't really sure how to prepare.

In comparison, this same student expounds on her experience with the content that was chosen for the second backchanneling session (comparing and contrasting three different articles, as opposed to a general discussion on one book):

But then for the second one, I definitely highlighted specific things I would be like, oh I can use this while we're back channeling. This is a plan to agree on or a question that I can post to either if I'm front channel or back channeling. I tried to focus more of my questions on the shorter one, so I knew I could like go back to easily and find the points that people were talking about.

In this case, the length and structure ( 1 book compared to 3 articles) of the chosen texts, influenced how students utilized the backchannel activity to understand the material.

The readability or complexity of the text the backchanneling sessions were based on was also a factor influencing interactivity amongst students, as well as how students related to or understood the content. Student D commented as she was referring to one of the more complicated articles: 
I hated that one. I did not understand it. It was frustrating and stuff, and so

I didn't read. And then hearing like everybody else had done

that, and stuff, I was okay, like it wasn't just me!

Although the article was challenging for her, the camaraderie and the feedback that was facilitated through the digital backchannel gave this student encouragement to keep participating in the discussion and interacting with her peers. In a similar manner, another student explained how the backchanneling activity influenced her student to content interaction, as well as her student to student (peer) interaction depending on the dissimilar content (length and topic) that each activity was based on. This student explained that for the first backchannel session she was completely prepared because she read the content and was interested in the material, but this same student goes on to say regarding the next set of articles:

I was kind of ... I had just briefly skimmed 'em. It (backchannel activity) allowed me to because we were allowed to have our laptops out. I could reference specific material... oh this is what the article quote was saying. . It's like, oh, this is what they're talking about and this is in that article. That's how it connects to this article, and stuff. So, I think that was the difference. I was learning as I was discussing.

This student did not elaborate on her reasoning for not being as prepared to discuss the content of the second backchannel compared to the first session, but again, she did mention she connected to the reading for the first backchannel more, therefore motivating her to complete the reading and prepare for the class session. Although this student was not as prepared for the second discussion, the digital backchannel platform allowed her to 
participate and interact with her classmates, as well as the content by "learning" as she was "discussing," effectively allowing her to catch up with the material and benefit educationally from the class session.

The content analysis of the front and backchannel transcripts revealed that a large portion of the verbal front channel conversation and the online dialogue were centered around class material, course content, as well as issues relating to teacher education as a whole. In fact, out of the six front channel transcripts and the 20 backchannel transcripts reviewed, a majority of the total comments were related to content in some way (course itself and/or teacher education issues in general), which indicated high levels of student content interactivity throughout the backchanneling activity.

Using Henri's (1992) model for content analysis of computer-mediated communication as a platform for the analysis, the content in both sets of transcripts was further coded according to categories associated with six levels of cognitive processing: (a) remembering, (b) understanding, (c) applying, (d) analyzing, (e) evaluating, and (f) creating (Anderson, Krathwohl, and Bloom, 2001). Anderson, Krathwohl, and Bloom (2001) built on Bloom's (1956) original taxonomy of cognitive processes to reflect thinking as more of an active process and to correlate better with contemporary thought processes and the $21^{\text {st }}$ century environment. The dialogue in the front and backchannel conversations were broken up into units of meaning and were then categorized according to social events, interactivity, cognitive processing, and metacognition (Henri, 1992). Each unit of meaning that fit into the "cognitive processing" category was further identified as one of the six levels of cognition (see Appendix C) outlined by Anderson, Krathwohl, and Bloom (2001). The content that was chosen for each class discussion is 
denoted in the previous table (Table 3). The following table (Table 5) displays the percentage of overall comments or units of meaning that involved interaction with content and were related to higher levels of cognitive processing (applying, analyzing, evaluating, and creating).

Table 5

Content Related Cognitive Processing Instructor/BC Session/Group \# $\%$ of total units of meaning (comments) that were coded as a cognitive event that utilized higher order cognitive processes: applying, analyzing, evaluating, creating

$\begin{array}{lc}\text { Instructor } \mathrm{A} / \mathrm{BC} 1 / \text { Group 1 BC } & 71 \% \\ \text { Instructor } \mathrm{A} / \mathrm{BC} 1 / \text { Group 2 BC } & 87 \% \\ \text { Instructor A/BC 1/Group 3 BC } & 76 \% \\ \text { Instructor A/BC 1/Group 4 BC } & 88 \% \\ \text { Instructor A/BC 2/Group 1 BC } & 73 \% \\ \text { Instructor A/BC 2/Group 2 BC } & 85 \% \\ \text { Instructor A/BC 2/Group 3 BC } & 84 \% \\ \text { Instructor A/BC 2/Group 4 BC } & 72 \% \\ \text { Instructor B/BC 1/Group 1 BC } & 92 \% \\ \text { Instructor B/BC 1/Group 2 BC } & 75 \% \\ \text { Instructor B/BC 1/Group 3 BC } & 62 \% \\ \text { Instructor B/BC 2/Group 1 BC } & 52 \% \\ \text { Instructor B/BC 2/Group 2 BC } & 68 \%\end{array}$

(Tables Continues) 


\begin{tabular}{|c|c|}
\hline Instructor/BC Session/Group \# & $\begin{array}{l}\% \text { of total units of meaning (comments) } \\
\text { that were coded as a cognitive event that } \\
\text { utilized higher order cognitive processes: } \\
\text { applying, analyzing, evaluating, creating }\end{array}$ \\
\hline Instructor $\mathrm{B} / \mathrm{BC}$ 2/Group $3 \mathrm{BC}$ & $53 \%$ \\
\hline Instructor $\mathrm{B} / \mathrm{BC} 2 /$ Group $4 \mathrm{BC}$ & $70 \%$ \\
\hline $\begin{array}{c}\text { Instructor } \mathrm{C} / \mathrm{BC} 1 / \text { Group } 1 \mathrm{BC} \\
\text { (rotating students) }\end{array}$ & $85 \%$ \\
\hline $\begin{array}{c}\text { Instructor } \mathrm{C} / \mathrm{BC} 2 / \text { Group } 1 \mathrm{BC} \\
\text { (rotating students) }\end{array}$ & $67 \%$ \\
\hline $\begin{array}{c}\text { Instructor } \mathrm{C} / \mathrm{BC} 2 / \text { Group } 2 \mathrm{BC} \\
\text { (rotating students) }\end{array}$ & $88 \%$ \\
\hline $\begin{array}{c}\text { Instructor } \mathrm{C} / \mathrm{BC} 2 / \text { Group } 3 \mathrm{BC} \\
\text { (rotating students) }\end{array}$ & $79 \%$ \\
\hline Instructor C/BC 2/Group 4 BC & $70 \%$ \\
\hline
\end{tabular}

Although students may have been uncomfortable with longer, more complex texts, which was indicated from some of the student interview responses, the percentage of comments related to higher levels of cognitive processing not only indicate interactivity with the content on a basic level, but gave evidence of higher order thinking and cognitive processing at the top of Bloom's revised taxonomy (Anderson, Krathwohl, and Bloom, 2001). Table 6 and Table 7 display examples of students applying, analyzing, evaluating, and creating when thinking about or cognitively processing the discussion content when participating in the digital backchanneling activity. 
Table 6

Examples of Higher Order Thinking in Student Dialogue - Applying/Analyzing

Instructor/Class Applying Analyzing

Instructor $\mathrm{A} / \mathrm{BC} 1$ "I think that some students today still feel this way because they have teachers who are not trying to get involved in their lives and education is a place to express themselves."

"It might just be the way that they were taught to teach and to follow regulations and strictly just teaching the students material that they will be tested on instead of going to a deeper level."

Instructor A/BC 2 "My uncle is an English teacher "Do you think the purpose and he likes to read what's popular at the time. When the Hunger of this article was to show Games blew up, they read them how literacy could be and they got to analyze the interpreted in many text and have discussions in different ways?" class. He said student participation skyrocketed because they were reading about something they were actually interested in and wanted to discuss."

Instructor B/BC 1 "I know that when I was younger, I would do the same thing with words I didn't know. But I think that it shows the student is attempting to make connections with the background knowledge they already have."

"I feel like re-playing the tapes with the students we work with is the best option because I am working with Social Studies students and comprehension and taking it slow is so key and And by them learning their pace and not trying to speed through it can be so valuable."

(Tables Continues) 
Instructor/Class

Applying

Analyzing

\begin{tabular}{|c|c|c|}
\hline Instructor $\mathrm{B} / \mathrm{BC} 2$ & $\begin{array}{l}\text { "For example, I used prompts } \\
\text { with my students and found } \\
\text { that that specific approach was } \\
\text { beneficial." }\end{array}$ & $\begin{array}{l}\text { "That is controversial } \\
\text { because studies show } \\
\text { traditional books help with } \\
\text { retention compared to } \\
\text { ebooks." }\end{array}$ \\
\hline Instructor $\mathrm{C} / \mathrm{BC} 1$ & $\begin{array}{l}\text { "In high school I enjoyed } \\
\text { individual practice of new } \\
\text { content when it was a new } \\
\text { math concept." }\end{array}$ & $\begin{array}{l}\text { "It actually takes more } \\
\text { brain power to read } \\
\text { graphic novels compared } \\
\text { To just reading an } \\
\text { ordinary novel - processing } \\
\text { the words and pictures." }\end{array}$ \\
\hline Instructor $\mathrm{C} / \mathrm{BC} 2$ & $\begin{array}{l}\text { "Yeah for my content, science, } \\
\text { I really think the scientific } \\
\text { method is something that should } \\
\text { be stressed because people use } \\
\text { it every day." }\end{array}$ & $\begin{array}{l}\text { "What's more important } \\
\text { Ur student knowing what the } \\
\text { root of an equation is? Or } \\
\text { being a good citizen and } \\
\text { good person? }\end{array}$ \\
\hline
\end{tabular}

Table 7

Examples of Higher Order Thinking in Student Dialogue - Evaluating/Creating

\begin{tabular}{lll}
\hline Instructor/Class Evaluating $\quad$ Creating &
\end{tabular}

Instructor $\mathrm{A} / \mathrm{BC} 1$ "The advanced classes can

"I think educating the class engage in deeper thought, group on a subject thoroughly discussion, and debates but the would help them engage in lower level classes are just discussion because they don't thrown worksheets and like to intervene in the required to memorize strands of facts." conversation unless they are well aware of the topic and everyone else's point of view on the topic."

(Table Continues) 


\begin{tabular}{|c|c|c|}
\hline Instructor/Class & Evaluating & Creating \\
\hline Instructor $\mathrm{A} / \mathrm{BC} 2$ & $\begin{array}{l}\text { "I was confused I couldn't tell } \\
\text { if it was a continuous story or } \\
\text { if each line was a different } \\
\text { unrelated sentence." }\end{array}$ & $\begin{array}{l}\text { "I think another interesting } \\
\text { way to use this in class } \\
\text { would be to give students a } \\
\text { text in words and to have } \\
\text { them choose images that } \\
\text { represent the words. They } \\
\text { could compare the images } \\
\text { that everyone chose!" }\end{array}$ \\
\hline Instructor $\mathrm{B} / \mathrm{BC} 1$ & $\begin{array}{l}\text { "It really is about knowing the } \\
\text { right questions to ask. Students } \\
\text { usually are comprehending and } \\
\text { making more connections than they } \\
\text { show." }\end{array}$ & $\begin{array}{l}\text { "In regards to class, I would } \\
\text { love to hear examples of all } \\
\text { types of readers between } \\
1-4 \text { instead of just } 1-2 \\
\text { because then we have a } \\
\text { baseline for what is an } \\
\text { acceptable score." }\end{array}$ \\
\hline Instructor $\mathrm{B} / \mathrm{BC} 2$ & $\begin{array}{l}\text { "The symbol reading is clearly a } \\
\text { student driven reading that } \\
\text { involves listening to students ideas. } \\
\text { It is a great way to view your } \\
\text { students minds, and how they } \\
\text { interpret a reading without written } \\
\text { language." }\end{array}$ & $\begin{array}{l}\text { "For social studies, students } \\
\text { could write about an } \\
\text { historical event from their } \\
\text { communities perspective, } \\
\text { different discourses } \\
\text { interpreted those events } \\
\text { differently." }\end{array}$ \\
\hline Instructor $\mathrm{C} / \mathrm{BC} 1$ & $\begin{array}{l}\text { The problem is, we aren't really } \\
\text { taught how to inspire this type } \\
\text { of learning. We are taught } \\
\text { classroom management to keep } \\
\text { them "on task" }\end{array}$ & $\begin{array}{l}\text { "You have to give them } \\
\text { the opportunity to } \\
\text { succeed independently." }\end{array}$ \\
\hline Instructor $\mathrm{C} / \mathrm{BC} 2$ & $\begin{array}{l}\text { "There's a fine line between } \\
\text { being a friend and } \\
\text { an authoritative figure } \\
\text { I think." }\end{array}$ & $\begin{array}{l}\text { "How do you connect } \\
\text { and make a relationship? } \\
\text { Teach them the skills } \\
\text { for difficult situations to find } \\
\text { the right help, not to go back } \\
\text { to you everytime." }\end{array}$ \\
\hline
\end{tabular}


Despite the fact that student interview responses indicated students had varying opinions regarding the chosen content and how effectively it was used within a digital backchanneling discussion, there was not much variation in the amount of dialogue dedicated to discussing content, as seen in Table 6 and Table 7. Students were able to contribute to the discussion activity using higher order thinking skills and seemed to utilize the backchanneling activity to go beyond lower cognitive processes such as remembering/recall and understanding/comprehension. There was ample evidence as displayed through the front and backchannel conversations that students were able to effectively utilize this type of communication technology to contribute to the discussion, build content understandings, question existing practices, and create alternative solutions, no matter what content was chosen for the digital backchannel discussion. In other words, not only was interaction with content apparent in all six class sessions, but the nature of the digital backchannel activity (separate discussions, risk free participation, use of peer interaction to construct knowledge) encouraged interaction with content at a relatively high level.

In addition, student to student interaction was influenced positively as seen through student conversation throughout the front and backchannel dialogue indicating there was interface "between one learner and other learners," in a group setting and in this case, with the "real-time presence of the instructor" (Moore, 1989, p. 4). During each backchannel discussion, student to student interaction was clearly observed and in some cases was effectively utilized to build new ideas and thought processes, as well as to either confirm or dispel someone's thinking on a particular issue. The following conversation is an example from one of the digital backchanneling sessions that 
demonstrates not only interaction among learners, but learners using one another's comments to build knowledge, draw conclusions, and to ultimately, ask more questions.

Student 1: It isn't so much about keeping them on task as it is inspiring them to pursue their own learning.

Student 2: I don't understand how this method works into a school day...

Student 3: I think we would need to start by teaching them how to succeed independently. Otherwise it could end up being a trial and error situation. And they would end up confused.

Student 4: But isn't teaching a lot of trial and error anyways?

Student 1: If you spend all day aiming to keep them on track then you miss the opportunity for personal growth and learning.

Student 6: You just can't throw them into the independent work. Like (Student 3) said, you have to teach them to be independent first.

Student 1: Just because they are doing the worksheet does not mean they are learning or caring about their learning.

Student 3: Yes, but just letting them go (which is what this sounds like to $\mathrm{me}$ ) isn't teaching. They need to be guided first.

Student 7: I think the success of this system would really depend on what type of work is being taught...Like are they undergoing instruction, then practice?

Student 3: I'm with you (Student 1) ....Being busy does not equal learning.

Student 1: True!

Student 2: I agree with (Student 4).

Student 8: I think teachers are trying to implement new ways and change the "old ways" but it probably is easier said than done.

Student 1: The problem is, we aren't really taught how to inspire this type of learning. We are taught classroom management to keep them "on task."

As seen through the above dialogue, there was evidence of Student 1 building knowledge based off the required reading and/or the prior comments made within the 
backchannel that were leading up to Student 1's initial comment. From this point on, various students responded to Student 1's opening remark (Student 3, Student 7, and Student 8), making statements indicating they were drawing conclusions based off the viewpoints of their peers and then, in some cases, connecting this knowledge to current experiences (Student 1's last comment). Furthermore, several students contributed to the conversation by asking additional questions (Student 4 and Student 7). Presumably, these students were considering the comments of others to build on their knowledge of the subject and explore other areas of the topic by asking additional questions and even challenging the stated responses.

\section{Backchannel Design}

The design or structure of the digital backchannel (Table 2) tended to influence all three types of interactivity. There were three factors concerning the backchannel activity design that influenced student interactivity: (1) Whether or not the separate backchannel groups were connected digitally to the front channel group, (2) The role the instructor took throughout the activity, and (3) The seating arrangement and number of group members in the backchannel groups.

The first factor of having a representative from each backchannel in the front channel served several purposes and was highly conducive to supporting interactivity amongst students, which in turn, encouraged more student interaction with content. Each faculty member/course involved in the study, opted to structure their second backchannel session with each front channel member having a connection to one of the backchannel groups. This structure was used the second time in comparison to the first backchannel sessions in each class where there was no digital connection between the front and 
backchannel conversations. All seven students interviewed indicated they preferred the backchannel structure where the front channel and the backchannel were connected by having a member of the front channel group serve as a representative of a backchannel group. When I asked the interviewee what backchannel structure seemed to be more beneficial for learning, Student E explained the difference between the two and why she preferred one over the other.

We were actually able to get the front channel involved because they saw what we were talking about. So it was kind of cool to get everyone's feedback, even the ones who were discussing, primarily, in the front channel. I feel like they kind of touched on both things, so it was kind of cool to see a connection between what we were discussing, what they were discussing, and that they correlated in some way.

This same student goes on to say how the additional connectivity and interaction that occurred when her backchannel group was represented in the front channel helped her make connections, build knowledge, and draw conclusions.

I personally liked the second one just because when the front channel had their input in, it was nice because we were going off what they're saying and they're commenting back and they were asking us if we had any more thoughts about certain things. I just liked having that person up there because we ... I feel like last time it kinda was random... they didn't really know what we were discussing. When you hear other people's experiences, too, or ... opinions, and other knowledge that they have, that ties into it even more, it just makes it stronger - the meaning stronger. 
Student F, who was one of the four out of the seven interviewed who experienced both the front and backchannel during the class discussion, described her thoughts regarding the first design which had no connection between the front and backchannel groups. He stated, "We felt a little bit disconnected. We definitely felt really disconnected from what everyone else was saying." This same student goes on to describe the second backchanneling experience in the class where the two channels were linked.

It was definitely nice to have a representative make sure our thoughts were being addressed. They could see what we were talking about, and then they could throw it to the forefront where other people could have a conversation off it. They could elaborate on it, and then kinda like address some of the questions we had, or address some of the thoughts we had.

An additional aspect of the digital backchannel design that influenced interaction had to do with the instructor's role during the activity. There were several differences in regards to the instructor's role across the six backchannel sessions. The following structures display the variations that took place within this study:

1. Instructor provided guiding questions posted on the overhead monitor

2. Instructor did not provide guiding questions

3. Instructor orally prompted the discussion with a few questions while introducing the activity and reintroducing the topic

4. Instructor contributed to the backchannel discussion throughout, occasionally interjecting prompting questions and guiding the discussion 
5. Instructor did not contribute to front or backchannel discussion once the activity had begun

Each instructor had access to the backchannel transcripts while the discussion was taking place, as well as after the class concluded. In addition, each instructor was present in the room during the entire digital backchanneling activity, starting the front channel discussion off while listening to the live discussion throughout the entire class period. Four out of the seven students interviewed, specifically indicated they preferred the backchannel structure where the instructor provided guiding questions, and one student explicitly stated she felt the need for more input from the instructor during the activity.

The following comments were made by Student A, who felt the guiding questions were beneficial. She described the first backchannel session where there were no guiding questions and students were basically moving through the discussion by making comments that were only intended to show the instructor they had completed the reading, rather than tackling issues they were interested in or concerned about in regards to the readings.

I was more concerned about ... we didn't really have a structure, like the second time we had questions to go off of. The first time we didn’t. So my group kinda was ... it was really messy. And then we decided to do the format of like asking questions, but the point in that discussion was to show to her that you did the reading. Student B gives her opinion regarding how the use of supports or prompts given by the instructor influences the class discussion. 
Some people think that supports can be hindering. Like we had the questions up on the screen that we could look at, but I thought that it was a beneficial support, cause if we didn't know what to talk about anymore we'd be okay, let's see which one of these questions we want to go more in depth with, or to address. So even though we didn't have to answer those questions if we didn't want to. She was letting it be our choice. In addition, the content analysis of the backchannel conversations revealed that two of the digital backchanneling sessions tended to have more non-related dialogue compared to the other eighteen transcripts. In both instances, when this occurred, the instructor neither provided guiding questions nor intervened with online remarks during the backchanneling sessions. The following dialogue is an example of a backchannel conversation that included a relatively high number of non-related (not related to the required reading or the class content) comments.

Student 1: Haha she is probably like, "Jesus that (Student A) kid can talk."

Student 2: Are we doing this for the entire class?

Student 3: That's another 20 minutes...

Student 3: but i think so

Student 4: it's until we stop talking

Student 1: They're able to stop whenever they want

Student 3: oh...

Student 3: do they know that?

Student 1: I dont think Student A does. 
Student 2: Lol now he's talking about hunger games.

Student 4: lol he didn't even read the article.

Student 3: That's why he's not talking about it.

Student 1: Haha well he sure knows how to BS.

Student 2: its making me cringe.

Student 2: He should get a medal.

Student 4: he tries too hard to bullshit.

Student 2: It's obvious.

At this point in the conversation, the students never did get "back on track" and ended up finishing the discussion with comments relating to "liking" an instagram account in order to get free concert tickets. The group members went back and forth telling one another their instagram accounts and asking questions about the concert.

The following dialogue provides the second example of a backchannel conversation that tends to stray off course, where a small portion of the discussion is nonrelated text. Again, with this example, the students are aware the instructor has access to their conversation, but unlike the first backchannel session in this class, the instructor is staying out of the discussion and not interjecting with ongoing prompts or comments. The students do manage to return to a content related discussion fairly soon after they started talking about the non-related issue of food.

Student 1: I just want to learn about kale in schools.

Student 2: baked in garlic hell ya

Student 3: What is kale? why is it such a huge thing? why? Let's unpack that. 
Student 4: How can something taste so bad, yet be so healthy?

Student 2: what? It's delicious!

Student 1: Kale chips are great actually

Student 2: Kale-pineapple smoothie is heaven on earth.

Student 3: That sounds so good.

At this point in the discussion, the students returned to talking about the topic of best practices in teaching content understandings, but towards the end of the conversation, they returned again to chatting about unrelated issues to the class, course, or teacher education as a whole. Surprisingly, the subject of food came up again and dominated the conversation for a brief period of time.

Student 2: can't stop thinkin about grilled cheese tho

Student 4: with the tomato soup

Student 3: so hungry

Student 1: I've got some dank sourdough at home

Student 2: lmao

Student 1: thats me

Student 4: truuuuuu

Student 2: heard that

Out of the 20 backchannel transcripts analyzed, the above three examples of excerpts from two different backchannel groups/discussions, were the only evidence of non-related dialogue and off topic discussion, other than basic greetings at the beginning or end of the digital conversation such as "hi," "I'm here," "what's up?" or "see ya!". According to Yacci (2000), all is not lost when students stray off course and are simply 
interacting about non-related issues. Yacci (2000) suggests that all types of interactivity in an online educational environment provide social presence and class gratification, possibly leading to benefits in attitude and overall course satisfaction.

Although this is true, ideally the main objective of conducting an in-class discussion is to focus on the class, course, or general subject content. In one occasion, even though the instructor was able to see the backchannel conversations in real time, as well as later, one of the students interviewed revealed in the interview that she, as well as the rest of her backchannel group, were unaware of the instructor's ability to see and monitor the online discussion. She admitted that the conversation would have probably been more focused if the whole group knew the transcript was saved and available for the instructor to review. Student G expressed the following comments:

For my group in the second time that we did it, we got off-topic really easily and really quickly. And it was ...kind of hard to get back onto what we were talking about, just because we were joking around about like what was happening in the front channel.

Obviously, I didn't find out 'til the end that she was actually going to be looking back at the transcripts. If I knew that they were gonna be read back, and like our teacher could see what we were talking about, I probably would've stayed more on-topic. I feel like the discussion would have been more beneficial if we were told that it was going to be monitored.

In this study, meaningful student to student interactivity, student to content interactivity, and student to instructor interactivity benefitted from the instructor taking 
on an active role in either providing guidance with supporting questions or initial prompts, or letting students know beforehand the conversations are seen and monitored by the instructor throughout, as well as after the completion of the digital backchannel session.

The last factor in regards to the backchannel design that influenced student to student interactivity was the structure of the backchannel group themselves. The number of students within the separate backchannel groups, as well as the physical placement of the group members, were two elements of the backchannel activity design that influenced interactivity amongst students.

Out of the 20 backchannel transcripts analyzed, all but one of those student groups consisted of either three or four students per group. One of the class sessions used a much larger number of students in the backchannel group by dividing the class into two sections, with one half taking on the role of the front channel and the other half of the class participating in the backchannel (roughly eleven students per group). After this particular class session ended, the instructor conducted a debriefing session and allowed students to voice their opinion concerning the backchannel design and the structure of the groups, etc. Toward the end of the first discussion, before the groups were going to switch roles, the following dialogue took place:

Instructor: The backchannel's minds are all about to explode right now.

Student 1: Mm-hum.

Group: Breaks out into small comments and chuckles.

Student 2: I don't like it. There's too many people in the backchannel. 
Student 3: I don't like it.

Student 4: Too many people in the backchannel. We should have more people in the front channel.

In comparison, several students from this same class offered their views on the structure of the second backchannel session that was conducted in this course. The second session was structured differently in that the front channel was still relatively large, but the backchannel groups were paired down to roughly three to four students per group. The comments below reveal these students' preference for smaller backchannel groups. At the end of the class period the instructor summed up the activity and asked the students for feedback on the comparisons of the two structures. The following comments took place among a few students who gave their opinions:

Student 1: I liked ... this structure better.

Student 2: This one.

Student 3: Way better.

Student 4: I honestly liked this one way better.

The students did not elaborate on their reasons for preferring the second structure over the first structure in this particular class. Presumably, based on the above comments that were made concerning the first structure, the smaller group sizes of the second structure made it easier for the second group of students to participate and keep track of the conversation. With both of the above sets of dialogue, the students were members of Instructor $\mathrm{C} /$ Course $\mathrm{C}$, where the first backchannel session utilized one relatively large backchannel group. The second session for this course utilized smaller backchannel groups with roughly five members per group at any one time, compared to ten members 
during the first backchannel session.

The second factor influencing student to student interactivity concerned the actual physical placement of backchannel group members during the activity. With this particular class, the instructor decided to keep backchannel group members in their original seats, resulting in students being dispersed throughout the classroom. For the second backchannel session, students were placed at the same table as their fellow backchannel group members, allowing the participants to have close physical proximity to the people they were conversing with online. Student B who was in this particular class discussed during the interview the differences of each set-up.

So the second structure being able to sit together, I feel like it facilitated conversation better because you could see if someone else was typing. So you would wait for them to get their thoughts out, and just like kind of establishing those rules of interacting online is easier when you're all sitting at the same table.

Student $\mathrm{C}$ remarked on how she preferred the second structure better due to the visual cues that enabled the online dialogue to run more smoothly.

Say I was typing, then like another person wouldn't type and answer because they knew I was about to answer. You would be planning to hear what you're saying and not typing because you don't want to interrupt ... so that was something interesting.

Student D, who was in this same classroom, emphasized the preference once again for the backchannel structure where group members sat at the same table instead of being randomly dispersed throughout the room. 
We were able to see the people we were interacting with in the second one. I saw when other people were typing so I knew like, oh just give it a second. So, as they were typing I could figure out my thought or whatever I wanted to say next. I also think it help me like make more connections to my classmates. Because, I really only knew a couple people...But actually having like that social aspect...

The second session facilitated an environment where online communication was easier simply because group members were able to visually see other students' body language, gestures, and typing, which helped the flow of the conversation and for the discussion to be more coordinated. With this being said, the anonymity that is normally associated with digital backchannels in larger settings was not present. In fact, the instructors that utilized digital backchannels for this study chose in all six cases to have students sign in under their regular names. For whatever reason, there were a few students who automatically chose a disguised name, possibly assuming this was the purpose of the activity.

\section{Summary of the Results for Question 1}

There was $100 \%$ interactivity on some level by all students who participated in the study and were present on the particular class day backchanneling took place. Out of the sixty-two students who participated in the study, each student interacted with either the content or with other students or, in many cases, the students interacted with both during the course of the activity. With the exception of two students, all of the other students who had the opportunity to participate in the front channel discussion interacted with the content and with other students at some point in time during the discussion. In 
regards to the seven students who contributed to the interview portion of the study, all of them responded favorably when asked if digital backchanneling encouraged interactivity amongst their classroom peers and with the course content.

Once the front and backchannel transcripts and student interview responses were analyzed, coded, and then categorized, two main themes emerged in relation to interactivity: (1) The content chosen for backchannel discussions influenced two types of interactivity (student - content interaction and student - student interaction) and (2) The design of the backchannel activity affected all three types of interaction.

The content analysis of the front and backchannel transcripts revealed that out of the six front channel transcripts and the 20 backchannel transcripts reviewed, the majority of the total comments were related to content in some way, whether that occurred by students conversing about the required reading in which the backchanneling activity took place or whether the issues were broader and related to teacher education topics in general. This finding indicated high levels of student - content interactivity throughout the tenure of the backchanneling activity. In particular, as revealed in Table 6 and Table 7, the percentage of comments related to higher levels of cognitive processing were relatively high, indicating interactivity with the content on a more advanced level and displaying evidence of higher order thinking and cognitive processing at the top of Bloom's revised taxonomy (Anderson, Krathwohl, and Bloom, 2001). In fact, interaction with content was apparent in all six class sessions, independent of the material or content that was chosen for the digital backchanneling discussion.

The design or structure of the digital backchannel discussion was the second element that influenced all three types of student interactivity. There were three factors 
concerning the backchannel activity design that influenced student interactivity: (1) The digital connection between the separate backchannel groups with the front channel group, (2) The role the instructor took throughout the activity, and (3) The seating arrangement and number of group members in the backchannel groups.

Based on the responses of the seven student participants who were interviewed, the connectivity between the front and backchannel groups influenced student to student and student to content interactivity positively. All seven students believed the link to the front channel supported the backchannel conversations and contributed to the perception of a whole class discussion rather than four or five separate conversations. In addition, the the seven students who were interviewed expressed their preference for the backchannel designs where the instructor provided more structure, whether that be through guiding questions that were posted in the beginning of the activity or more involvement in regulating the conversations. The content analysis revealed the three incidents where students veered off topic occurred during sessions where there were no guiding questions and instructors were not interjecting throughout the discussion. Lastly, according to student responses in the debriefing transcripts, smaller backchannel groups (three to four students), was preferable over larger groups, and four out of the seven interviewees responded favorably to a seating arrangement that enabled students to use visual cues and body language to aid in the flow of the conversation. Three of the seven students interviewed were not exposed to a variation in seating arrangement, therefore, had no opinion on this matter. In all six backchannel sessions, anonymity was not a factor, considering students were encouraged to use their real names when signing into the sessions. 


\section{Question 2:}

In what way does digital backchanneling contribute to student reflection in a teacher education course?

Student reflection during the digital backchanneling activity was evaluated by analyzing both front channel and backchannel transcripts that resulted from the six inclass digital backchanneling sessions. To add to this, student participant interview responses were assessed and several questions were devoted to gaining knowledge on student reflection.

Through the process of the content analysis and coding of the front and backchannel transcripts, student dialogue was broken up into units of meaning inspired by Henri's (1992) model and further coded into structural primary codes with corresponding subcodes (see Appendix C) to accurately assess the content of the front and backchannel conversations. The primary code of metacognition was used as the main descriptor for five metacognitive processes: evaluation, planning, regulation, selfawareness, and reflection. Students' comments were classified as "reflective" using Rodgers (2002) breakdown of Dewey's (1929) perception of reflection. First, learners must be engaged in meaning-making and should be making continual connections between what they have learned to other experiences and ideas. Secondly, learners' thoughts must be purposeful, systematic, and disciplined, and lastly, there needs to be evidence of connection and interaction happening with others within a social environment. These three parameters were used to classify student dialogue as reflective thinking.

The concept of reflection or reflective thinking in an educational setting has been 
widely discussed and researched (Boud, Keogh, \& Walker, 2013; Dewey, 1916; Dewey, 1929; Fernsten \& Fernsten, 2005; Moon, 2013; Rodgers, 2002; Schubert, 2014). Dewey (1916) expressed how important reflection is for linking educational material to lifeexperiences in order to teach information that becomes useful for students in their future existence. Dewey (1929) goes on to emphasize how schooling should be connected to the social experience and should be designed to prepare students for all aspects of societal participation.

With this past research in mind, this study focused on using the student participant's own words while they were participating in the digital backchanneling activity to ascertain whether reflection was present. Furthermore, numerous questions during the student participant interviews addressed reflective thinking by gaining information in regards to how backchanneling encouraged the act of thoughtful comments, mindful interaction with peers, and continual consideration of past, present, and future life experiences.

After coding the front and backchannel transcripts and the student participant interview transcripts, one primary theme was revealed in regards to reflection: (1) The digital backchanneling activity encouraged reflective thinking within an in-class discussion.

\section{The Presence of Reflective Thinking}

Out of the 20 backchannel transcripts that were analyzed, there was evidence of reflective thinking in all 20 discussions. Table 8 gives examples of comments from each of the classes involved in the study of the backchannel conversations that met the 
requirements of reflective thinking in an educational setting as proposed by Dewey

(1916, 1929) and confirmed by Rodgers (2002).

Table 8

Examples of Reflective Thinking in Student Dialogue with Digital Backchanneling

Instructor/Class Purposeful, Systematic, and Disciplined
Thought Processes that Connect Learning to Past Experiences, Current Situations, and New Ideas

Instructor $\mathrm{A} / \mathrm{BC} 1$

Instructor $\mathrm{A} / \mathrm{BC} 2$

Instructor $\mathrm{B} / \mathrm{BC} 1$
"I had one teacher who was also my softball coach. He really talked down to students and I was always terrified to be called on because if it wasn't said exactly how he wanted it said, he would call you out in front of everyone."

"I've done the thumbs up strategy mentioned in the article too. One of my previous teachers did it where students have their heads on their desks and put their fingers in the air, because he said that way they weren't embarrassed if they admitted they weren't understanding something."

"I thought that article was interesting because it correlated with the material that we learned in class. I feel like as a student, I was nervous about someone judging my performance, so I can see how that can affect a student." 


\begin{tabular}{|c|c|}
\hline Instructor/Class & $\begin{array}{l}\text { Purposeful, Systematic, and Disciplined } \\
\text { Thought Process that Connect Learning to } \\
\text { Past Experiences, Current Situations, and } \\
\text { New Ideas }\end{array}$ \\
\hline Instructor B/BC 2 & $\begin{array}{l}\text { "I liked how the article mentioned that } \\
\text { teachers should work on skills and advance } \\
\text { to comprehending the information. This, to } \\
\text { me, made me think of the bottom up } \\
\text { approach we talked about in class because it } \\
\text { focused on starting from the foundation. I } \\
\text { think that is important because students need } \\
\text { to learn the foundation first, and then work } \\
\text { their way up." }\end{array}$ \\
\hline Instructor $\mathrm{C} / \mathrm{BC} 2$ & $\begin{array}{l}\text { "I was just talking about this in my last } \\
\text { class. It is not necessarily teaching our } \\
\text { content, but it's about teaching our students } \\
\text { how to think." }\end{array}$ \\
\hline Instructor $\mathrm{C} / \mathrm{BC} 2$ & $\begin{array}{l}\text { "I would say I had teachers that were friends } \\
\text { to me and they were always the best teacher. } \\
\text { I'd say I learned most of my life lessons in } \\
\text { school. You see your teachers more often } \\
\text { than you see your parents." }\end{array}$ \\
\hline
\end{tabular}

Rodgers' (2002) classification of Dewey's perception of reflection was used to make decisions regarding whether students' comments were classified as reflective thinking. Rodgers (2002) extracts from Dewey’s writings the following four criteria, clarifying Dewey's conception of reflection, while outlining its purpose and process in an educational setting (p. 845).

1.) Reflection is a process where learners are engaged in meaning-making and are making continual connections between what they have learned to other experiences and ideas. 
2.) Reflection is purposeful, systematic, and disciplined, finding its roots in scientific inquiry.

3.) Reflection needs to happen in a social environment, where connection and interaction is happening with others.

4.) Reflection requires a set of dispositions that value life-long learning of oneself and others.

These four criteria were used as guidelines when determining whether or not a student's statement constituted reflective thinking. In each example excerpt, students were making purposeful statements, oftentimes connecting what they have learned to past, present, and even future educational situations. Each excerpt also exemplifies how students were thinking about these comments while interacting with one another in a social environment. The fourth criterion is essentially a set of characteristics (enthusiasm, selfawareness, open-mindedness, and responsibility) espoused by Dewey as being important to open the way for reflective thought (Rodgers, 2002). This criterion is more difficult to ascertain within each statement, but presumably the attitudes of open-mindedness and self-awareness were present considering students were agreeably discussing various teaching and learning scenarios and seemed self-aware of their viewpoints and mindsets. For instance, the excerpt derived from Instructor $\mathrm{B} / \mathrm{BC} 1$ gives an example of a student reflecting on the content of the required reading and how it correlated with what she had previously learned in class (meaning-making and connection of material to prior experiences). This student then goes on to make a purposeful, well thought out statement about her experience as a student and how she often felt teachers were judging her performance. Lastly, the student makes a conclusion regarding current students by 
relating the reading to the learned class knowledge, as well as her past educational experiences. This is simultaneously happening while she is connecting and interacting with peers in a social environment.

The seven students interviewed had various ways of describing reflection during the digital backchanneling activity, but all seven agreed that the digital aspect of the discussion gave them the opportunity to carefully deconstruct what others were saying and then use the digital platform to gather their thoughts and pensively contribute to the discussion. Student A described how the act of conversing was different for her in the backchannel compared to a verbal in-class discussion. This student found that the digital backchannel was beneficial to her reflective thinking process.

I do think though in the digital back channeling that sometimes the comments can be a lot better then maybe a verbal discussion because, you're typing so we all are used to using academic language within our writing ... related to our content. So when we're typing like we discussed this in class, too, we want to type it out and really make a good point. In a sense, I guess, you really do have to think hard about what you're going to say... where if they just said it in class you'd be like, that didn't make sense, but you wouldn't think about it as much.

Student E concurred by offering her thoughts on the difference in her level of thinking in a backchannel compared to a traditional lecture situation.

I feel like it just made me think more. Usually when I'm in a lecture like I pay attention, I take notes. But I feel like I don't really think about it ... 
cause I feel like the content is..., there's just so much of it, and in so little time you don't have time to reflect on what is going on.

This same student expressed how she utilized the digital backchannel to offer her perspective and to gain insight on how the content is related to her future as a teacher.

She was able to directly reflect on the material and socially construct knowledge through the "personal stories" of her classmates and then interrelate her thoughts to her lived circumstances of being a pre-service educator in teacher education.

I was kind of thinking cause we were talking about the impact of teachers and how we want to be better in the future because we know how important it is to have someone who cares. So I feel like that was something that was triggering thoughts and made me realize that it's really important, especially hearing those personal stories about how we can make that impact.

All seven students interviewed felt they would be able to use the digital backchanneling activity as a class discussion technique in their future classrooms. They were also able to reflect on their experiences within this study and offer ideas on how they could transfer what they learned on backchanneling to their own classrooms someday. Five of the students interviewed were middle level education majors and two of the students were elementary education majors. For most of the students who participated in the interview portion of the study, this was their first digital backchanneling experience. Two of the seven students had only experienced backhanneling in either a previous course or during an on-campus meeting for a university organization. 
Although the digital backchanneling activity seemed to have positively contributed to the interviewed students' ability to reflect during the in-class discussion, six out of the seven students agreed that the method of digital backchanneling did not influence their out of class reflection on the topic. In several instances, students mentioned that using this structure to conduct an in-class discussion did not affect their level of reflection on the topic after they left the class. In fact, they felt their post class reflective thinking was comparable to if they had participated in a traditional in-class verbal discussion.

Student G mentioned that she felt the activity may have caused her to contemplate the topic directly after the period when she was walking with a classmate discussing what had occurred in class. She admitted though, most of the conversation had to do with the method of backchanneling itself, rather than the actual course content.

I would definitely do it again, and in my own classroom I would definitely try it just to see if I can get those students who don't talk as much to talk more and to see... if they can stay on task or not. Like, if they can keep their discussion going, and just to see if they're able to make the discussion a good one.

\section{Summary of the Results for Question 2}

Once the front and backchannel transcripts, as well as the interview responses were coded and categorized, one primary theme emerged in relation to research question 2. For this study, digital backchanneling was used to conduct an in-class discussion and during this activity student reflective thinking was present and supported. All 26 front 
and backchannel transcripts displayed evidence of reflective thinking as measured by Rodgers (2002) criteria for reflection in an educational setting (Table 8).

In addition, although the seven students interviewed responded to questions concerning reflection in different ways, there was general agreement that reflective thinking was present in class during the activity and was supported by the digital backchanneling technique. The interviewed students made various comments related to how backchanneling enabled them to deconstruct the content, offer their perspectives on issues, gain insight on other's perspectives and then directly connect the experience to their future teaching practice and pedagogy toolbox.

\section{Question 3:}

How does digital backchanneling influence the overall learning experience associated with in-class discussions in a face-to-face educational setting?

The third research question in this study was designed to capture the overall learning experience associated with utilizing a digital backchannel design to conduct an in-class discussion within a teacher education setting. After coding and categorizing the front and backchannel transcripts, as well as the student interview responses, two main themes emerged in relation to question three: (1) Digital backchanneling resulted in a meaningful, positive, and focused learning experience, and (2) Millennials/digital natives seem to be less comfortable with technology and multi-tasking when used in an educational environment.

\section{Positive Overall Learning Experience}

Meaningful, focused, and positive learning was defined for this study as learning, where students are engaged with the course content, the class activity, and their fellow 
learners, and at the same time, new knowledge is being constructed through social interaction and reflective thinking (Burr, 1995; Rodgers, 2002; Vygotsky, 1978; Wertsch, 1985). As mentioned earlier, participation in the digital backchannel activity was high, resulting in high levels of student interactivity with content and student interactivity with other learners. The content analysis of the 20 backchannel transcripts indicated low levels of non-related dialogue, with only a small percentage of total remarks dedicated to nonrelated issues, demonstrating a focused discussion. Metacognition and reflective thinking were present in all 26 discussions (20 backchannel groups and six front channel groups) using Henri's (1992) breakdown of metacognition into four categories and Rodgers (2002) description of reflective thinking to categorize discussion remarks. In conjunction with the content from the front and backchannel conversations, the seven student participant interview responses were positive when asked about their learning experience associated with digital backchanneling. All seven interviewees indicated they would most likely be using digital backchanneling in their future teaching practices and felt the digital discussion activity will be a good way to incorporate student centered learning in their teaching pedagogy.

The comment below was from Student A, who summed up her feelings on digital bakchanneling by describing how the activity was supportive of learners who were not as comfortable speaking publicly.

I am in other you know content related courses where some students don't feel comfortable in those big discussions. It's kind of intimidating. You speak and everybody's listening you know ...the teacher's listening. I think it's a positive experience for those students that are nervous to speak 
up, to have the chance to show that they are comprehending and doing the reading.

This particular student also remarked on the technique of backchanneling itself and how her preparation for the backchannel activity contributed to a more meaningful, productive learning experience.

Writing really helps me remember things more, like with that huge book that we read... because we're doing back channeling I took better notes, and then I was writing things, again, that I remembered or like answering questions. Or, I was even having to like write my own questions so we could keep ... the discussion going in the back channeling.

Student A addresses the differences between a teacher led lecture and the digital backchanneling activity that was used in this study to support an in-class discussion. He clearly articulated his view regarding the level of engagement and focus during the backchannel activity when he expressed how, by participating in the backchannel, the material will be remembered more, stating that many times in a traditional lecture, students are not completely focused for a variety of reasons.

I'll come to you know, remember the material more, because I mean everybody has days where — like myself included — where you know you sit in the lecture and you're just ... you're tired, or it's not ... your mind may not engage at all. And you can easily, especially now, a lot of teachers put you know their PowerPoints online, so you don't even have to take notes. You could just sit there and make it look like you're engaged, but really not. It's all just in one ear, out the other. Like I mentioned 
before where it's like you ... your listening to it. You're hearing what she's saying but it's ... you're not grasping it.

To add to the above opinion, Student B described how digital backchanneling made learning more significant for her. The student led aspect of the activity, as well as the risk free nature of participating digitally, contributed to the overall positive comments she made regarding the use of backchanneling in an educational setting.

I feel like it prompted more inquiry from us then if it was just a normal teacher led discussion with the whole group. I feel like as students we felt more comfortable being unsure or asking questions. So someone would say something, and we'd be like you know what, we're really not sure. And like me neither, I'm kinda confused about this, or I have this question. So when we would just work together, to use what we got from the text, to um just connect each other's ideas. I think it's just important for us to be able to form our own opinions and not just be fed information and think that we have to think that way, or do things that way, just being able to explore it more.

The above interview responses were examples of positive comments that clearly indicate the student responses were favorable towards digital backchanneling and students were planning on using this educational technology to enhance their teaching methods for conducting an in-class discussion. These interview responses pointed to students explicitly expressing their viewpoints on how digital backchanneling encouraged deeper engagement and participation levels, prompted more inquiry compared to a teacher led discussion, and provided a environment for more in-depth consideration of 
material. In addition, the online, risk free aspect of the technology was emphasized as being positive and encouraging for students who are normally not as comfortable verbally contributing to a discussion.

\section{Tech Savviness May Not Translate to an Educational Setting}

Although the general consensus of the student participants interviewed was that digital backchanneling was a worthwhile pedagogy for conducting an in-class discussion, numerous remarks were made within the backchannel transcripts and throughout the interview process that pointed to frustration and confusion concerning the mechanics of the educational technology itself. As mentioned previously, many of the participants were first time backchannel users within an educational setting, therefore contributing to a general lack of knowledge of how exactly the technology fit into an in-class discussion. With this in mind, digital bakchanneling is nothing more than using technology to host a secondary conversation to support the primary dialogue, which seems to mimic the multitasking that is required in the daily activities of many millennials through social media, online interactions, and digital entertainment (Kennedy, Judd, Churchward, Gray, \& Krause, 2008; Tapscott, 2009). According to Tapscott, this generation is more accurately described as the Net Generation and has been bathed in bits, so to speak, for the better part of their lives, consequently opening up an opportunity for educators, employers, and marketers to appeal to this new type of technological thinking. In fact, Kennedy et al. (2008) reported in their study assessing first-year college students' experiences with technology that $73 \%$ of the students surveyed in the study have Internet access and even more have unhindered access to a mobile phone (96\%) and a desktop computer (90\%). 
Generally, these types of devices are used to a great degree for communication in a social context (Prensky, 2005), over issues that may be trivial in nature, which might be the deciding factor on why using technology to "chat" about educational issues and using it to "chat" about social issues is an entirely different scenario. Contrary to Tapscott (2009), Hargittai (2010) purports there is a wide range of technological skill levels amongst net generation users, with socioeconomics and other background factors playing a major role in these proficiencies. Student A describes some of the challenges she experienced when contributing to the discussion by typing in the backchannel compared to verbally speaking out.

The multitasking is more difficult to read and ... and think of your ideas rather than gauging off of your students verbal contributions.

So I think the one thing with the back channeling, like I said it feels really fast-paced cause it's hard to read it completely, and then finish typing your ideas if somebody else like pops up another idea.

Surprisingly, this student seemed slightly frustrated by the backchannel format, although the situation she described above is quite similar to what a person would experience in a group text or by looking at a typical snapchat. Another student commented during the interview that she feels "it's hard, like I said, because it feels fastpaced." Again, comments such as this one were somewhat unanticipated considering the age group of the students who were involved in this study. Most, if not all of the students who contributed to the research were roughly between the ages of 18 and 22 and would seem to be exposed to "fast-paced" digital conversations quite frequently. 
Student $C$ anxiously expressed in the interview how it was difficult for her to handle the barrage of questions and comments that came in at the same time during the beginning of her group's backchannel discussion.

So our group started talking and posing questions at the same time and you're like we didn't know which ones to answer. People started answering blind, they kept moving on so ... so it was like all right, like one person can pose a question.

Student D mentioned during the interview, "There was like seven questions asked at one time. And then you didn't know which one you should go back to, or which one you shouldn't address, so..." The backchannling activity was also described with phrases such as "the epitome of multi-tasking" and "our brains are going different ways."

Additionally, the content analysis of the front and backchannel transcripts revealed comments indicating confusion or frustration over the digital aspect of the conversation. Out of the six front channel transcripts, there was no mention of the verbal dialogue being too fast-paced or too many thoughts running simultaneously. In contrast, below is an example of a portion of a backchannel dialogue where participants were somewhat overwhelmed.

Student 1: When having a detailed discussion, especially when the content is important to you, it is hard to hear another discussion at the same time. Again, sorry for the off topic response. I just realized I haven't heard a thing that they have said up front in a while.

Student 2: I like that you said that Student 1. I do find it hard to pay attention to them because I'm enjoying this conversation.

One of the students from Course $\mathrm{C}$ comments on how the second backchannel experience was easier for her by stating "This backchannel is a lot easier than the last one. lol. Less to keep track of." The second backchannel for this specific student involved 
fewer students per group and there was a connection between each backchannel group and a representative in the front channel. Based on this student's statement, it would be safe to say, the smaller group and the additional connection reduced the level of multitasking, which made the experience less overwhelming.

Interestingly enough, as mentioned earlier in the study, the seven students interviewed preferred the additional link to the front channel, which obviously results in an additional line of communication to keep track of. One would think, given the comments made in the student interviews, as well as the debriefing sessions, that by adding the front channel group as a connected group, this would increase frustration over multi-tasking and the keeping track of multiple voices and topics. But in reality, the added communication between the front channel and the backchannel seemed to help students slow down and use the added connectivity with their peers to make sense of new information and reflect on how this information could be transposed to their individual situations. Therefore, the frustration over multi-tasking seemed to be delineated with increased connection to and understanding of another group's conversation.

\section{Summary of the Results for Question 3}

The 26 total front and backchannel and the seven student interview responses were coded and categorized and two primary themes resulted from this analysis: (1) Digital backchanneling resulted in a meaningful, positive, and focused learning experience, and (2) Millennials/digital natives seem to be less comfortable with technology and multi-tasking when used in an educational environment.

High levels of content related comments within the front and backchannel dialogues and relatively low levels of non-related dialogue during the activity indicated 
the overall learning experience associated with backchanneling was meaningful and focused. In addition, students who participated in the interview portion of the study made a variety of remarks signifying the experience was positive for all types of learners and that they would be using the discussion activity to appeal to different personalities and learners when they become future teaching professionals.

Surprisingly, the data also revealed students were somewhat uncomfortable with the fast-paced nature of the discussion and the high level of multitasking that was required during the activity. The student interview responses and the front and backchannel transcripts gave evidence of frustration at times, indicating that students' comfort level with using digital communication for educational purposes is not has high as it is for using technology in social situations. 


\section{CHAPTER V \\ OVERVIEW, DISCUSSION OF RESULTS, RECOMMENDATIONS, AND \\ FUTURE RESEARCH \\ Overview of the Study}

The existing study was designed to analyze the use of digital backchanneling during in-class discussions in teacher education classrooms. Twenty-six total front and backchannel transcripts from three different courses and six different class sessions, along with seven student participant interview transcripts, were examined to determine the influence of backchanneling on student interactivity, reflective thinking, and overall learning.

Henri's (1992) content analysis designed for evaluating computer mediated communicated provided an initial platform for the methodology of the study, followed by various stages of categorizing and coding (Miles, Huberman, \& Saldana's 2014; Saldana, 2013). A first cycle coding method called structural coding was used as an initial categorization technique to separate the sizable amounts of texts that resulted from the front and backchannel transcripts (Saldana, 2013). Miles, Huberman, Saldana's (2014) subcoding technique was also utilized to further analyze the data according to a revised version of Henri's (1992) content analysis classifications (Table 2). The second order coding or subcoding enabled me to incorporate past research on interactivity, reflection, 
and cognitive processing to effectively categorize the data, adhere to the purpose of this study, and to specifically answer the research questions at hand (Anderson, Krathwohl, and Bloom 2001; Bloom, 1956; Dewey, 1916; Dewey, 1929; Moore, 1989; and Rodgers, 2002). In conjuction with the previously mentioned coding techniques, In Vivo coding (Saldana, 2013) was utilized to analyze the data resulting from the seven student interview transcripts and to incorporate the student's voice into the data analysis process. Social constructivism purports that meaning results from individuals' experiences and interactions with other human beings and the world around them (Bandura, 2001; Bruner, 1990; and Vygotsky, 1978). With this theory in mind, the subjective interpretations of a student's experience with backchanneling were assessed and interpreted in order to understand digital backchanneling's influence on the learning process as a whole and specifically on aspects of interactivity and reflection.

The purpose of this study was to examine the particular educational technology of digital backchanneling used in a teacher education classroom to facilitate an in-class discussion. As a student and educator, I realize the importance of understanding and utilizing educational technology to meet a variety of learner's needs and to effectively incorporate digital methods and techniques that follow the requirements of a $21^{\text {st }}$ century learning environment. The multicase study design was chosen for this research using qualitative data from front and backchannel transcripts and student participant interviews to answer the following research questions:

1. In what way does digital backchanneling contribute to student interactivity during in-class discussions by teacher education students?

2. In what way does digital backchanneling contribute to pre-service teacher 
reflection in a teacher education course?

3. How does digital backchanneling influence the overall learning experience associated with in-class discussions in a face-to-face educational setting?

\section{Discussion of the Results}

Educators, administrators, and policy makers generally agree and are aware of the need for higher education to adapt to the advancements in technology in our society and to effectively incorporate technology into teaching and learning to meet the needs of a variety of learners functioning in a $21^{\text {st }}$ century environment. Other higher education stakeholders such as parents and students are expecting faculty to utilize, model, and teach digital practices to align with the expectations of their respective discipline and to thrive in today's workforce.

Research question one was intended to explore digital backchanneling's influence on student interactivity using Moore's (1989) philosophy on interactions between students, content, and instructors in an educational setting. The content analysis and the coding of qualitative data that followed, revealed two main themes that corresponded to the first research question: (1) The content chosen for backchannel discussions influenced two types of interactivity (student - content interaction and student - student interaction) and (2) The design of the backchannel activity affected all three types of interaction.

According to Barbour (2007), depending on the content being taught, different topics and lessons should be approached with a variety of teaching techniques and a diversification of how the material is presented. In addition, Barbour suggests the "smart use of multimedia," and other educational technologies, proposing to use these 
techniques to enhance certain material, rather than using the technology just because it is available or seems to be the "trendy" method at the time. Past research suggests digital backchannels have been successful in many contexts, such as large college lectures (Aagard, Bowen \& Olesova, 2010 and Pohl, Gehlen-Baum, \& Bry, 2011), sizable industry conferences (Harry, Green, \& Donath, 2009; Jacobs \& McFarlane, 2005; and McCarthey \& Boyd, 2005) and small middle and high school classes (Carpenter, 2015 and Poleon \& Krishnan, 2013). Although this is true, the student interactivity component of digital backchannling may actually be influenced by the learning content or the particular learning context and require the type of thought process that Barbour (2007) is suggesting when making decisions about the use of technology and the content chosen for the situation. Moreover, Goodson and Mangan (1995) describe the phenomenon of subject cultures and how a "general set of institutionalized practices and expectations have grown up around a particular school subject, and shapes the definition of that subject," and can create a certain set of norms that go along with the teaching and learning of that subject (p. 614). Many times educators are reluctant in adopting a technology or digital activity if it seems incompatible with a subject matter's standards and norms.

The results of this study take Barbour (2007) and Goodson and Mangan's (1995) research into consideration and seems to parallel their findings stating that content must be considered when making educational technology decisions, and the different elements of the learning process such as student interactivity can be affected by how the technology is used depending on the particular content chosen. This study revealed that teacher education content did indeed "pass the test," in regards to being appropriate for 
digital backchanneling as a method for conducting an in-class discussion. Although student participants compared and contrasted the various content/material that was chosen for the in-class discussion and had different views, concerns, and comments about each one of them, digital backchanneling worked well with teacher education content in general, and facilitated high levels of student interactivity. This research would argue that the use of educational technology (digital backchannels in this case) is not a "one size fits all" decision, and content area, as well as course specific material, may determine the suitability of using digital backchannels for certain courses/subjects and more importantly, certain course material or topics.

The digital backchannel design for this study varied on three main factors: (1) Whether or not the separate backchannel groups were connected digitally to the front channel group, (2) The role the instructor took throughout the activity, and (3) The seating arrangement and number of group members in the backchannel groups.

In the literature reviewed concerning the explicit digital backchanneling technology, the backchannel groups or group had some sort of digital connection with the front channel. Depending on the study, the front channel role was different. For instance, with large industry conferences, the front channel consisted of a conference speaker and with large lecture survey courses, the front channel was the course instructor. In all cases of the digital backchanneling research reviewed, the connectivity between the two channels was present and seemed to be inherent in the overall structure and purpose of using a backchannel to implement a lecture or discussion.

Providing an environment where students are promoted to interact and build interdependence has been noted by Song \& McNary (2011) as being the "necessary 
ingredients" of a successful learning situation (p. 3). According to Garrison, Anderson, \& Archer (2001) building a sense of community in an online learning environment is extremely important component to learning success when interacting in an online environment. In addition, Shackelford \& Maxwell (2012) emphasize the importance of social, cognitive, and teaching presence in leading to a more comprehensive, all-inclusive community of learners.

The results of this study concur with the abundance of literature pointing to the importance of connectivity, interactivity, and presence when using online communication tools in a learning environment. The added connectivity between the backchannel groups and the front channel groups that was apparent in all three courses during the second backchannel session, proved to benefit student interactivity, thereby contributing to better learning outcomes (deeper understanding of material and affirmation of group ideas and comments).

The role of the instructor was another factor influencing all levels of student interactivity. Song and McNary (2011) found that course design and instructor involvement did influence student posts and level of interaction over time. Students in this study were required to respond to a prompting question posed by the instructor to improve their understanding of various topics related to the class. Schwier \& Seatin (2013) found that providing a structure or setting for connectivity and interaction is essential in promoting participation in an online learning environment. To add to this research, Gehlen-Baum, Pohl, and Bry (2011) contend in their study involving Backstage, a prepackaged digital backchanneling program, that participants appreciated the ability to directly communicate with the lecturer or instructor and found the direct 
feedback of the quiz functionality of the program to be helpful in understanding the material.

Student directed learning has been applauded by many researchers (Garrison, 1997; Morrow et el, 1993; and Taylor, 1995), where teacher direction and guidance is even discouraged in order to develop student self-monitoring, self-direction, and greater awareness of their responsibilities.

A more participatory instructor role was seen as an advantage in this study and the results tend to lean toward the research findings of Song and McNary (2011) and GehlenBaum, Pohl, and Bry (2011). Student interview responses indicated the use of guiding questions, whether they were included in the introduction of the activity or they were used to prompt students during the activity, were extremely helpful in keeping group discussions on task and more focused on the content. The nature and scope of the digital backchanneling activity inherently provides a setting and structure where students are encouraged to openly discuss the class material and develop a deeper understanding of content related issues through a relatively risk-free online dialogue with classmates. Therefore, the results of this study demonstrates a balance can be struck between too much teacher involvement and not enough, if the instructor interjects some questioning and provides a limited number of guidelines during the backchannel discussion.

The results of this study pertaining to research question one is in line with aspects of Moore's (1989) Transactional Distance Theory, and at the same time, is contrary to elements of the theory. For instance, Moore states the transactional distance in a distance education or online course is reduced with less structure and more opportunities for connection and dialogue, leading to a stronger, more beneficial learning experience 
(Moore, 2013). Based on this study's findings, more structure, whether that be in the way of instructor guidance or specified seating arrangements seemed to positively influence student attitude and participation, thereby contributing to a more attractive class experience. On the other hand, the opportunity for constant dialogue amongst learners and interactivity between learners and content, enabled students to experience two types of interactivity that has been outlined by Moore. Although the digital backchannel activity did not provide direct interactivity between learner and instructor per se, the structure, design, and content was influenced by the instructor, therefore providing a sense of indirect interaction between the instructor and the learner. As Moore (2007) has noted, all three types of interactivity are an important component to online learning and this aspect of the study may warrant further investigation on how to incorporate effective instructor - student interaction during a digital backchannel discussion.

Research question two was included to evaluate how digital backchanneling influences student reflection in a teacher education course. Reflective thinking has been shown to be a crucial component to the learning process and obviously some methods of teaching would seem to promote it better than others. This question was designed to explore how student reflection is affected by an activity such as digital backchanneling.

The results of this study tend to support the notion that online communication gives students the opportunity to closely monitor their words and stop and think about how they are going to contribute to a conversation before they do so. In other words, students are able to be more calculated with their thoughts and textual contributions compared to a verbal discussion where oftentimes, comments and remarks are spoken without thoughtful consideration. According to Huang and Hsiao (2012), online 
communication allows "for higher quality discussions as students would have more time to think and refine their answers than they would have in real-time discussions" (p. 27). An essential feature of reflective thinking, is the idea that students purposely connect new knowledge to past experiences, peer contributions, and current circumstances. Dewey's philosophies on reflection and its place in the educational process highlight the concept of reflection in the context of a social experience. In Dewey's (1929) Pedagogic Creed, he eloquently promotes the idea of reflection by stating, "Through the responses that others make to his own activities he comes to know what these mean in social terms. The value that they have is reflected back in them" (p. 75). Yardi (2008) argues the premise of successful "peer-to-peer learning in a chat room is rooted in the theory of constructivist learning," where reflection has proven to be an essential element of this type of educational process (p. 149).

This study supports the above research in that the results indicated digital backchanneling in particular, is a form of online communication, where the involved students felt they were given the opportunity to participate in an in-class discussion without the stress and pressure associated with a live verbal discussion. At the same time, students felt they had the time and resources available to them to reflect on their words and well as others, and then contribute effectively to the class dialogue.

Research question three asked how digital backchanneling contributed to the overall learning experience in a face-to-face classroom discussion. Two key themes in regards to this question were exposed through the data analysis process: (1) Digital backchanneling resulted in a meaningful, positive, and focused learning experience, and (2) Millennials/digital natives seem to be less comfortable with technology and multi- 
tasking when used in an educational environment.

Any particular teaching technique or mode of instruction delivery cannot possibly be everything for everybody. In most cases, a certain number of students will gravitate and thrive with the use of one specific strategy, and there will always be a portion of the class that is not comfortable with that strategy and seem to excel under a different set of conditions. As Toledo and Peters (2010) contend, backchanneling in an educational setting does have its constraints and several participants involved in their research spoke to the fact that backchanneling may not suit all types of learners. Toledo and Peters (2010) go on to conclude, "just as with face-to-face group discussions, there will be those who are comfortable, those who will be passive, and those who will dominate" (p. 83).

With that being said, the results of this study indicate digital backchanneling provided the majority of students who were involved in the backchanneling session a meaningful, positive, and focused learning experience. All seven of the students who were interviewed had an overall positive opinion of the digital discussion technique, stating they would be more than willing to incorporate the discussion activity into their future teaching practice. The dialogue in the front and backchannel transcripts complemented the views of the seven students interviewed by providing ample evidence of meaningful learning through interaction with content on a high cognitive level and little evidence of straying from the material and discussing non-related issues.

Serving as a structure for this study, Laurillard's Conversational Framework for Teaching theory $(2002,2008,2009)$, proposes a protocol that is necessary for effective learning and is applicable to any educational setting. This theory includes a reiterative process of communication, feedback, reflection, and adaptation primarily between the 
learner and the instructor. In addition, this framework is utilized to make decisions on the effective use of learning technologies in university teaching (Laurillard, 2002). Laurillard's Framework emphasizes the discursive nature of learning (dissemination of knowledge and ideas) through teacher directed instruction and a continual line of communication between the learner and the instructor to re-describe information according to the student's initial conception of the information. Although learner to learner interaction is somewhat incorporated through the reflective process, with the learner using past experiences to reformulate their idea of the content, Laurillard's theory focuses heavily on the iterative conversation between instructor and learner in the teaching and learning process. The results of this study upholds the assertion of instructor guidance being important in the learning cycle, but explicitly adds to Laurillard's theory by giving evidence of student learning at a relatively high level by using an activity where students are primarily communicating with other students during the entire class session. The digital backchannel activity demonstrated students communicating frequently, pensively, and attentively with other students, as well as the course content, resulting in a meaningful, focused learning experience.

Although digital backchanneling was a positive experience for most students, comments made during the student interviews and debriefing sessions contributed to the notion that digital backchanneling was difficult to implement at times, simply because of the multitasking involved and the challenging aspects of online synchronous communication (lack of body language or physical gestures to fully interpret people and to understand the timing of the conversation).

Worley (2011) examines the student characteristics of the net generation and 
describes millennials (those born between 1980 and 2000) (Gloeckler, 2008), as being "technologically advanced," with the ability to multitask. This research also concludes that this generation is "impatient," "extremely social," and "self-centered," and as a result, the ways they "live and learn are much different than previous generations" (Worley, 2011, p. 33). Worley (2011) adds to this commenting on how technology has had a clear impact on students of this age group in regards to the social aspect of their lives. Students have instant access to text and visual communication through social networking sites, chat rooms, and web blogs and are able to be in constant contact with their social network.

The findings in the texts analyzed for this study seem to match aspects of Worley's (2011) contentions that millennial students are "technologically advanced," but at the same time, the "impatient" characteristic of this generation may have led some of the students involved in the study to become easily frustrated and irritated with the multitasking component of the activity. This may be especially true, considering the digital backchanneling activity was used to augment a fairly high level content-related conversation compared to a more informal social conversation, which seem to be the type of conversations net generation students are more used to when using technology to communicate.

Current literature purports the learning environment in higher education is changing and educators and institutions need to meet students where they are (involved in ubiquitous communication, digitally connected, and technologically advanced) (Kukulska-Hulme, 2012; Staley and Trinkle, 2011; and Worley, 2011). Although this may be true, further consideration needs to be taken on how best to incorporate the 
technological skills of the net generation in an educational context. Tech savviness on a social scale does not necessarily translate to tech savviness on a professional or academic level.

\section{Recommendations}

Higher education institutions have a responsibility to provide students with an educational experience that prepares students to live, work, and thrive in a $21^{\text {st }}$ century environment. Specifically, administrators, educators, and policy makers in teacher education need to strategically consider educational technologically that makes sense and can be passed on to future educators as a viable and workable teaching technique to meet the needs of the ever present diverse learner. As early as 1980, Howard Gardner pioneered the idea of a variety of intelligences, giving way to a movement where educators are rethinking the notion of intelligence and how individuals learn. Educational technology is just one piece of the changing landscape in higher education and needs to be utilized effectively in order for students to realize all of the benefits post secondary education has to offer (Christensen, Horn, \& Johnson, 2008).

Using what we already know about teaching and learning and leveraging that

knowledge to make informed, productive decisions regarding educational technology, will not only help teacher education faculty to teach better, but will give teacher education students the opportunity to learn content, as well as practice technique. The premise behind much of Laurillard's $(2002,2008,2009)$ research and the eventual development of the Conversational Framework for Learning theory, emphasizes the importance of utilizing past educational research to effectively make current and future decisions on best practice techniques for incorporating technology into the classroom. 
Laurillard's (2002) Conversational Framework for Learning theory states that the teaching and learning process requires various critical exchanges between the instructor, the learner, and the learners' peers, with a continuous cycle of feedback, reflection, and adaptation. Educational technology decisions need to be considered in light of these crucial elements that have proven to be necessary for the learning process.

This study explored the use of digital backchannling in a teacher education classroom. The backchanneling activity was used to conduct an in-class discussion in a face-to-face classroom. The concept of student interactivity and reflection were specifically chosen as aspects of the learning process to be focused on. This research explored how digital backchannels influenced these two essential components and based on the findings of this study, educational technology decisions in a teacher education classroom need to consider the following factors:

- Already existing theories on teaching and learning

- Appropriately matching content to the technology

- Experimentation with design and structure of the technology in order to best meet the needs of students

- Leveraging the benefits of what works (increased interactivity, reflective thinking, and meaningful, focused learning)

- Addressing the challenges and concerns of what does not work (frustration over multitasking and lack of instructor guidance) and making appropriate adaptations to meet learners' needs

The above implications can be further broken down to inform instructional decisions in the teacher education classroom. As seen through this research, quality 
interaction and frequent student reflection was evident during the in-class discussions utilizing backchannels. Teacher education faculty should consider the results of this study and utilize digital backchannels in courses where students tend to be more independent in their thinking and group work is more difficult to integrate. In addition, teacher education faculty should take into account the results of this study concerning the content used for backchanneling, the level of teacher involvement, and the design/structure of the activity when making decisions on exactly how to integrate backchannels into their courses.

Teacher educators may also consider utilizing digital backchannels to increase interactivity and reflection in out of class learning situations. In many cases, interaction and reflection can be the missing elements when students are doing out of class work (homework), simply due to the lack of face-to-face contact with the instructor and other students. For instance, based on the results of this study, digital backchannels would effectively support some of the activities that would take place in a "flipped classroom" model where oftentimes lectures/information dissemination is video recorded and asynchronously presented outside of class time. Teacher educators could make use of backchannels to encourage and support students to interact with the content, instructor, and other learners outside of class time to make sense of the information presented.

This study also has implications for K-12 educators who want to provide a variety of modes of content delivery to their students, as well as comply with technology standards that guide the use of educational and instructional technology in the $21^{\text {st }}$ century classroom. Many states align themselves with the National Educational Technology Standards, requiring teachers of all levels of experience to design and adapt digital-age learning experiences and assessments (International Society for Technology in 
Education, 2008). Furthermore, over the last fifteen years, schools have invested heavily in technological resources to enable K-12 classrooms to become digitalized and to actually practice these standards (Culp, Honey, \& Mandinach, 2003; Dickard, 2003).

Digital backchannels are cost effective and easily accessible, particularly for schools with one-to-one computer accessibility or mobile computer/iPad carts for student use. Although more research is needed in this area, digital backchannels should be contemplated for use in the K-12 classroom as a viable, accessible and effective educational technology.

As with teacher education classrooms, digital backchannels can also be used in K12 learning scenarios to stimulate interactivity, student reflection, and meaningful and focused content delivery. The results of this study indicated students engaged in frequent reflective thinking throughout the backchannel activity. This specifically may benefit younger students, considering reflection is an aspect of metacognition that is oftentimes difficult to understand, as well practice within this level of schooling.

Lastly, educational administrators of all levels should consider technologies such as digital backchannels as appropriate for a professional development topic in the area of educational technology. Higher educators, as well as K-12 instructors will be less likely to implement backchannels as a new way to host an in-class discussion if they are not familiar with setting up or navigating the online programs (chatzy.com, todaysmeet.com, backchannelchat.com, etc.) used to facilitate a backchannel. Professional development opportunities should be made available for instructors to not only learn about the functions of these online programs, but to actually have a chance to practice digital backchanneling in the training sessions. 


\section{Future Research}

This study was designed to research the use of a digital backchanneling in a teacher education classroom. The backchanneling technology was utilized to conduct an in-class discussion based on a predetermined course text that was chosen for the activity. The results of this study reveal that digital backchannels were positively received by teacher education students and were effectively utilized to influence student interactivity, reflective thinking, and overall learning. Nevertheless, there are many opportunities for future research on the subject of backchannels, with many aspects of the educational technology not yet discovered and many questions still to be answered.

For this study, digital backchanneling was analyzed in a teacher education context, specifically using courses that were involved with middle or secondary school literacy instruction. One of the results discussed how digital backchannels worked differently and similarly, depending on the content/material that was chosen for the discussion. The opportunity for future research exist by evaluating digital backchannels in different educational contexts altogether such as K-12 environments. Limited research has been conducted in these areas (Jarrett \& Devine, 2010; Markett, Arnedillo Sanchez, Weber, \& Tangney, 2006; Poleon \& Krishnan, 2013), and based on the results of this study, there would seem to be potential opportunities for increasing interactivity, student reflection, and more focused learning amongst students in different subject matters and at different levels. To add to that, the above mentioned studies focus more on participation and engagement, leaving a large area of the educational process at this level (K-12) left for exploration (student motivation, content retention, critical thinking, essential literacy skills, etc.) For instance, are backchannels more effective in social science courses that 
involve more literacy skills and aptitudes, or are they appropriate for math and science curriculums as well? Can digital backchannels work in noncore subjects such as art, music, and physical education? With what age group or grade level are digital backchannels most effective? These are examples of questions that are still unanswered and would be worth devoting more research to in order to fully understand the capabilities and scope of how backchannels can be utilized and in what context they are most effective.

An additional result of this study indicated the particular design of the backchannel influenced aspects of learning differently. There are a variety of ways instructors can structure a digital backchannel in a classroom.

- Supplementing a lecture - the front channel consists of the instructor and the backchannel consists of the students

- Facilitating an in-class discussion - the class is split into equal size groups with one group consisting of the front channel and the remaining groups making up the numerous backchannels

- Augmenting an activity - the front channel is essentially a video, a performance, a reading, etc. and the backchannel is either one large group or several small groups of students

These are just a few of the examples of how a digital backchannel can be structured and within these structures there are even more options on how to arrange the activity. For instance, with this study, within each course the digital backchannel was constructed differently each time, varying the levels of instructor guidance, sizes of backchannel groups, connectivity of front and backchannel groups, and the seating 
arrangement of backchannel groups. As one can see, there are many factors to consider regarding how a digital backchannel is structured and utilized within a classroom. Future research must explore the variety of ways digital backchannels can be structured and what designs match up best with what particular educational setting. Does the "facilitating an in-class discussion model" work best in a higher education classroom or are there possibilities of using this model in a secondary or even middle school classroom? What are the appropriate sizes for front and backchannel groups (is 4 the magic number for group size or can it be done with 2 or 10)? Do certain designs work better with certain subjects or particular student levels? How much is too much freedom with what is being said and what is being monitored? All of these questions are worth considering and would enable researchers to shed light on some important issues regarding backchannels. In addition, educators in particular would benefit from this information, making it more feasible to incorporate this technology into their classrooms in a timely and effective manner. While looking at the different aspects of digital backchannels as mentioned above, stakeholders would benefit from more action or practitioner research on the subject. Teachers need to see concrete examples of how the technology is used in the classroom and what are the pros and cons as a result of it. Resources are scarce in education and planning time is a luxury, therefore teachers need "to the point" literature on best practice techniques in incorporating educational technology into their classrooms such as a digital backchannel.

Although this study focused on the influence of digital backchannels on student interactivity and reflective thinking, there are other aspects of the learning process that could be further explored in conjunction with the technology. How do digital 
backchannels influence student interest and motivation? What are the effects of using backchannels on student comprehension? In what way do digital backchannels influence technology competence? How do backchannels contribute to student confidence and efficacy?

Lastly, there is an abundance of research pointing to the fact that technology in our society is ever-present and not going away any time soon. In fact, technological advancements are happening at this very moment, and will even change from this instant until the time this research is complete. To supplement this, there is also research stating digital age students will need to be catered to, in a sense, and every educational institution needs to "jump on board" with integrating technology at their earliest convenience.

The findings of this study complement many aspects of the past research, but one finding did indicate that digital age students may not be as tech savvy in a more formal environment such as a classroom. With this being said, future research needs to further examine how digital age students react and respond to technology in the classroom.

Educational scholars must not make assumptions regarding this generation and future generations' technological competencies. Rather, more research needs to be devoted to unpacking the aptitudes and deficiencies of digital age students to best understand how to effectively implement new technologies into the teaching and learning process.

\section{Final Thoughts}

As I am completing this scholarly endeavor and introspectively thinking about what has transpired over the last year and half, I am realizing the impact of research such as this and am hoping to see higher education institutions responding to the economic, 
cultural, and political forces that are pushing technological advancements and progression in our society. The higher education community needs to be at the forefront of this movement, leading the way in research and development, and providing society with solutions on technology integration, rather than trying to play catch up in order to appease parents and students, or to prove to politicians and future employers the cost of higher education is worth it. Although I firmly believe education can change society and administrators and teachers need to be activists in promoting change and reform, I am a pragmatist at heart. What I mean by this is, educators need to do a better job embracing what we already know about teaching and learning and what we already have at our fingertips as a result of ubiquitous technology. Simple adaptations, such as instituting a digital backchannel to conduct a few classroom discussions throughout the semester, can make the world of difference for students who are not as comfortable speaking in a traditional face-to-face classroom. Furthermore, for those students who are simply bored, unengaged, or have problems focusing, adding a digital backchannel can help them utilize what they already know (digital communication) to make the learning process more interesting and up to date.

Colleges of education are making critical decisions every semester relating to online class choices, educational technology pedagogy, and faculty professional development related to instructional technology. Students are also deciding on plans of study and course choices to fit into their personal circumstances and appeal to their interests and meet the requirement of being technologically prepared in order to function and thrive in the teaching profession. Teacher education administrators, faculty, and students would benefit from consideration of this research and the other literature that 
exists on the subject, when making ongoing decisions regarding the effective utilization of technology in the teacher education classroom.

\section{Limitations of Study}

The student participants had varying degrees of experience with using backchannels within an in-class discussion, thereby influencing their levels of proficiency while using the technology itself. Only one out of the seven students interviewed had participated in a backchannel discussion and that particular instance was not in a classroom setting. In addition, the student participants general technological proficiency varied across students, influencing the level of adaptation to utilizing the online communication for an in-class discussion.

The data collection period was conducted over one semester, therefore limiting the number of in-class discussions/topics that were used to review the influence of backchannels on interactivity and reflection. The influence of backchannels on interactivity and reflection was explored in the context of a Teacher Education classroom, with the discussions mainly focusing on educational issues, specifically related to literacy instruction. Digital backchannels may have contributed differently to student interactivity and reflection when utilized with various subject matters and with different topics/issues.

Furthermore, this study did not address out of class interactivity that may have occurred as a result of the backchannel/front channel in-class discussion model. The type and quality of interactivity was strictly evaluated during the in-class backchanneling sessions, therefore not capturing possible interactions that took place directly following class or during discussion of the material at a later time. Interactions that took place 
during study sessions or casual conversation may have been a direct result of the backchanneling discussion, but were not explored due to the nature and scope of this study.

Although there was an attempt to measure student reflection by questions posed during participant interviews, many aspects of reflective thinking may not be entirely captured, simply due to the intangible nature of this aspect of learning. Student reflection may have been occurring during the backchanneling activity (metacognitively), without students noting this within the online dialogue, making it difficult to capture those thoughts and perspectives. Similarly, out of class student reflection was not deeply explored with this study, with only one interview question devoted to this type of reflection. The data collection method of student interviews was designed to complement and support the analysis of reflective thinking during the in-class digital backchanneling discussions, therefore, the questions were mostly focused on reflection as an educational process while making meaning during the class in a social setting. 


\section{REFERENCES}

Aagard, H., Bowen, K., \& Olesova, L. (2010). Hotseat: Opening the backchannel in large lectures. Educause Quarterly, 33(3), 2.

Allen, I. E., \& Seaman, J. (2013). Changing course: Ten years of tracking online education in the United States. Babson Park, MA: Babson Survey Research Group and Quahog Research Group.

Allsopp, D., McHatton, P., \& Cranston-Gingras, A. (2009). Examining perceptions of systematic integration of instructional technology in a teacher education program. Teacher Education and Special Education, 32(4), 337-350.

Anderson, L. W., Krathwohl, D. R., \& Bloom, B. S. (2001). A taxonomy for learning, teaching, and assessing: A revision of Bloom's taxonomy of educational objectives. Allyn \& Bacon.

Archer, W., Anderson, T., \& Garrison, R. (1999). Adopting disruptive technologies in traditional universities: Continuing education as an incubator for innovation. Canadian Journal of University Continuing Education, 25(1), 13-30.

Armstrong, A., \& Thornton, N. (2012). Incorporating Brookfield's discussion techniques synchronously into asynchronous online courses. Quarterly Review of Distance Education, 13(1), 1.

Balaji, M. S., \& Chakrabarti, D. (2010). Student interactions in online discussion forum: 
Empirical research from 'media richness theory' perspective. Journal of Interactive Online Learning, 9 (1), 1-22.

Bandura, A. (2001). Social cognitive theory: An agentic perspective. Annual review of psychology, 52(1), 1-26.

Barbour, M. K. (2007). Principles of effective web-based content for secondary school students: Teacher and developer perceptions. International Journal of E-Learning \& Distance Education, 21(3), 93-114.

Bean, J. C. (2011). Engaging ideas: The professor's guide to integrating writing, critical thinking, and active learning in the classroom. John Wiley \& Sons.

Beauchamp, G., \& Kennewell, S. (2010). Interactivity in the classroom and its impact on learning. Computers \& Education, 54(3), 759-766.

Becker, H. S., \& Geer, B. (1970). Participant observation and interviewing: A comparison. 2013-07-12]. http://blogs. ubc.ca/qualresearch/files/2009/09/BeckerGeer. pdf.

Belcher, D. D. (1999). Authentic interaction in a virtual classroom: leveling the playing field in a graduate seminar 1. Computers and Composition, 16(2), 253-267.

Bernard, R. M., Abrami, P. C., Borokhovski, E., Wade, C. A., Tamim, R. M., Surkes, M. A., \& Bethel, E. C. (2009). A meta-analysis of three types of interaction treatments in distance education. Review of Educational Research, 79(3), 12431289.

Betrus, A. (2012). Historical evolution of instructional technology in teacher education programs: A ten-year update. TechTrends, 56(5), 42-45. 
Bigum, C., \& Rowan, L. (2008). Landscaping on shifting ground: teacher education in a digitally transforming world. Asia-Pacific Journal of Education, 36 (3), 246-255.

Bloom, B. S. (1956). Taxonomy of educational objectives. Vol. 1: Cognitive domain. New York: McKay.

Bogdan, R. C., \& Biklen, S. K. (2007). Research for education: An introduction to theories and methods. New York: Pearson.

Bordia, P. (1997). Face-to-face versus computer-mediated communication: A synthesis of the experimental literature. Journal of Business Communication, 34(1), 99-118.

Boud, D., Keogh, R., \& Walker, D. (2013). Promoting reflection in learning A modeli. Boundaries of Adult Learning, 1, 32.

Bowen, G. A. (2009). Document analysis as a qualitative research method. Qualitative research journal, 9(2), 27-40.

Breault, D. A., \& Breault, R. (Eds.). (2013). Experiencing Dewey: Insights for today's classrooms. Routledge.

Brown, D., \& Warschauer, M. (2006). From the university to the elementary classroom: Students' experiences in learning to integrate technology in instruction. Journal of Technology and Teacher Education, 14(3), 599-621.

Bruner, J. S. (1990). Acts of meaning (Vol. 3). Harvard University Press.

Burr, V. (2003). Social Constructionism (2nd Ed). London: Routledge.

Cain, S. (2013). Quiet: The power of introverts in a world that can't stop talking. Broadway Books.

Camp, G. (1996). Problem-based learning: A paradigm shift or a passing fad. Medical Education Online, 1(2), 1-6. 
Card, K. A., \& Horton, L. (2000). Providing access to graduate education using computer-mediated communication. International Journal of Instructional Media, 27(3), 235.

Carpenter, J. P. (2015). Digital Backchannels: Giving Every Student a Voice. Educational Leadership, 72(8), 54-58.

Chen, J. \& Chang, C. (2006). A comprehensive approach to technology training for early childhood teachers. Early Education \& Development, 17(3), 443-465.

Christensen, C. M., Horn, M. B., \& Johnson, C. W. (2008). Disrupting class: How disruptive innovation will change the way the world learns (Vol. 98). New York, NY: McGraw-Hill.

Coffey, A. \& Atkinson, P. (1996). Making sense of qualitative data. London: Sage.

Conole, G., Galley, R., \& Culver, J. (2010). Frameworks for understanding the nature of interactions, networking, and community in a social networking site for academic practice. The International Review of Research in Open and Distance Learning, 12(3), 119-138.

Culp, K. M., Honey, M., \& Mandinach, E. (2005). A retrospective on twenty years of education technology policy. Journal of Educational Computing Research, 32(3), 279-307.

Council for the Accreditation of Educator Preparation. (2015). As approved by the CAEP Board of Directors, p. 1-56.

Creswell, J. W. (2013). Research design: Qualitative, quantitative, and mixed methods approaches. Sage publications. 
Crotty, M. (1998). The foundations of social research: Meaning and perspective in the research process. Sage.

Crystal, D. (2001). Language and the Internet. Cambridge University Press.

Darling-Hammond L., \& Bransford, J. (Eds.). (2005). Preparing teachers for a changing world. San Francisco, CA: John Wiley \& Sons. Inc.

Davis, S. (2003). Observations in classrooms using a network of handheld devices. Journal of Computer Assisted Learning, 19(3), 298-307.

Dennis, A. R., \& Valacich, J. S. (1999, January). Rethinking media richness: Towards a theory of media synchronicity. In Systems Sciences, 1999. HICSS-32. Proceedings of the 32nd Annual Hawaii International Conference on (pp. 10-pp). IEEE.

Denzin, N. K. (1978). Sociological methods: A sourcebook. McGraw-Hill Companies.

Denzin, N. K., \& Lincoln, Y. S. (2009). The elephant in the living room: Or extending the conversation about the politics of evidence. Qualitative Researcher, 9(2), 139-160.

Dewey, J. (1916). Democracy and Education. New York, NY: MacMillan.

Dewey, J. (1929). My pedagogic creed. Journal of the National Education Association, 18(9), 291-295.

Dewey, J. (1980). The school and society (Vol. 151). SIU Press.

Dickard, N. (2003). The Sustainability Challenge: Taking EdTech to the Next Level. For full text: http://www2. edc. org/CCT/admin/publications/report/EdTechSustainability. pdf.. 
Dillenbourg, P., Järvelä, S., \& Fischer, F. (2009). The evolution of research on computersupported collaborative learning. In Technology-enhanced learning (pp. 3-19). Springer Netherlands.

Draper, S. W., \& Brown, M. I. (2004). Increasing interactivity in lectures using an electronic voting system. Journal of computer assisted learning, 20(2), 81-94.

Driscoll, M. P. (2005). Psychology of learning for instruction. Boston: Pearson Education.

Donnelly, H., \& Kyei-Blankson, L. (2014). Administrator insights, evaluation, and support of new teacher use of educational technology. Journal of Education and Training, 2(1), 110-133.

Donnelly, R., \& Gardner, J. (2011). Content analysis of computer conferencing transcripts. Interactive Learning Environments, 19(4), 303-315.

Edmonson, S., \& Irby, B. (2008). Ten tips for producing a top qualitative research study. Boston: Pearson.

Emerson, R. M., Fretz, R. I., \& Shaw, L. L. (1995). Fieldnotes in Ethnographic Research (Fragments de texte). University of Chicago Press.

Emerson, R. M., Fretz, R. I., \& Shaw, L. L. (1998). Writing ethnographic fieldnotes. 1995. University of Chicago, Chicago Google Scholar.

Ellis, R. A., \& Calvo, R. A. (2004). Learning through discussions in blended environments. Educational media international, 41(3), 263-274.

Falloon, G. (2011). Making the connection: Moore's theory of transactional distance and its relevance to the use of a virtual classroom in postgraduate online teacher education. Journal of Research on Technology in Education, 43(3), 187-209. 
Fernsten, L., \& Fernsten, J. (2005). Portfolio assessment and reflection: enhancing learning through effective practice. Reflective Practice, 6(2), 303-309.

Fisher, M., \& Baird, D. E. (2005). Online learning design that fosters student support, self-regulation, and retention. Campus-Wide Information Systems, 22(2), 88-107.

Garrison, D. R. (1997). Self-directed learning: Toward a comprehensive model. Adult education quarterly, 48(1), 18-33.

Garrison, D. R., Anderson, T., \& Archer, W. (2001). Critical thinking, cognitive presence, and computer conferencing in distance education. American Journal of distance education, 15(1), 7-23.

Garrison, D. R., Cleveland-Innes, M., \& Fung, T. S. (2010). Exploring causal relationships among teaching, cognitive and social presence: Student perceptions of the community of inquiry framework. The Internet and Higher Education, 13(1), 31-36.

Garrison, D. R., \& Kanuka, H. (2004). Blended learning: Uncovering its transformative potential in higher education. The internet and higher education, 7(2), 95-105.

Gehlen-Baum, V., Pohl, A., \& Bry, F. (2011, September). Assessing Backstage—A backchannel for collaborative learning in large classes. In Interactive Collaborative Learning (ICL), 2011 14th International Conference on (pp. 154160). IEEE.

Giossos, Y., Koutsouba, M., Lionarakis, A., \& Skavantzos, K. (2009). Reconsidering Moore's transactional distance theory. European Journal of Open Distance and ELearning, 2009(2), 1-6. Retrieved from http://www.eurodl.org/?article=374 
Glaser, B. S., \& Strauss, A. (1971). A.(1967). The discovery of grounded theory. New york.

Gloeckler, G. (2008). Here come the millennials. Business Week, (4109), 46-50.

Goetz, J. P., \& LeCompte, M. D. (1984). Ethnography and qualitative design in educational research (Vol. 19). Orlando, FL: Academic Press.

Goetze, S. K., \& Stansberry, S. (2003). Implementing Instructional Technology in Teacher Education Programs: The How and the Why of IT: Commentary. Action in Teacher Education, 24(4), vii-x.

Goodson, I. F., \& Mangan, J. M. (1995). Subject cultures and the introduction of classroom computers. British Educational Research Journal, 21(5), 613-628.

Gunawardena, C. N., Lowe, C. A., \& Anderson, T. (1997). Analysis of a global online debate and the development of an interaction analysis model for examining social construction of knowledge in computer conferencing. Journal of educational computing research, 17(4), 397-431.

Hanford, E. (2011). Don't Lecture Me: Rethinking the Way College Students Learn. American Radio Works, podcast audio. Retrieved November, 15, 2013.

Hanson, E. (2011). Don't lecture me (Audio podcast). Retrieved from http://americanradioworks.publicradio.org/features/tomorrows-college/lectures/

Hara, N., Bonk, C. J., \& Angeli, C. (1998). Content analysis of online discussions in an Applied Educational Psychology. Centre for Research on Learning and Technology (CRLT) Technical Report, (2-98), 1-33. 
Harry, D., Green, J., \& Donath, J. (2009, April). Backchan. nl: integrating backchannels in physical space. In Proceedings of the SIGCHI conference on Human factors in computing systems (pp. 1361-1370). ACM.

Hatt, B. (2008). Teaching theory through performance: role playing cultural capital in the classroom. In J. Diem \& R. J. Helfenbein (Eds.), Unsettling beliefs: teaching theory to teachers (555- ). Information Age Publishing.

Harwell, M. R. (2011). Research design in qualitative/quantitative/mixed methods. The Sage handbook for research in education. 2nd ed. Los Angeles, CA: Sage, 147.

Henri, F. (1992). Computer Conferencing and Content Analysis. In Collaborative learning through computer conferencing (pp. 117-136). Berlin: Springer-Verlag.

Hicks, M., Reid, I., \& George, R. (2001). Enhancing on-line teaching: Designing responsive learning environments. International Journal for Academic Development, 6(2), 143-151.

Hsieh, H. F., \& Shannon, S. E. (2005). Three approaches to qualitative content analysis. Qualitative health research, 15(9), 1277-1288.

Hung, D., Tan, S. C., \& Chen, D. T. (2005). How the internet facilitates learning as dialog: Design considerations for online discussions. International Journal of Instructional Media, 32(1), 37.

Jacobs, N., \& McFarlane, A. (2005). Conferences as learning communities: some early lessons in using 'back-channel' technologies at an academic conferencedistributed intelligence or divided attention?. Journal of Computer Assisted Learning, 21(5), 317-329. 
Jarrett, K., \& Devine, M. A. (2010). How to use backchanneling in your classroom. Education Digest: Essential Readings Condensed for Quick Review, 76(1), 41-44.

Johnson, R. B. (1997). Examining the validity structure of qualitative research. Education, 118, 282-292.

Johnson, D.W. \& Johnson, R.T. (2005). Learning groups. In Susan A. Whelan, Ed. The Handbook of Group Research and Practice (pp. 441-462). Thousand Oaks, CA: Sage Publications, Inc.

Jones, I. M. (2011). Can you see me now? Defining teaching presence in the online classroom through building a learning community. Journal of Legal Studies Education, 28(1), 67-116.

Kay, R.H. (2006). Evaluating strategies used to incorporate technology into pre-service education: a review of the literature. Journal of Research on Technology in Education. 38(4), 383-408.

Kaye, A. R. (Ed.). (2012). Collaborative learning through computer conferencing: the Najaden papers (Vol. 90). Springer Science \& Business Media.

Ke, F., \& Kwak, D. (2013). Online learning across ethnicity and age: A study on learning interaction participation, perception, and learning satisfaction. Computers \& education, 61, 43-51.

Kennedy, K. \& Cavanaugh, C. (2008). Student perceptions of transactional distance in online teacher education courses. In K. McFerrin et al. (Eds.), Proceedings of Society for Information Technology \& Teacher Education International Conference (pp. 485-490). Chesapeake, VA: AACE. 
Kennedy, G. E., Judd, T. S., Churchward, A., Gray, K., \& Krause, K. L. (2008). First year students' experiences with technology: Are they really digital natives. Australasian journal of educational technology, 24(1), 108-122.

Kern, R. G. (1995). Restructuring classroom interaction with networked computers: Effects on quantity and characteristics of language production. The Modern language journal, 79(4), 457-476.

Krippendorff, K. (2012). Content analysis: An introduction to its methodology. Sage.

Kuehn, S. A. (1994). Computer-mediated communication in instructional settings: A research agenda. Communication Education, 43(2), 171-183.

Kukulska-Hulme, A. (2012). How should the higher education workforce adapt to advancements in technology for teaching and learning?. The Internet and Higher Education, 15(4), 247-254.

Kyei-Blankson, L. \& Donnelly, H. (2014). Interaction and Presence as Important Elements in Student Learning in Online Environments. In Proceedings of World Conference on E-Learning in Corporate, Government, Healthcare, and Higher Education 2014 (pp. 1055-1058). Chesapeake, VA: Association for the Advancement of Computing in Education (AACE).

Lai, T. L. (2004). Service quality and perceived value's impact on satisfaction, intention and usage of short message service (SMS). Information Systems Frontiers, 6(4), $353-368$.

Laurillard, D. (2002). Rethinking university teaching: a conversational framework for the effective use of learning technologies (2nd ed.) London: Routledge Falmer). 
Laurillard, D. (2008). Technology enhanced learning as a tool for pedagogical innovation. Journal of Philosophy of Education, 42(3-4), 521-533.

Laurillard, D. (2009). The pedagogical challenges to collaborative technologies. International Journal of Computer-Supported Collaborative Learning, 4(1), 520.

Lee, S. J. (2009). Online communication and adolescent social ties: Who benefits more from Internet use? Journal of Computer-Mediated Communication, 14(3), 509-531.

Leu, D. J., Kinzer, C. K., Coiro, J. L., \& Cammack, D. W. (2004). Toward a theory of new literacies emerging from the Internet and other information and communication technologies. Theoretical models and processes of reading, 5(1), $1570-1613$.

Mathison, S. (1988). Why triangulate? Educational Researcher, 17(2), 13-17.

Marjanovic, O. (1999). Learning and teaching in a synchronous collaborative environment. Journal of Computer Assisted Learning, 15, 129-138.

Markett, C., Sánchez, I. A., Weber, S., \& Tangney, B. (2006). Using short message service to encourage interactivity in the classroom. Computers \& Education, 46(3), 280-293.

Mayo, N. B., \& Kajs, L.T. (2005). Longitudinal study of technology training to prepare future teachers. Educational Research Quarterly, 29(1), 3-14.

McCarthy, J. P., \& Anderson, L. (2000). Active learning techniques versus traditional teaching styles: two experiments from history and political science. Innovative Higher Education, 24(4), 279-294.

McCarthy, J. \& Boyd, D. 2005. Digital Backchannels in Shared Physical Spaces: 
Experiences at an Academic Conference. Proceedings of the SIGCHI Conference on Human Factors in Computing Systems (CHI '05) Extended Abstracts. ACM Press, NY

Merriam, S. B. (2009). Qualitative research: A guide to design and implementation. San Francisco: Jossey-Bass.

Merrill, M. D. (2002). First principles of instruction. Educational technology research and development, 50(3), 43-59.

Miles, M. B., \& Huberman, A. M. (1994). Qualitative data analysis: An expanded sourcebook. Sage.

Miles, M. B., Huberman, M. A., \& Saldana, J. (2014). Drawing and verifying conclusions. Qualitative data analysis: a methods sourcebook.

Moon, J. A. (2013). Reflection in learning and professional development: Theory and practice. New York: Routledge.

Moore, M. (1989). Three types of interaction. The American Journal of Distance Education, 5(3), 1-6.

Moore, M. G. (1993). Theory of transactional distance. In D. Keegan (Ed.), Theoretical principles of distance education (pp. 22-38). New York: Routledge.

Moore, M. G. (2007). The theory of transactional distance. In M. G. Moore (Ed.), Handbook of distance education (2nd ed., pp.89-105). Mahwah, NJ: Lawrence Erlbaum Associates.

Morgan, T. (2011). Online classroom or community-in-the-making? Instructor conceptualizations and teaching presence in international online contexts (Winner 2011 Best Research Article Award). International Journal of E-Learning \& 
Distance Education, 25(1).

Morrow, L. M. (1993). Promoting Independent Reading and Writing through SelfDirected Literacy Activities in a Collaborative Setting. Reading Research Report No. 2.

National Educational Technology Plan. (2010). Transforming American Education: Learning Powered by Technology. Washington, DC: U.S. Department of Education.

O'Connor, E. A. (2006-2007). A case study of the approach to teaching and to technology of three new teachers in an alternative teacher certification program. Journal of Educational Technology Systems, 35(3), 357-382.

Opdenakker, R. (2006, September). Advantages and disadvantages of four interview techniques in qualitative research. In Forum Qualitative Sozialforschung/Forum: Qualitative Social Research (Vol. 7, No. 4).

Papert, S., \& Harel, I. (1991). Situating constructionism. Constructionism, 36, 1-11.

Patton, M. Q. (2002). Qualitative research and evaluation methods (3rd ed.). London: Sage.

Picciano, A.G., Seaman, J., \& Allen, I. E. (2010). Educational transformation through online learning: to be or not to be. Journal of Asynchronous Learning Networks, $14(4), 17-35$.

Pohl, A., Gehlen-Baum, V., \& Bry, F. (2011). Introducing backstage-a digital backchannel for large class lectures. Interactive Technology and Smart Education, 8(3), 186-200.

Poleon, E., \& Krishnan, J. (2013). Digital Backchanneling: A strategy for maximizing 
engagement during a performance-based lesson on Shakespeare's Macbeth. Teaching English with Technology, (4), 38-48.

Prensky, M. (2005). Listen to the natives. Educational leadership, 63(4).

Professional Standards for the Accreditation of Teacher Preparation Institutions. (2008).

Washington, DC: National Council for the Accreditation of Teacher Education (NCATE).

Redfern, S., \& Naughton, N. (2002). Collaborative virtual environments to support communication and community in internet-based distance education. Journal of Information Technology Education: Research, 1(1), 201-211.

Reigeluth, C. M. (Ed.). (1983). Instructional Design Theories and Models: an overview of the current status. Lawrence Erlbaum Associates.

Rice, R. E., \& Love, G. (1987). Electronic emotion socioemotional content in a computer-mediated communication network. Communication research, 14(1), 85108.

Rodgers, C. (2002). Defining reflection: Another look at John Dewey and reflective thinking. The Teachers College Record, 104(4), 842-866.

Rubin, H. J., \& Rubin, I. S. (2011). Qualitative interviewing: The art of hearing data. Sage.

Saldana, J. (2009). The coding manual for qualitative researchers. Los Angeles: SAGE.

Saldaña, J. (2013). The coding manual for qualitative researchers. Sage.

Saltmarsh, S., \& Sutherland-Smith, W. (2010). Stimulating learning: Pedagogy, subjectivity and teacher education in online environments. London review of education, 8(1), 15-24. 
Saunders, N., Beltrão, P., Jensen, L., Jurczak, D., Krause, R., Kuhn, M., \& Wu, S. (2009). Microblogging the ISMB: a new approach to conference reporting. PLoS Comput Biol, 5(1), e1000263.

Scardamalia, M., \& Bereiter, C. (2006). Knowledge building: Theory, pedagogy, and technology (pp. 97-115). na.

Schubert, W. H. (2014). Active learning as reflective experience. In D. A. Breault \& R. Breault (Eds.), Experiencing Dewey: Insights for today's classroom (71-75).

New York: Routledge.

Schwier, R. A., \& Seaton, J. X. (2013). A comparison of participation patterns in selected formal, non-formal, and informal online learning environments. Canadian Journal of Learning and Technology, 39(1), n1.

Shackelford, J. L., \& Maxwell, M. (2012). Sense of community in graduate online education: Contribution of learner to learner interaction. The International Review of Research in Open and Distance Learning, 13(4), 228-249.

Sharples, M., Taylor, J., \& Vavoula, G. (2005). Towards a theory of mobile learning. Proceedings of mLearn 2005, 1(1), 1-9.

Silverman, D. (2006). Interpreting qualitative data: Methods for analyzing talk, text and interaction. Thousand Oaks, CA: Sage.

Slavin, R. E. (1999). Comprehensive approaches to cooperative learning. Theory into practice, $38(2), 74-79$.

Smith, S., Salaway, G., \& Borreson Caruso, J. (2009). The ECAR study of undergraduate students and information technology, 2009 (Research Study, Vol. 6). Boulder, CO: EDUCAUSE Center for Applied Research. 
Soller, A. (2001). Supporting social interaction in an intelligent collaborative learning system. International Journal of Artificial Intelligence in Education (IJAIED), 12, 40-62.

Song, L., \& McNary, S. W. (2011). Understanding students' online interaction: Analysis of discussion board postings. Journal of Interactive Online Learning, 10(1), 1-14.

Staley, D. J., \& Trinkle, D. A. (2011). The changing landscape of higher education. FormaMente: Rivista internazionale di ricerca sul futuro digitale, (1-2011), 15.

Stake, R. E. (2013). Multiple case study analysis. Guilford Press.

Sutherland-Smith, W., \& Saltmarsh, S. (2010). Minding the 'P's for implementing online education: Purpose, pedagogy, and practicalities. Australian Journal of Teacher Education, 35(7), 6.

Sweller, J. (1994). Cognitive load theory, learning difficulty, and instructional design. Learning and instruction, 4(4), 295-312.

Taylor, B. (1995). Self-Directed Learning: Revisiting an Idea Most Appropriate for Middle School Students.

Toledo, C., \& Peters, S. (2013). Educators' perceptions of uses, constraints, and successful practices of backchanneling. in education, 16(1), 75-88.

Vercellone-Smith, P., Jablokow, K., \& Friedel, C. (2012). Characterizing communication networks in a web-based classroom: Cognitive styles and linguistic behavior of self-organizing groups in online discussions. Computers \& Education, 59(2), $222-235$.

Volery, T., \& Lord, D. (2000). Critical success factors in online education. International Journal of Educational Management, 14(5), 216-223. 
Vygotsky, L. S. (1978). Mind and society: The development of higher mental processes.

Walther, J. B. (1996). Computer-mediated communication impersonal, interpersonal, and hyperpersonal interaction. Communication research, 23(1), 3-43.

Waring, S. M. (2010). The impact of a technology coordinator's belief system upon using technology to create a community's history. Computers in the Schools, 27, 76-98.

Weigel, V. B. (2002). Deep Learning for a Digital Age: Technology's Untapped Potential To Enrich Higher Education. Jossey-Bass, 989 Market Street, San Francisco, CA 94103-1741.

Wenger, E., McDermott, R. A., \& Snyder, W. (2002). Cultivating communities of practice: A guide to managing knowledge. Harvard Business Press.

Wertsch, J. V. (1980). The significance of dialogue in Vygotsky's account of social, egocentric, and inner speech. Contemporary Educational Psychology, 5(2), 150162.

Wertsch, J. V. (1985). Vygotsky and the social formation of mind. Cambridge, MA: Harvard University Press.

Williams, C. (2002). Learning on-line: A review of recent literature in a rapidly expanding field. Journal of further and Higher Education, 26(3), 263-272.

Williams, K. C. M. (2000). Reproduced and emergent genres of communication on the World Wide Web. The Information Society, 16(3), 201-215.

Willig, C. (2013). Introducing qualitative research in psychology. New York: McGrawHill International.

Wolcott, H. (1994). Transforming qualitative data: Description, analysis, and 
interpretation. Thousand Oaks, CA: Sage.

Worley, K. (2011). Educating college students of the net generation. Adult Learning, 22(3), 31-39.

Yacci, M. (2000). Interactivity demystified: A structural definition for distance education and intelligent CBT. Educational Technology, 40(4), 5-16.

Yardi, S. (2008). Whispers in the Classroom. Digital youth, innovation, and the unexpected, 143-164.

Yin, R. K. (2003). Case study research: Design and methods (3rd ed.). Thousand Oaks, CA: Sage.

Yuen, A, \& Deng, L., \& Fox, R. (2009). Use of WebCT in online and blended modes. Interactive Technology and Smart Education, 6(4), 254-260. 
APPENDIX A

MATRIX FOR MESSAGE CLASSIFICATION - UNITS OF MEANING 
Instructor/Course:

Backchannel Session:

Backchannel Group:

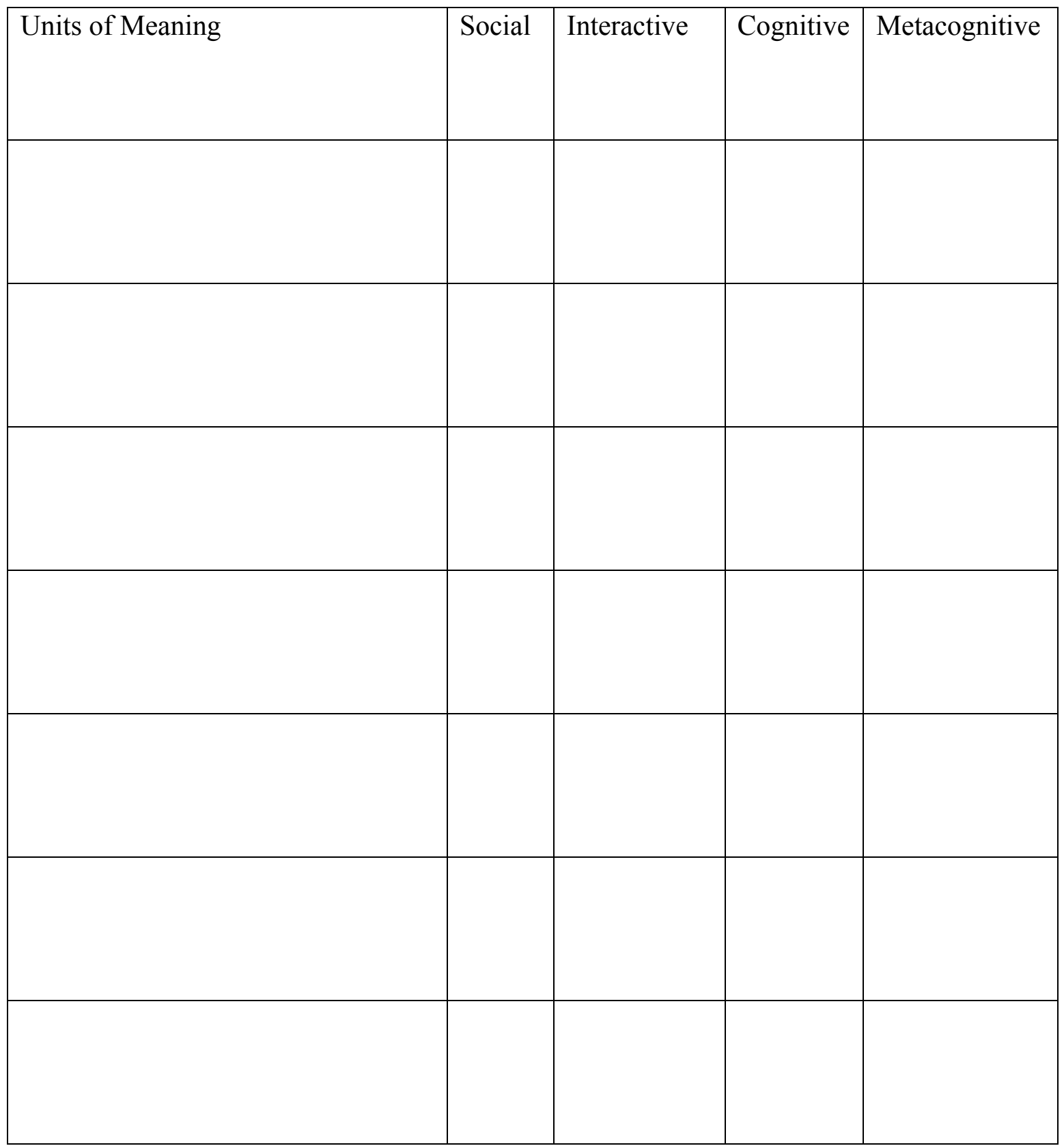


APPENDIX B

INTERVIEW PROTOCAL 
Research Questions:

- In what way does digital backchanneling contribute to student interactivity during in-class discussions by teacher education students?

- In what way does digital backchanneling contribute to student reflection in a teacher education course?

- How does digital backchanneling influence the overall learning experience associated with in-class discussions in a face-to-face educational setting?

Interview Questions

1. Please tell me your program of study and how long you have been a student at Illinois State University?

2. During the courses you have taken at the college level, have you ever been exposed to digital backchanneling in a classroom setting? If so, how often and describe the course and your experience?

3. Have you ever been exposed to digital backchanneling in any other context (convention, lecture, seminar, etc.)? If so, describe your experience?

4. When you learned you would be using digital backchanneling in this course, can you describe your feelings, concerns, and thoughts and what was your conception of how this technique would operate?

5. During the backchanneling experience (whether you were in the FC or BC), did you feel this structure changed the amount of non-related dialogue that went on compared to a traditional in-class discussion?

6. Describe how BC influenced your interactions with fellow students, course content, and the instructor?

7. What are your views on $\mathrm{BC}$ as a method or technique for teaching and learning? What did you learn about this particular method for structuring an in-class discussion and would you feel comfortable using this technique as part of your future pedagogy?

8. Describe digital backchanneling's effect on whether or not you have made connections between what you have learned to other life experiences and ideas?

9. Can you elaborate on the influence of digital backchanneling on your process of meaning-making concerning the course content?

10. Did the BC discussion structure allow you to effectively analyze and evaluate information from the assigned text (s)? If so, please elaborate. 
11. Did the BC discussion structure allow you to effectively create new ideas and ways of thinking about the discussed information? If so, please elaborate.

12. Was your ability to plan, regulate, and reflect on your words influenced by the BC structure?

13. Describe digital backchanneling's effect on how you reflected on the educational conversations you had with the instructor or your peers? Were your thoughts more purposeful, systematic, and disciplined compared to a traditional in-class discussion? Explain.

14. As a result of the BC structure, did you feel more or less connected with classmates, the instructor, and the content? Explain.

15. What BC structure are you most confortable with and what structure is the most beneficial to your learning? Why?

16. What are your feelings regarding the instructor's involvement in the BC activity? Meaning, do you think the instructor should be involved with prompting questions? Contributing to BC? Setting up guidelines? Why? How do you feel this would change your experience?

17. Overall, how would you describe your experience with digital backchanneling within this course? Engagement, attention level, frustration, satisfaction, learning, etc. 
APPENDIX C

STRUCTURAL PRIMARY CODES - SUBCODES 
Code

$\mathrm{SE}-\mathrm{G}$

SE - NRD

INT - SS

INT - SI

INT - SC

COG - REM
Working Definition

Social Events - Greetings, expression of welcoming or recognizing

Social Events - Non-related Dialogue, comments nonrelated to course, content, or teacher education

Interaction - Student to Student, interactions amongst students relating to class, course, and/or teacher education, or backchanneling in general where students are directly responding to one another's comments

Interaction - Student to Instructor, interactions between student and instructor relating to class, course, and/or teacher education content, or backchanneling in general

Interaction - Student to Content, meaningful interactions between student and content resulting in construction of knowledge, connections to lived circumstances, and application to problem solving

Cognition - Remembering, comments relating to remembering or recalling information concerning class, course and/or teacher education content 
COG - UNDS

COG - APP

COG - ANAL

COG - EVAL

COG - CREATE

META - EVAL

META - PLAN
Cognition - Understanding, comments relating to understanding or interpreting information concerning class, course, and/or teacher education content

Cognition - Applying, comments relating to applying or executing the information concerning class, course, and/or teacher education content

Cognition - Analyzing, comments relating to analyzing or deconstructing information concerning the class, course and/or teacher education content

Cognition - Evaluating, comments relating to evaluating or critiquing information concerning the class, course and/or teacher education content

Cognition - Creating, comments relating to creating or designing information based off the class, course and/or teacher education content

Metacognition - Evaluation, comments relating to the assessment of one's knowledge and skills

Metacognition - Planning, comments relating to selecting an action or strategy 
META - REG

META - SA

META - REFLECT
Metacognition - Regulation, comments relating to redirecting one's efforts or strategies

Metacognition - SelfAwareness, ability to identify the feelings and thoughts associated with an aspect of a task

Metacognition Reflection, purposeful, systematic, and disciplined thought processes that connect learning to past experiences, current situations, and new ideas 
APPENDIX D

ORIGINAL LIST OF IN VIVO CODES 


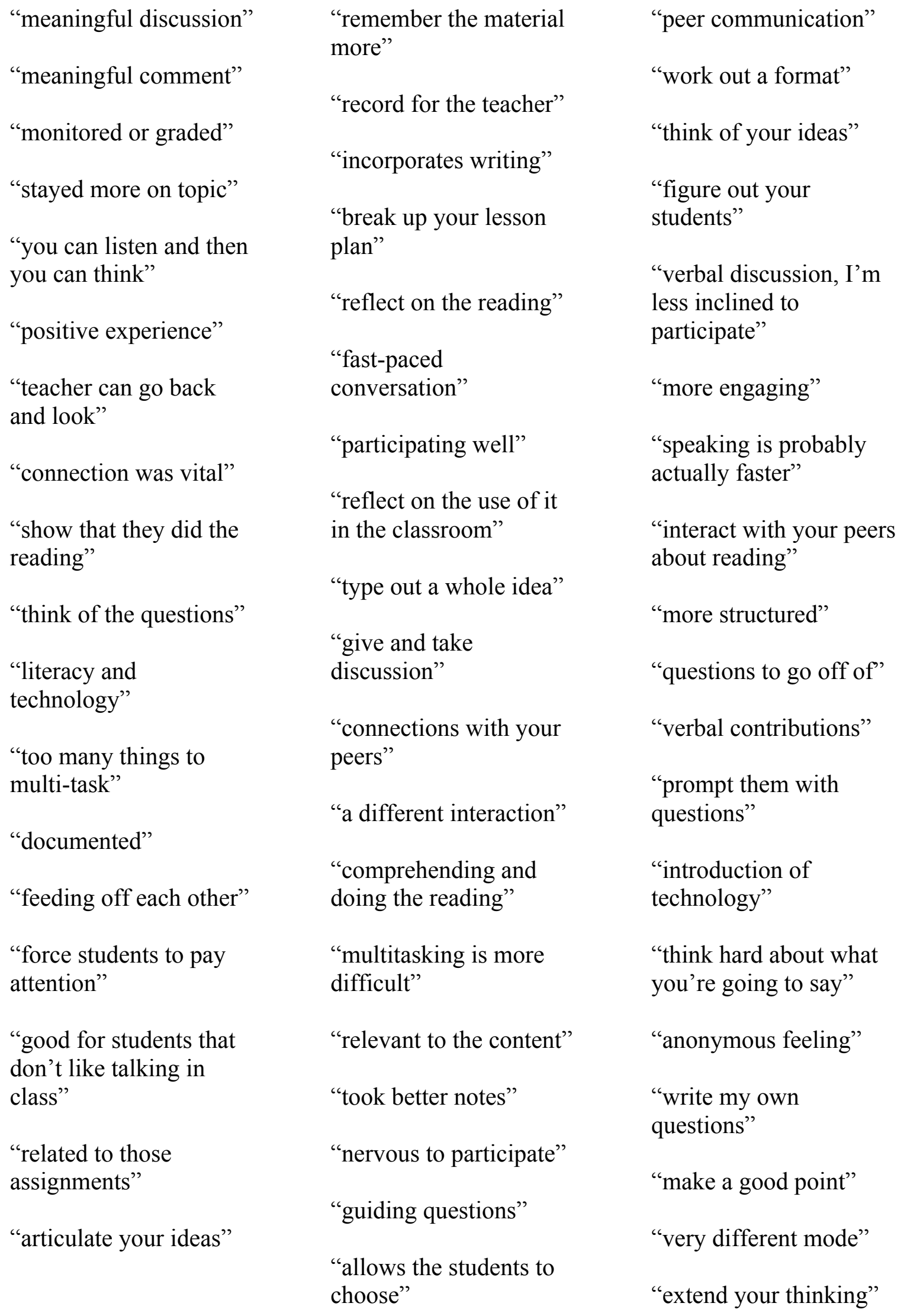




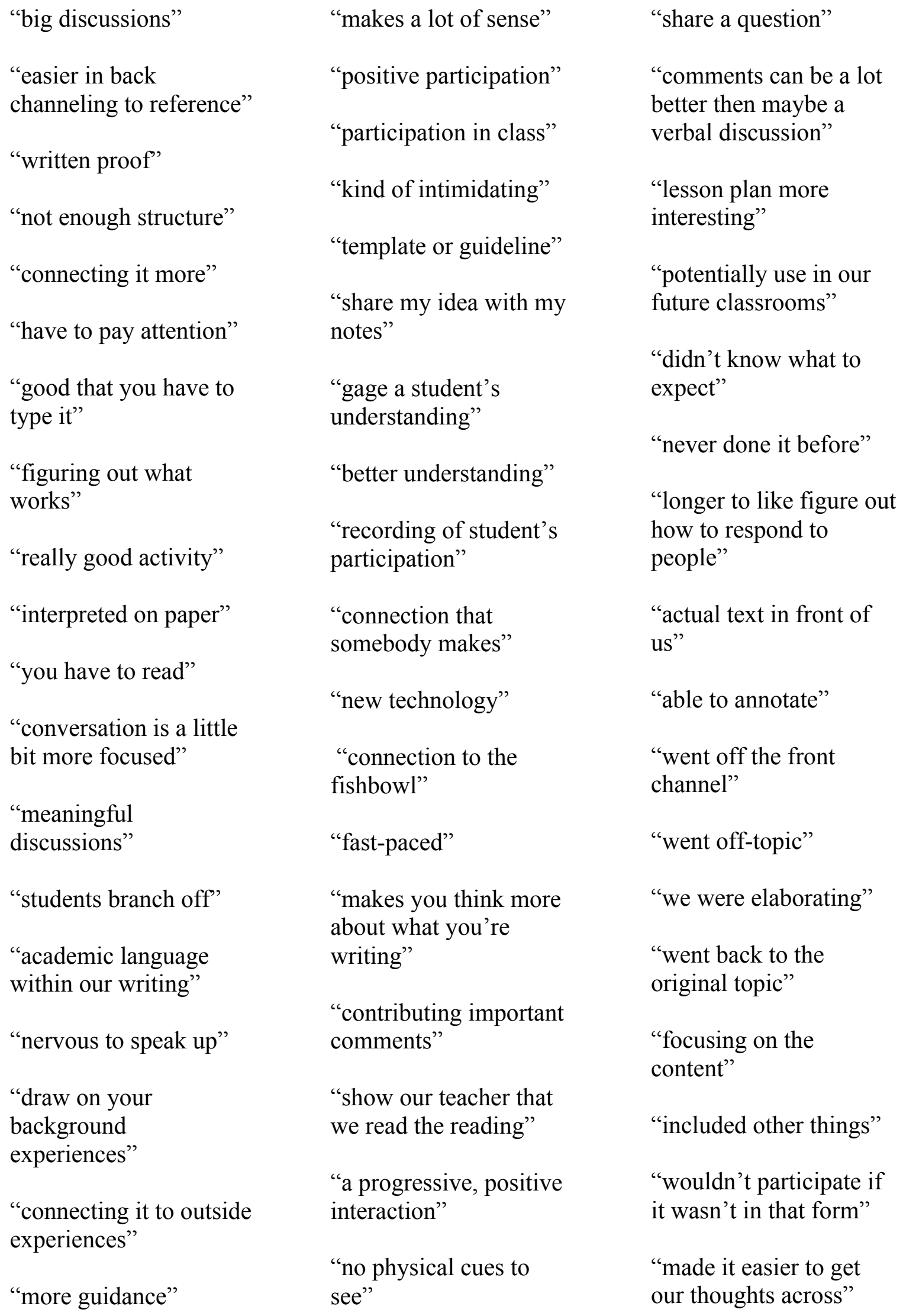




\begin{tabular}{|c|c|c|}
\hline "able to elaborate" & $\begin{array}{l}\text { "allowed to type a } \\
\text { certain amount" }\end{array}$ & $\begin{array}{l}\text { "all kind of contributed } \\
\text { back-and-forth" }\end{array}$ \\
\hline $\begin{array}{l}\text { "bring that experience } \\
\text { into it" }\end{array}$ & $\begin{array}{l}\text { "keep on switching my } \\
\text { thoughts around" }\end{array}$ & "more in depth" \\
\hline $\begin{array}{l}\text { "don't like speaking in } \\
\text { front of people" }\end{array}$ & $\begin{array}{l}\text { "certain amount of } \\
\text { characters" }\end{array}$ & $\begin{array}{l}\text { "able to focus on certain } \\
\text { things and elaborate" }\end{array}$ \\
\hline $\begin{array}{l}\text { "technologically based" } \\
\text { "option to actually }\end{array}$ & $\begin{array}{l}\text { "couldn't get my whole } \\
\text { thought across" }\end{array}$ & $\begin{array}{l}\text { "nice to get everyone's } \\
\text { perspective" }\end{array}$ \\
\hline $\begin{array}{l}\text { participate" } \\
\text { "like to type" }\end{array}$ & $\begin{array}{l}\text { "got ideas shared from } \\
\text { each of us" }\end{array}$ & $\begin{array}{l}\text { "bounce ideas off each } \\
\text { other" }\end{array}$ \\
\hline $\begin{array}{l}\text { "nice to get everyone's } \\
\text { voice heard" }\end{array}$ & $\begin{array}{l}\text { "everybody contributing } \\
\text { different things" }\end{array}$ & $\begin{array}{l}\text { "helps with the learning } \\
\text { process" }\end{array}$ \\
\hline $\begin{array}{l}\text { "some people are more } \\
\text { digital" }\end{array}$ & $\begin{array}{l}\text { "saw their perspective } \\
\text { on certain things" }\end{array}$ & $\begin{array}{l}\text { "more connected with } \\
\text { the classmates" }\end{array}$ \\
\hline $\begin{array}{l}\text { "incorporate every } \\
\text { student in the } \\
\text { classroom" }\end{array}$ & $\begin{array}{l}\text { "how we could } \\
\text { incorporate that in our } \\
\text { classrooms later on" }\end{array}$ & $\begin{array}{l}\text { "we don't have this } \\
\text { much time to talk to one } \\
\text { another" }\end{array}$ \\
\hline $\begin{array}{l}\text { "helped reading a text } \\
\text { before" }\end{array}$ & $\begin{array}{l}\text { "thinking about what I } \\
\text { was gonna say" }\end{array}$ & $\begin{array}{l}\text { "nice to kind of get } \\
\text { those student's } \\
\text { perspective" }\end{array}$ \\
\hline "hard to stay on track" & $\begin{array}{l}\text { "everyone comments at } \\
\text { the same time" }\end{array}$ & $\begin{array}{l}\text { "we were able to get our } \\
\text { points across" }\end{array}$ \\
\hline $\begin{array}{l}\text { "know what she wants } \\
\text { from us" }\end{array}$ & $\begin{array}{l}\text { "waiting for them to } \\
\text { comment back" }\end{array}$ & $\begin{array}{l}\text { "form thoughts about } \\
\text { what was going on" }\end{array}$ \\
\hline $\begin{array}{l}\text { "repetition of what was } \\
\text { in the text" }\end{array}$ & "kept on adding stuff" & $\begin{array}{l}\text { "it did make you } \\
\text { connect more" }\end{array}$ \\
\hline $\begin{array}{l}\text { "everyone's speaking } \\
\text { about something else" }\end{array}$ & "I was reflecting" & "it was more centered" \\
\hline "trying to connect it" & $\begin{array}{l}\text { "wasn't really on task } \\
\text { with it" }\end{array}$ & $\begin{array}{l}\text { "able to get the front } \\
\text { channel involved" }\end{array}$ \\
\hline $\begin{array}{l}\text { "brains are going } \\
\text { different ways"" }\end{array}$ & "made me think more" & "trying to be on a topic" \\
\hline $\begin{array}{l}\text { "hard to get back in like } \\
\text { the same page" }\end{array}$ & $\begin{array}{l}\text { "hearing those personal } \\
\text { stories" }\end{array}$ & $\begin{array}{l}\text { "connecting with the } \\
\text { material" }\end{array}$ \\
\hline
\end{tabular}


"they didn't know what we were discussing"

“there's always that one, or a few people who do like most of the work"

"really confused at the time"

"opportunity to actually reflect"

"likes to write and reflect"

"connect with the material more"

"able to recall certain things from the article"

"focused on certain topics"

"made connections"

"no guidelines"

"all had different thought processes"

"more attentive"

"very enlightening"

"elaborate on it with my own personal thoughts"

"have to be really engaged"

"make sure your focus is exactly on what they're saying" "typing about what you're talking about"

"you're not getting distracted"

"wanna make sure you're focusing"

"elaborate on it"

"in the front channel, you're really focusing"

"off track a little bit"

"talked about the clinical more than the actual article"

"am I not typing

enough"

“paying attention"

"epitome of multitasking"

"great way of learning"

"might be typing things that they shouldn't"

"connecting that back to what they were talking about'

"back channeling kinda limits some of the creativeness"

"only have so many words typing" "skip around trying to find what you were saying"

"strayed away too much"

"find the points that people were talking about"

"straying away also created new ideas"

“different experiences"

"interesting to hear different experiences"

"creates new

knowledge"

"brought new ideas to the forefront"

"take later on as you go into the teaching field"

"planning on what I'm gonna say"

"make sure you're insightful"

"bringing the conversation forward"

"you have time"

"front channel you don't really have that time"

"hard cause it was on an ... an entire text" 
"I don't even know what this means"

"easier back channeling the second time because our articles were obviously shorter"

"more than one that I wanted to discuss"

"for that one I would just like fold my pages"

"it's okay to reference things"

"students were a little bit closer"

"likes how the conversation's going"

"content was definitely strong"

"grow from it as a class"

\author{
"there's a lot of \\ multitasking" \\ "our representative, she \\ actually commented on \\ what we said' \\ "our thoughts were \\ being heard" \\ "address some of the \\ questions we had" \\ "first group that I was \\ in, was ... we felt a little \\ bit disconnected" \\ "everyone really \\ struggled on that" \\ "felt really disconnected \\ from what everyone else \\ was saying" \\ "nice to have a \\ representative" \\ "make sure our thoughts \\ were being addressed" \\ "other people could \\ have a conversation off \\ it" \\ "great experience" \\ "nice to see that \\ everyone else is kinda \\ having some of the \\ thoughts you are having \\ about content and other \\ teacher education related \\ issues" \\ "frustration except for \\ the limit of characters" \\ "overall positive" \\ "for the second one I \\ definitely highlighted \\ specific things"
}


APPENDIX E

MEANINGFUL, FOCUSED LEARNING 


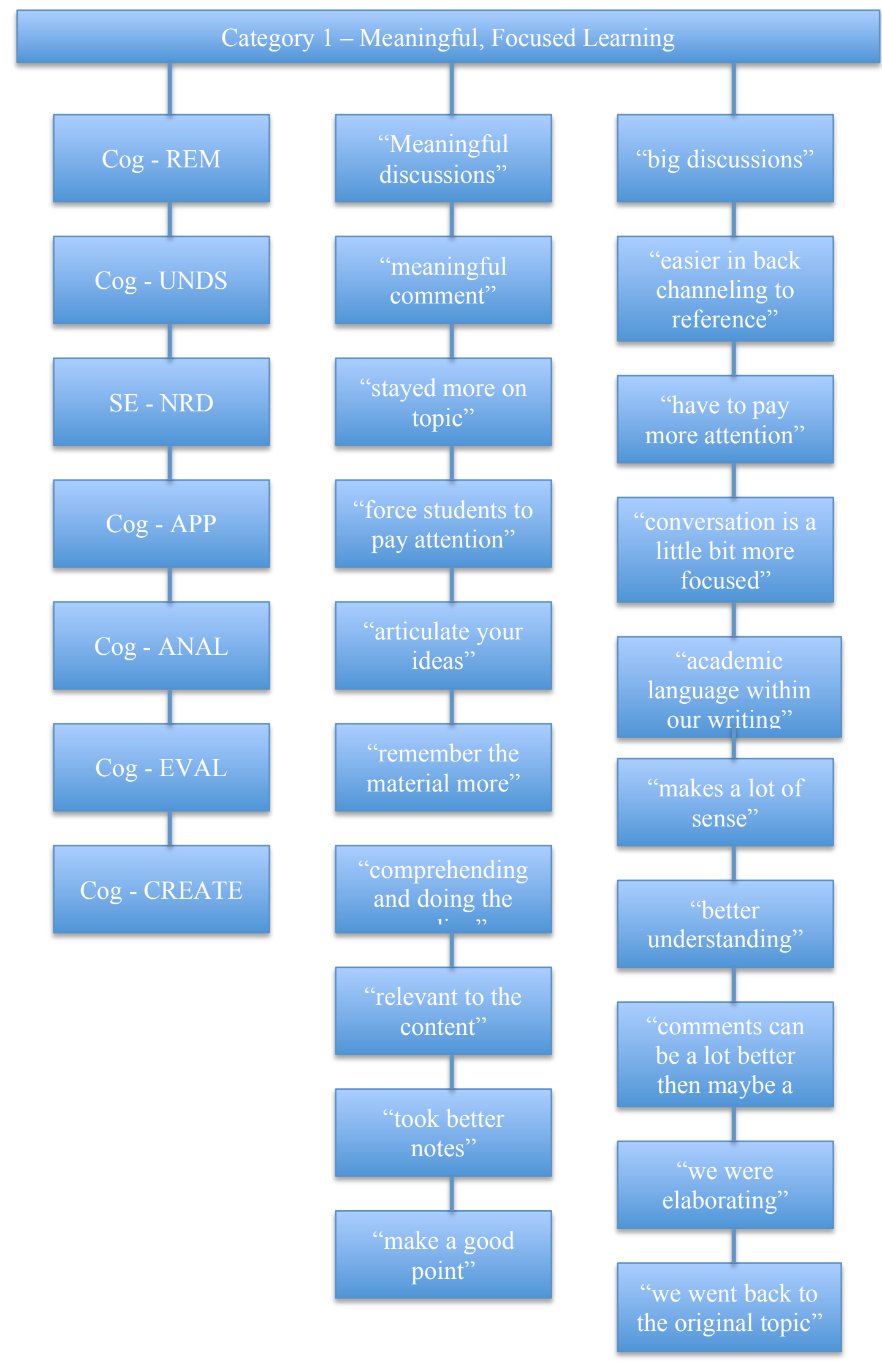



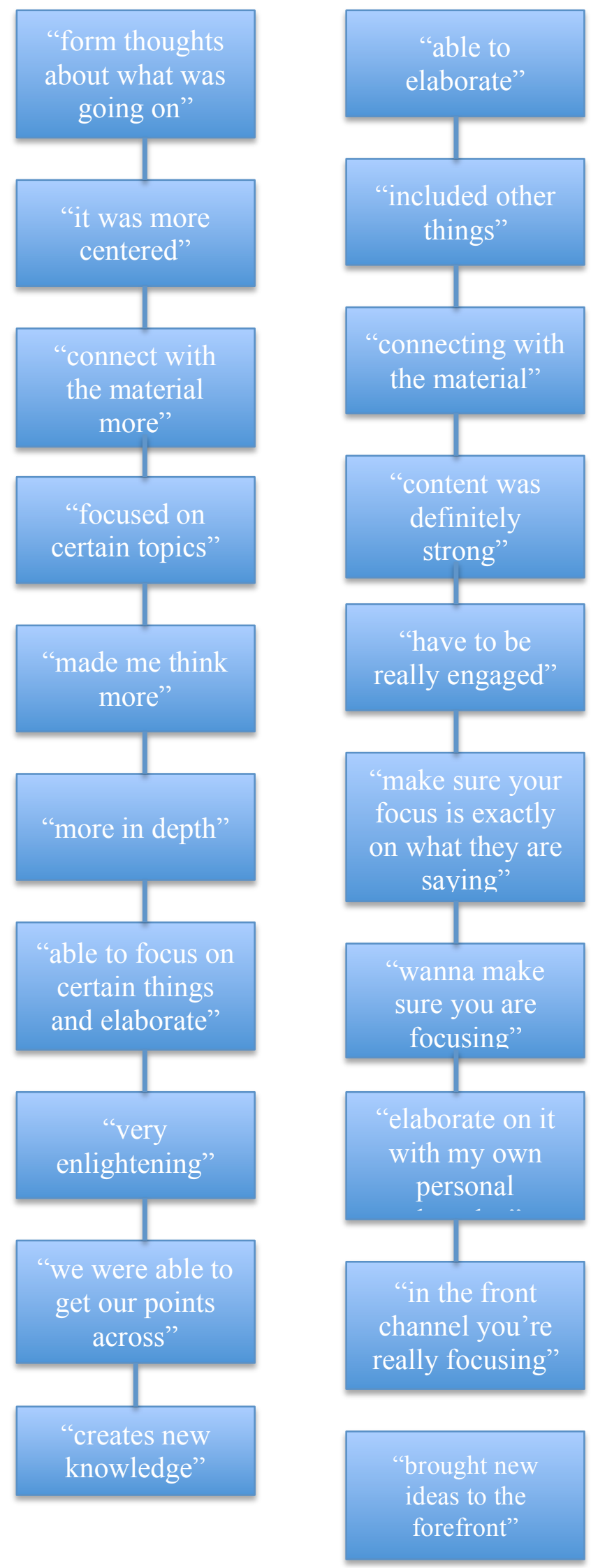
APPENDIX F

CONNECTION TO PEERS 


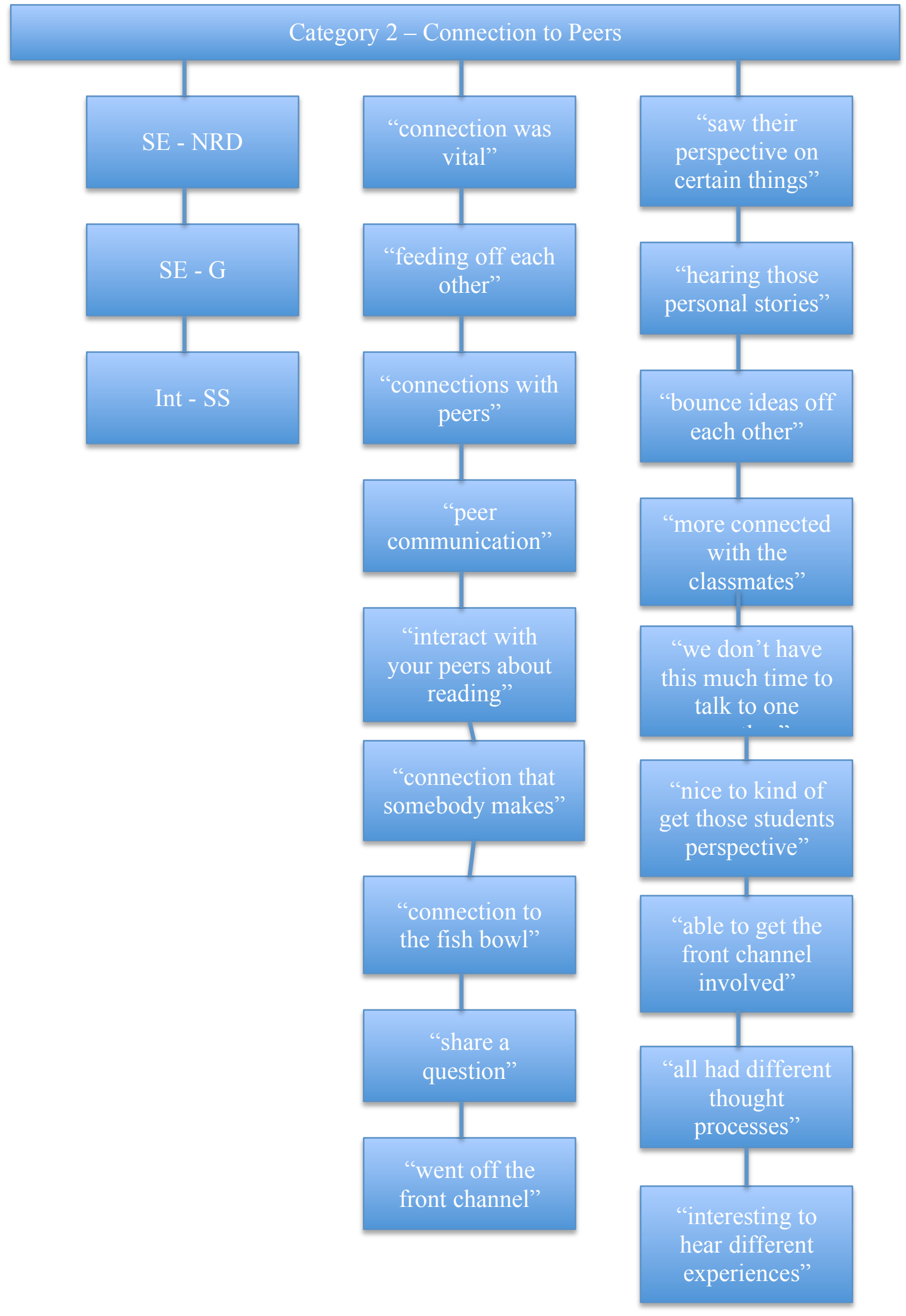



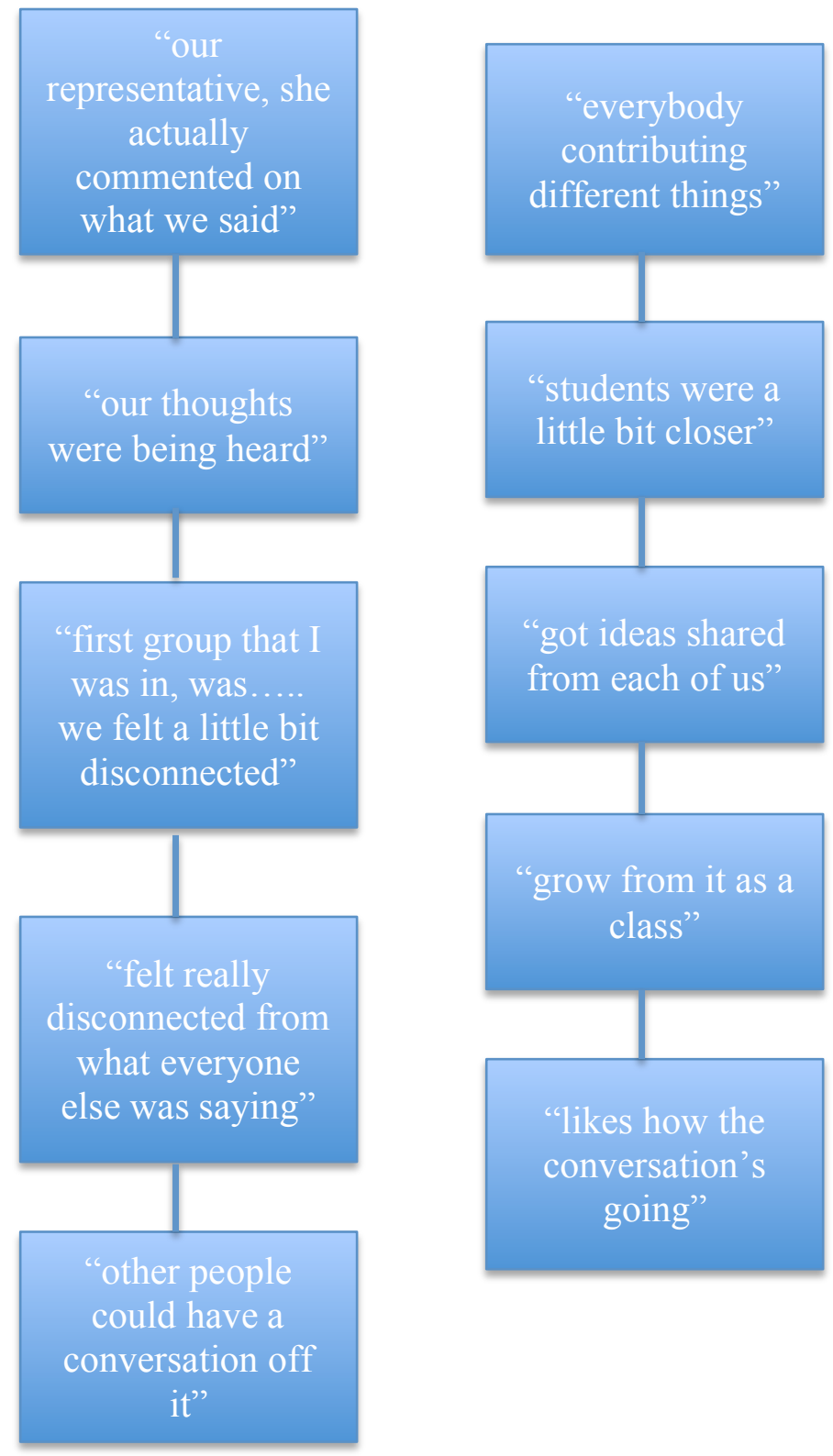
APPENDIX G

USE OF EDUCATIONAL TECHNOLOGY 


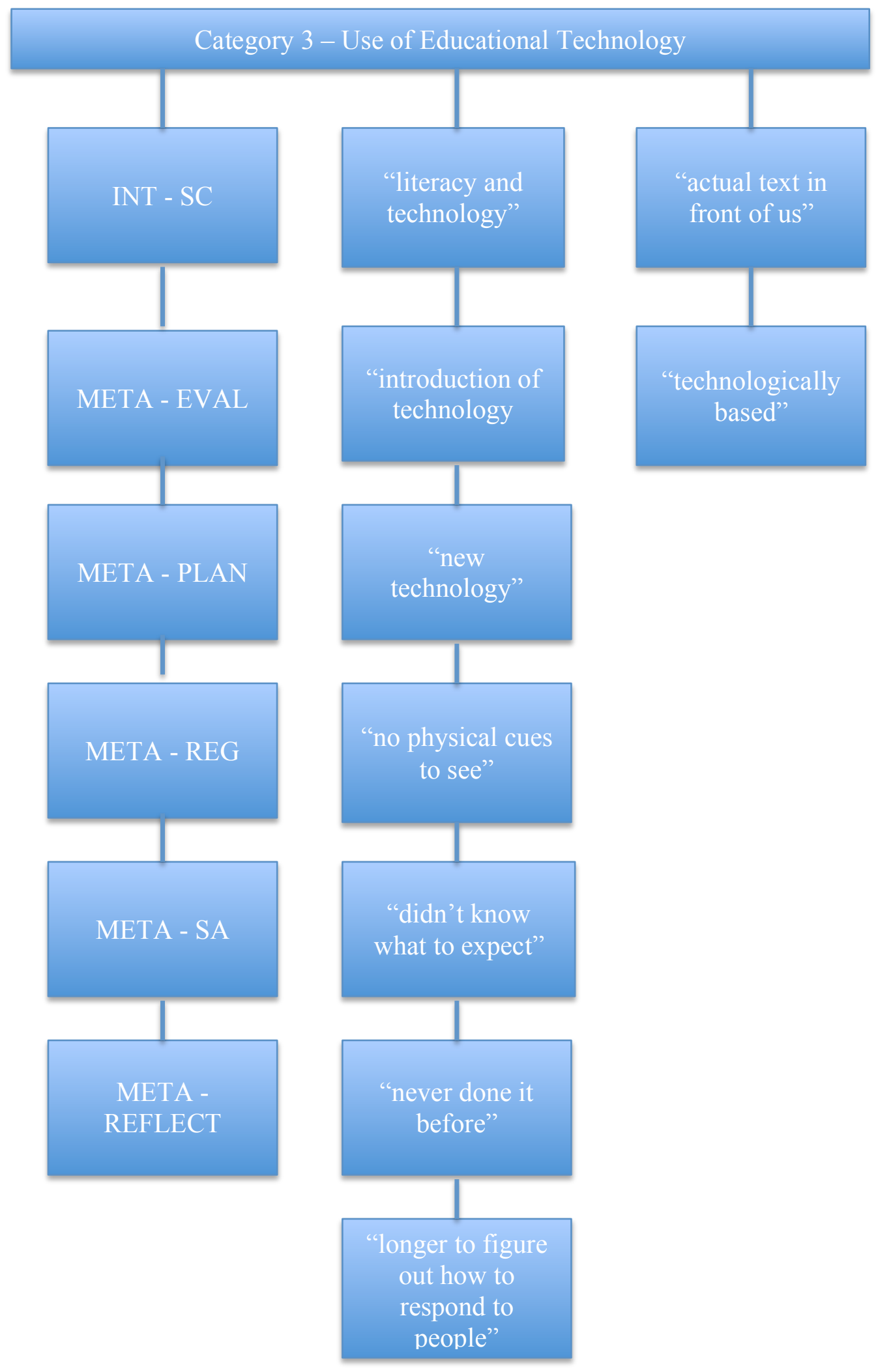


APPENDIX H

\section{PARTICIPATION, ENGAGEMENT}




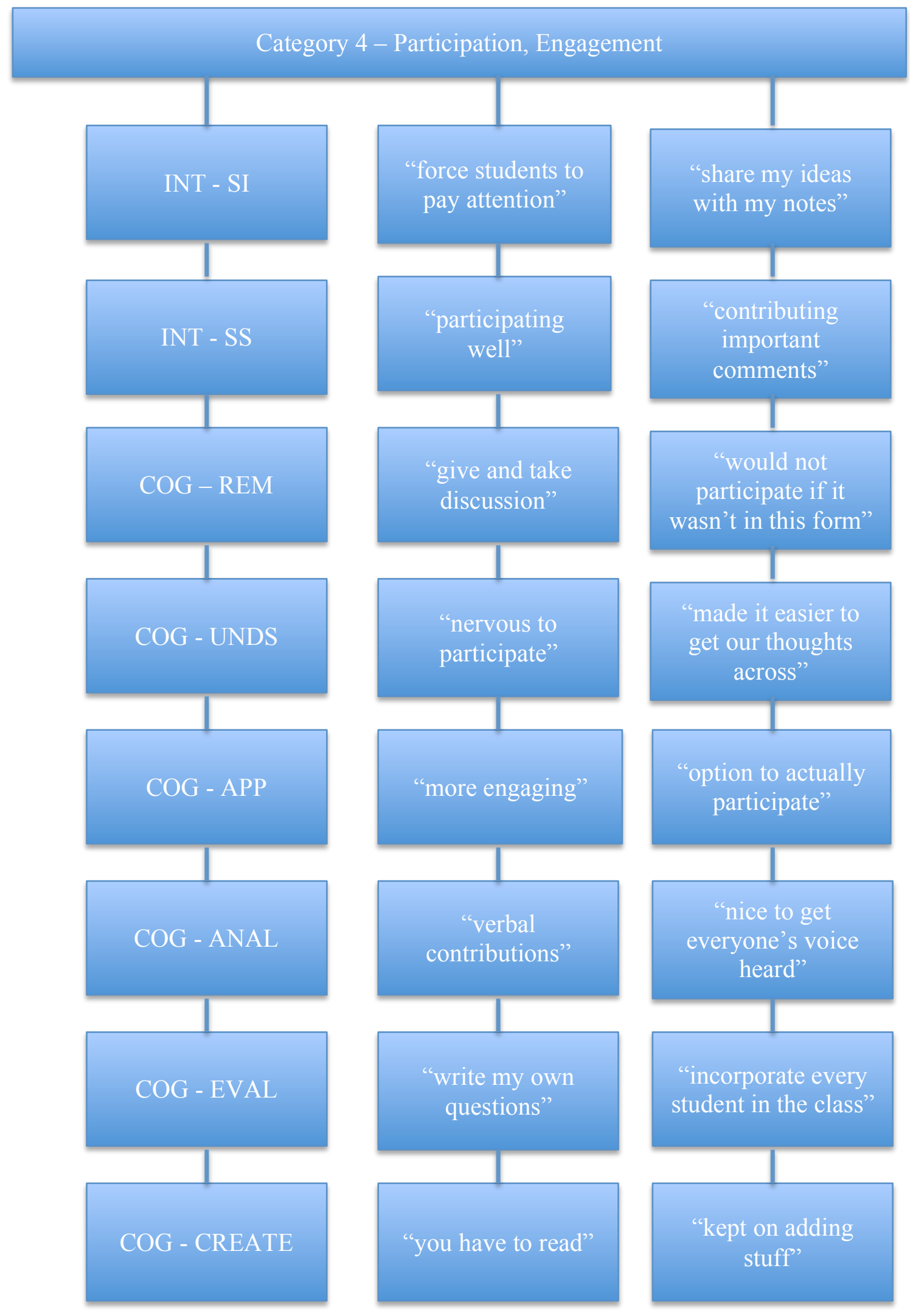



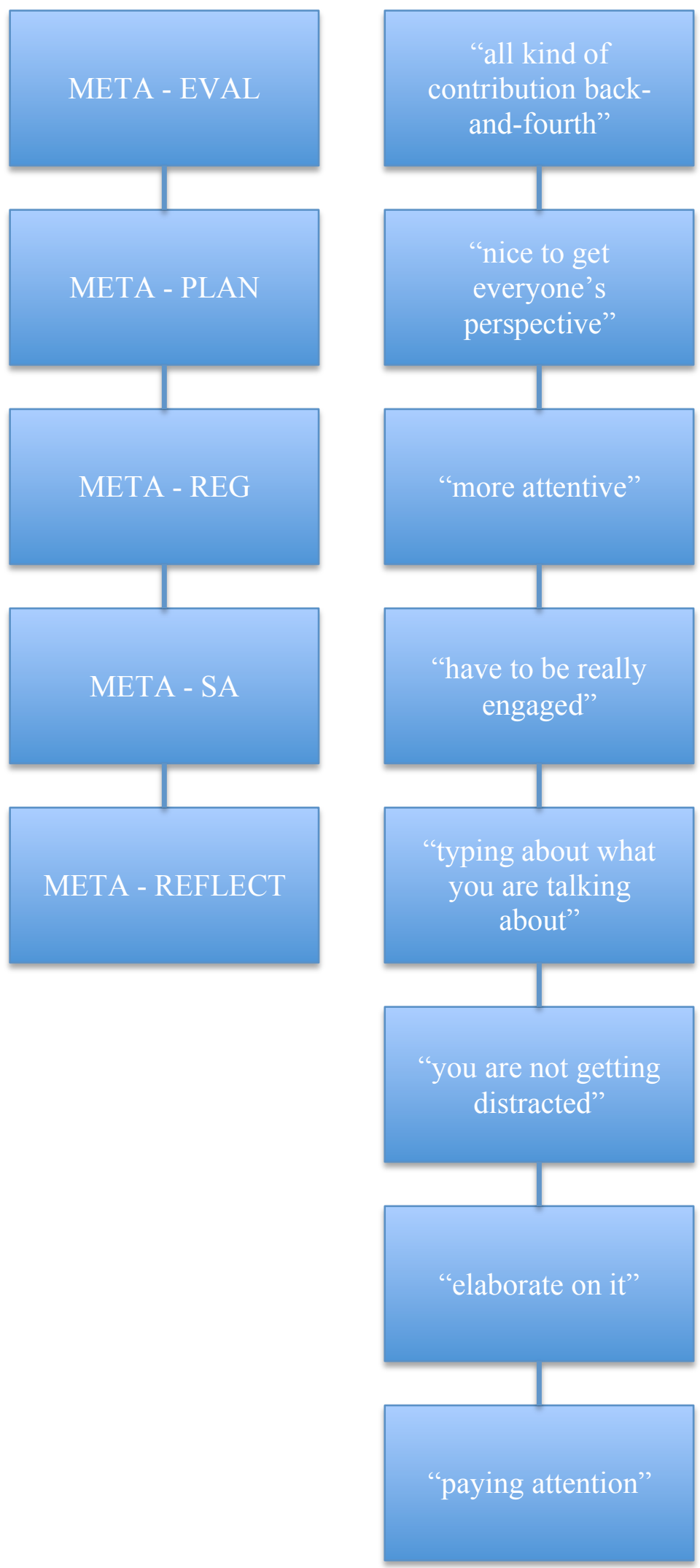
APPENDIX I

INSTRUCTOR MODERATED 
Category 5 - Instructor Moderated
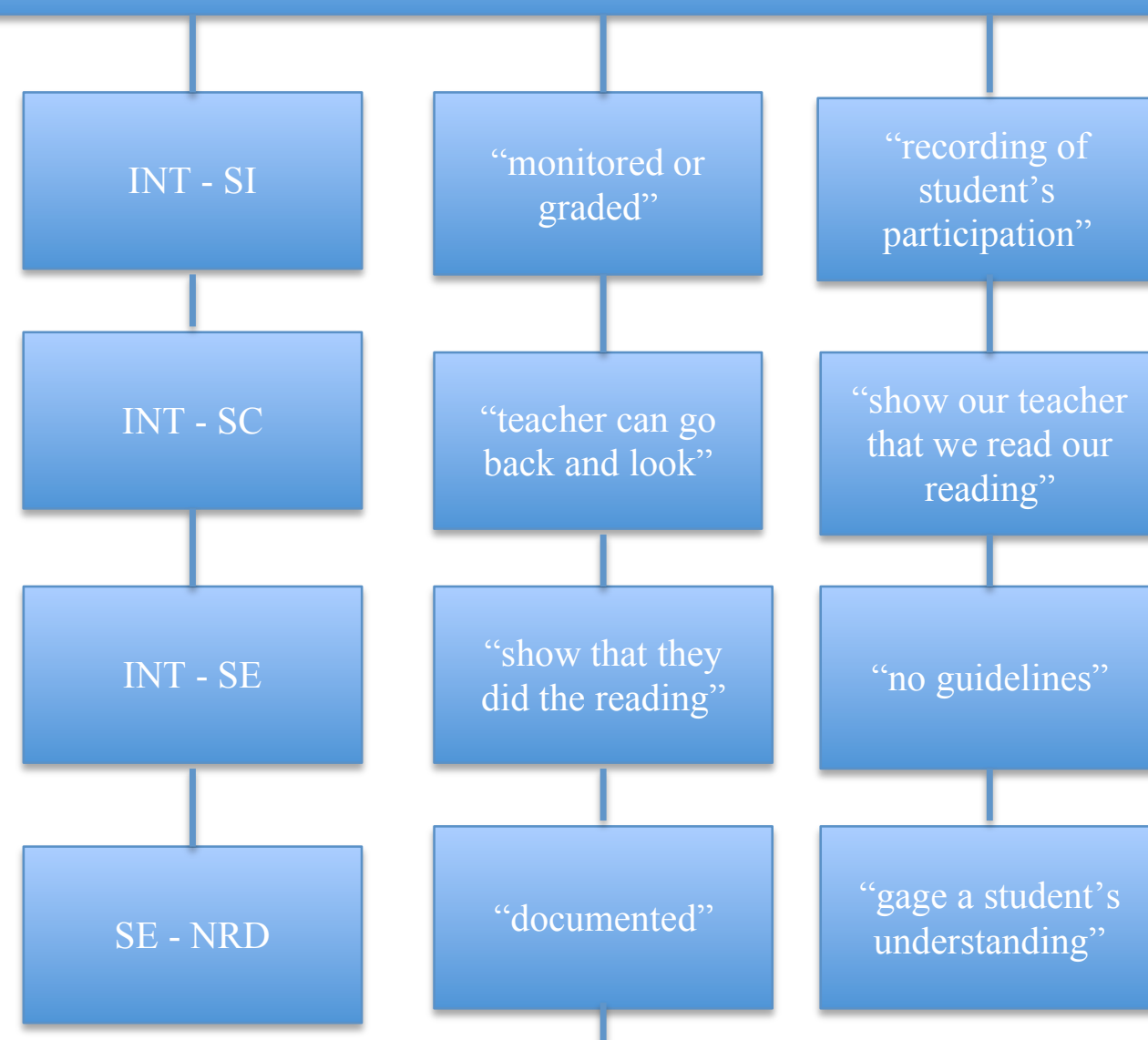

"teacher can go

back and look"

"show our teacher

that we read our

reading"
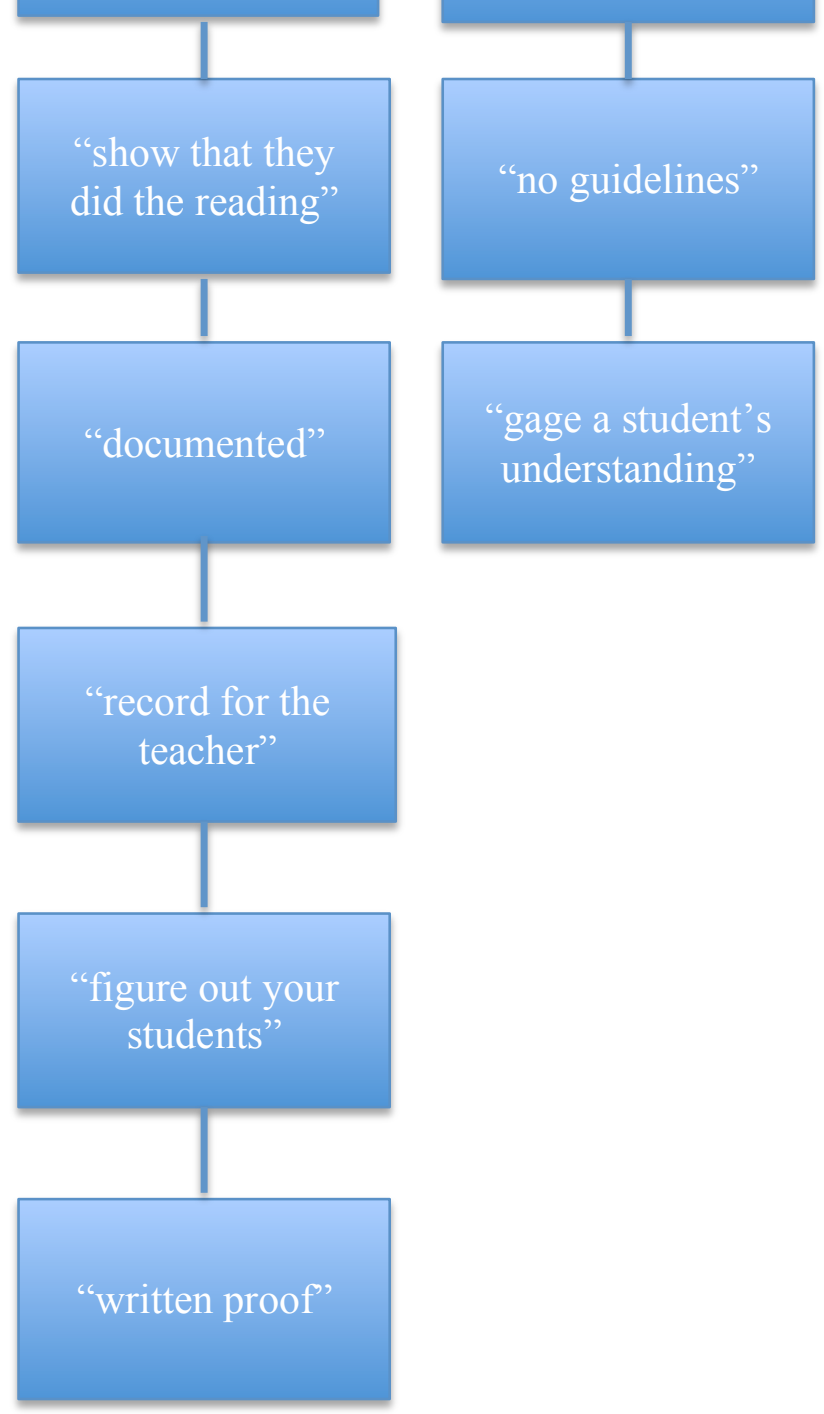
APPENDIX J

REFLECTIVE THINKING 


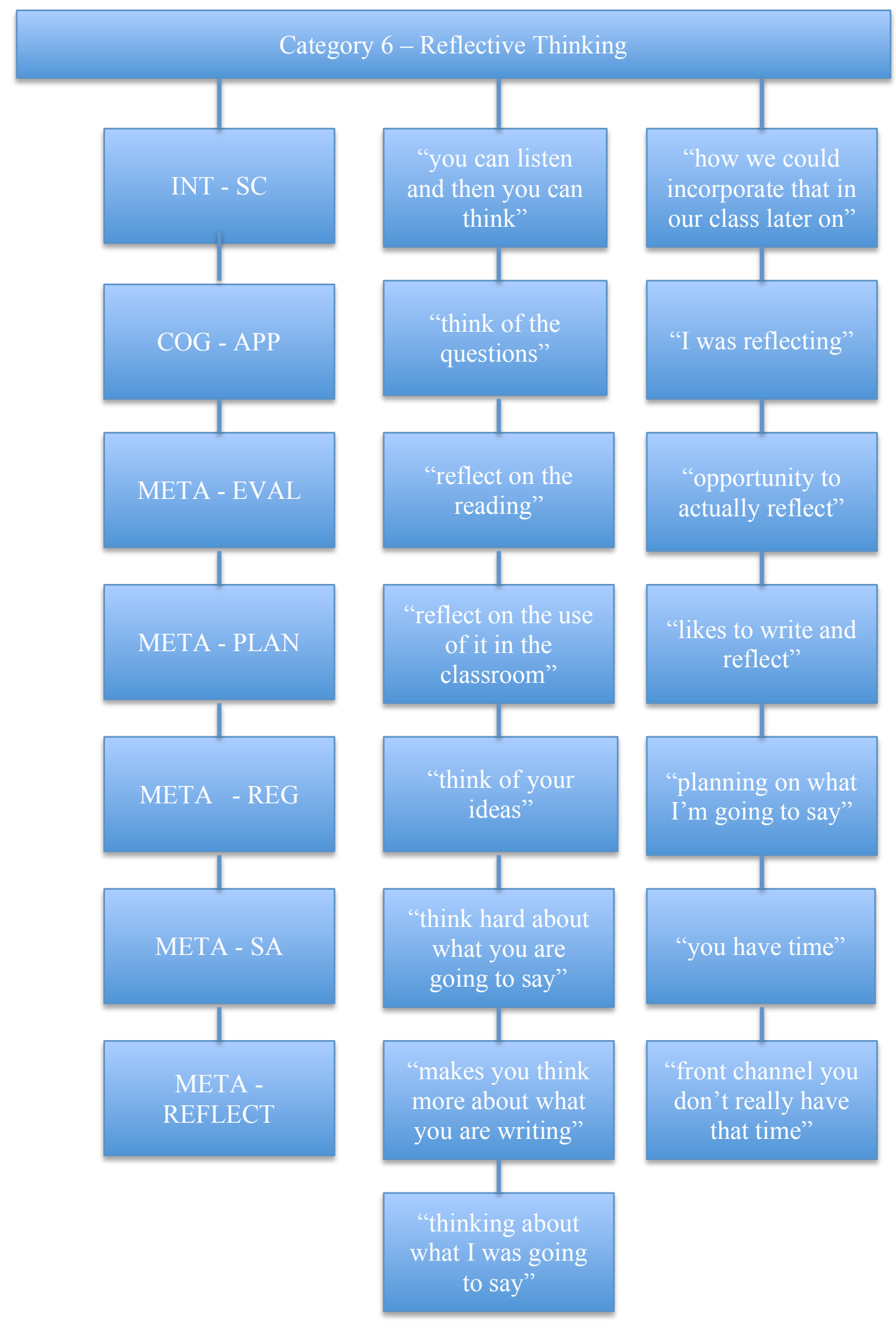




\begin{abstract}
APPENDIX K
STRUCTURE, DESIGN, AND INSTRUCTOR ROLE
\end{abstract}


Category 7 - Structure, Design, Instructor Role
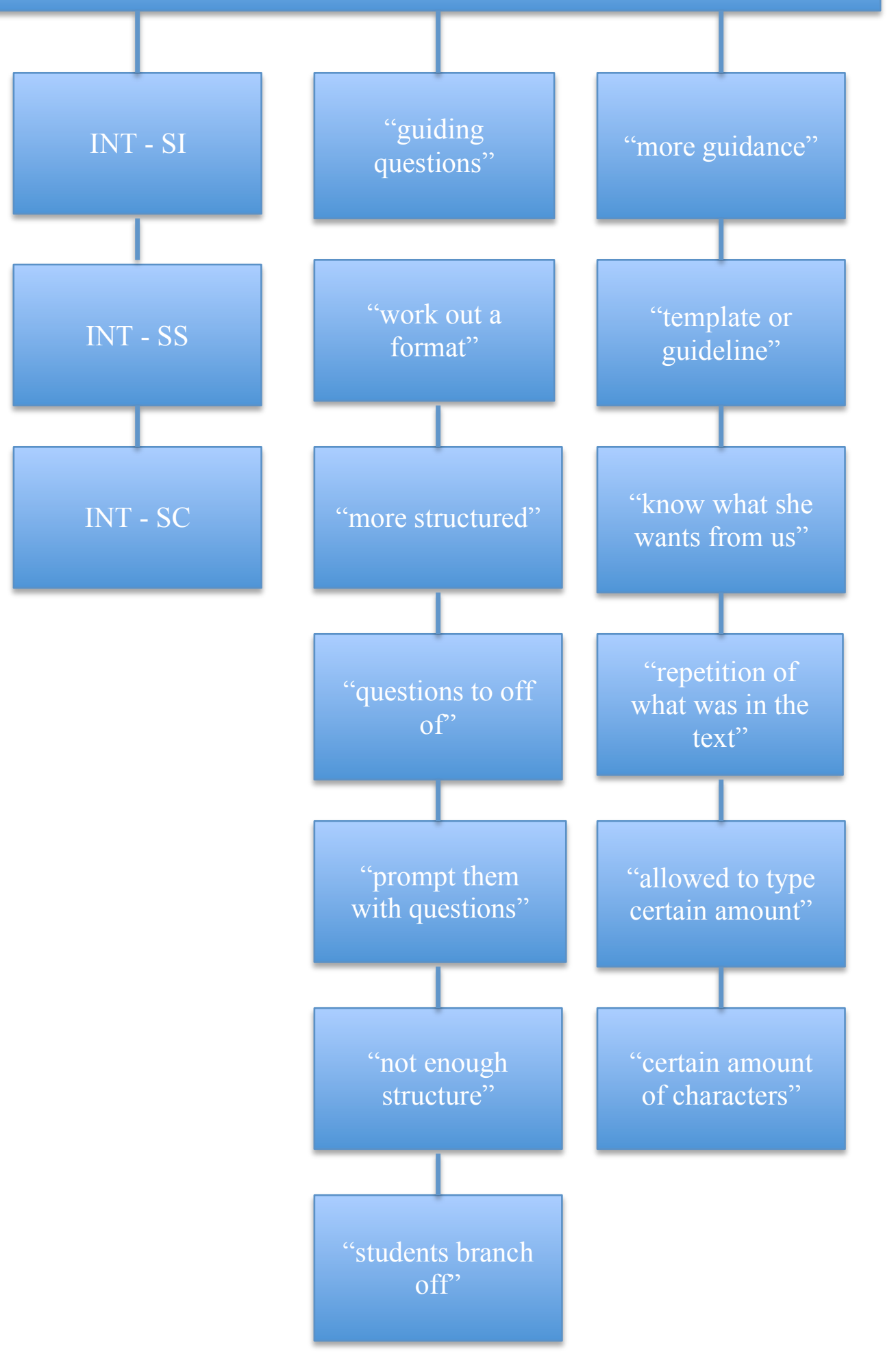


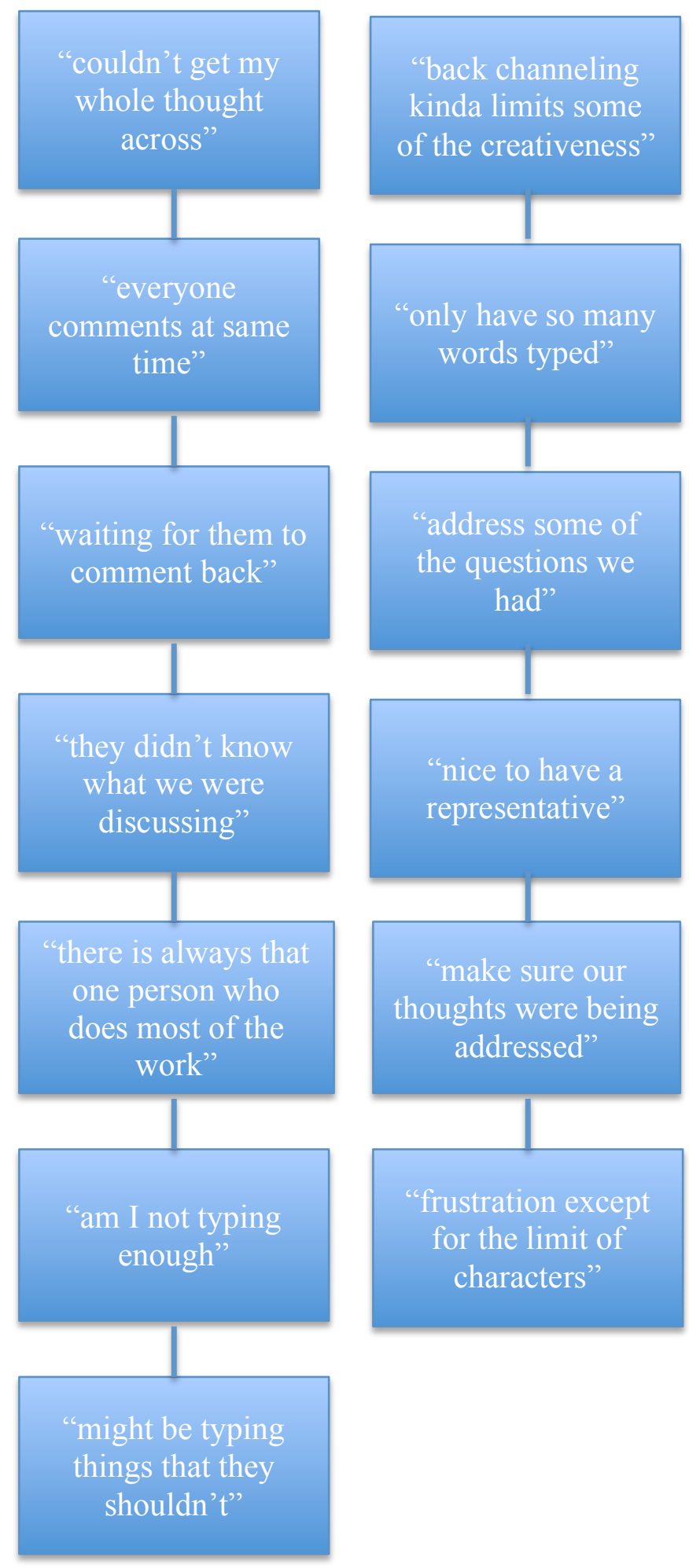


APPENDIX L

CONNECTION TO PRIOR LEARNING AND/OR LIVED EXPERIENCES 


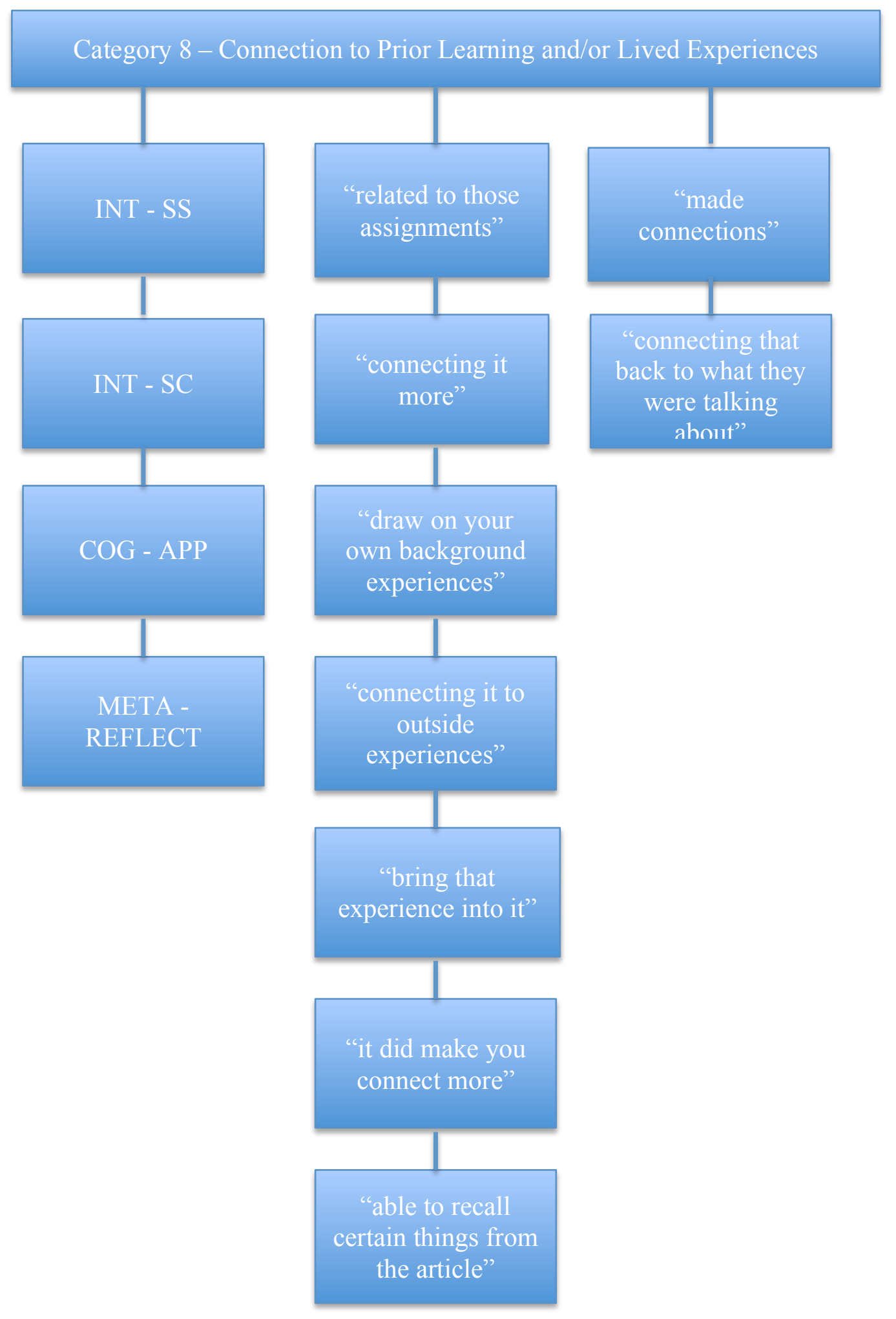


APPENDIX M

MULTI-TASKING DIFFICULT 


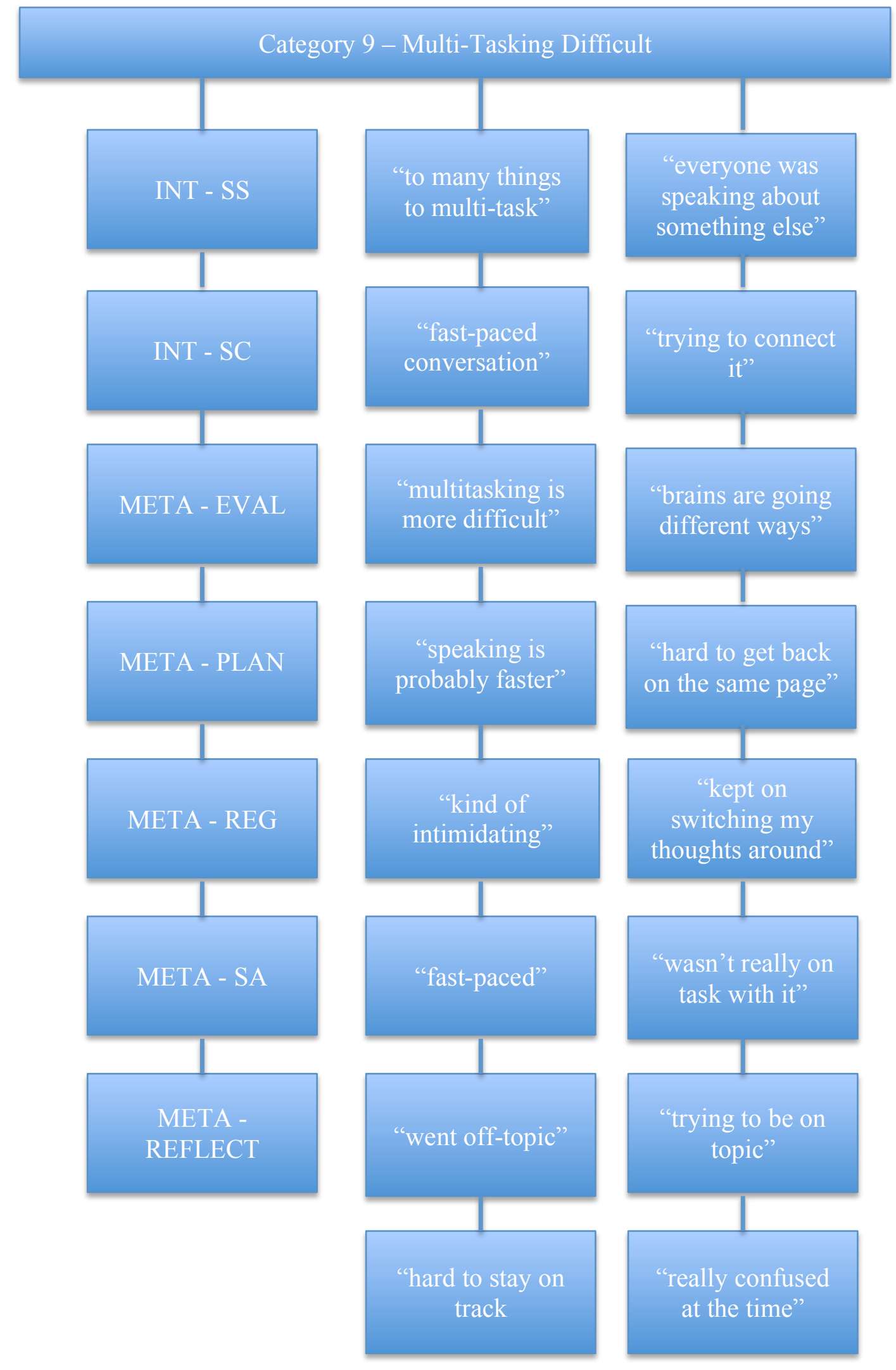




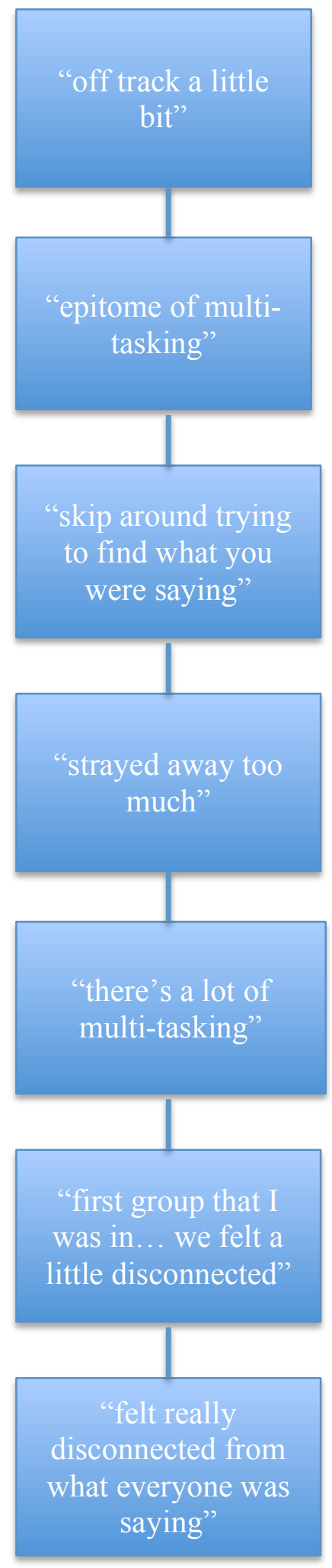


APPENDIX N

FLEXIBLE MODE FOR LEARNING 


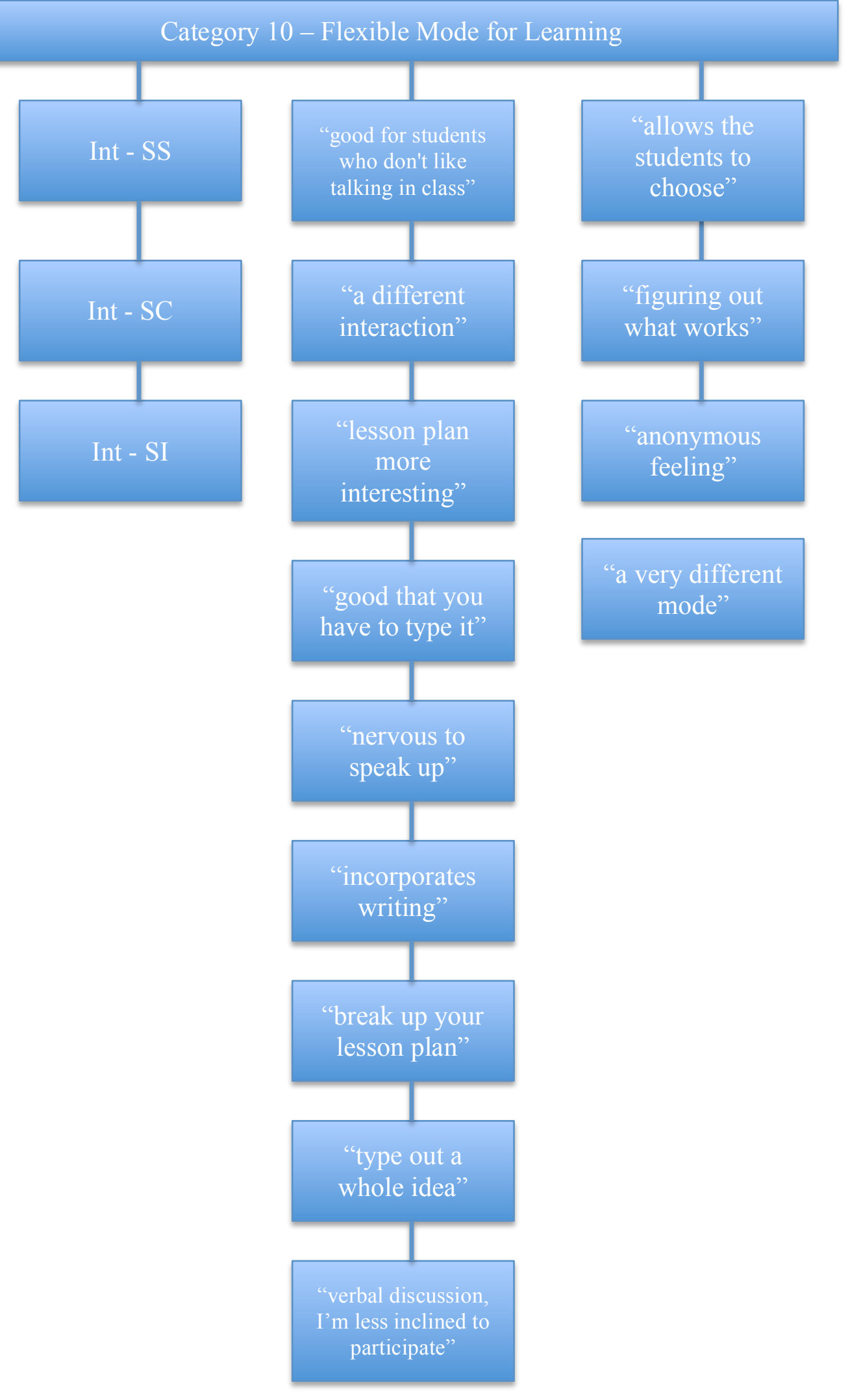


APPENDIX O

POSITIVE LEARNING EXPERIENCE 


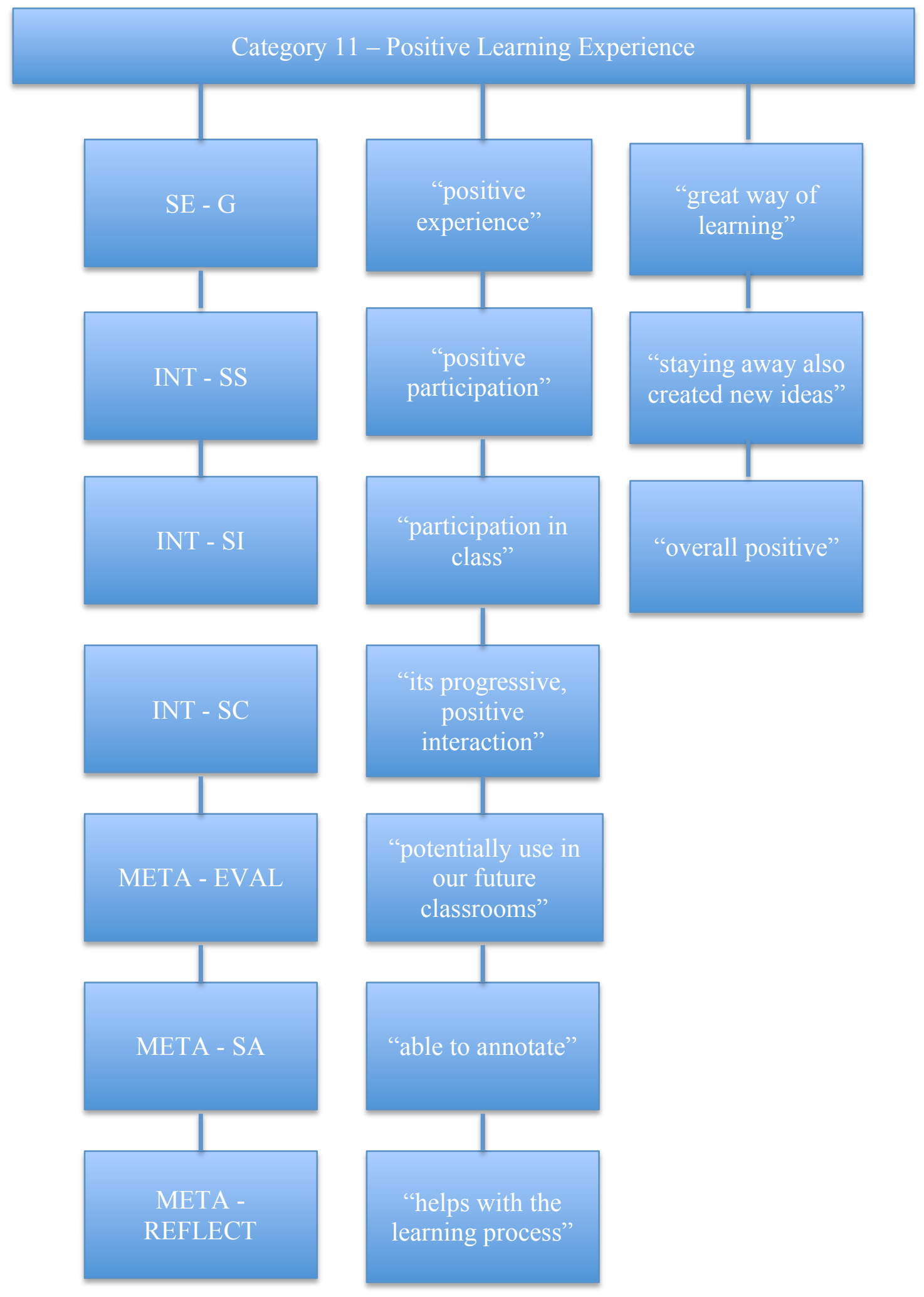


APPENDIX P

\section{CONTENT INFLUENCES INTERACTION}

AND FINAL ANALYSIS 
Category 12 - Content Influences Interaction
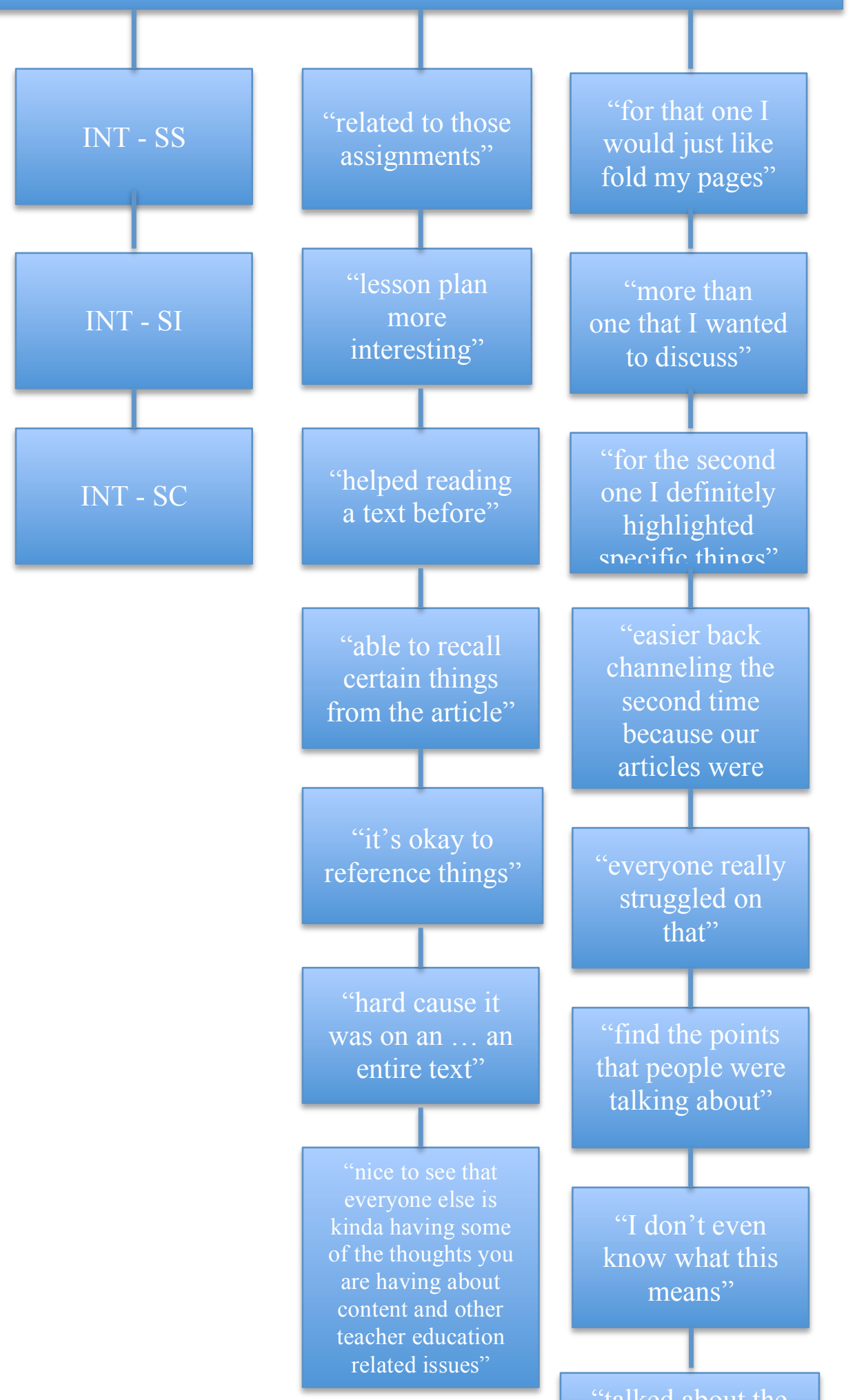

for that one I would just like fold my pages"

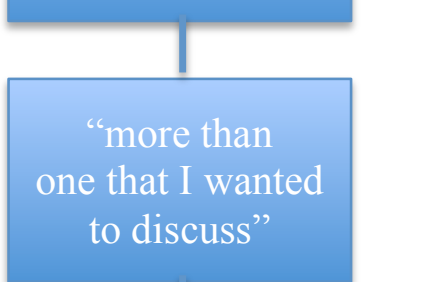

"for the second one I definitely highlighted snerific thinos"

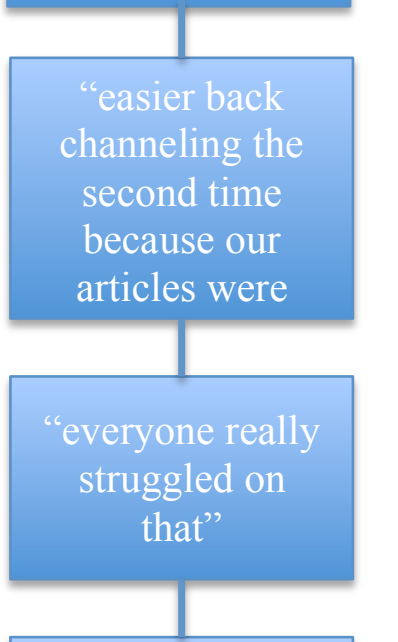

"find the points that people were talking about"

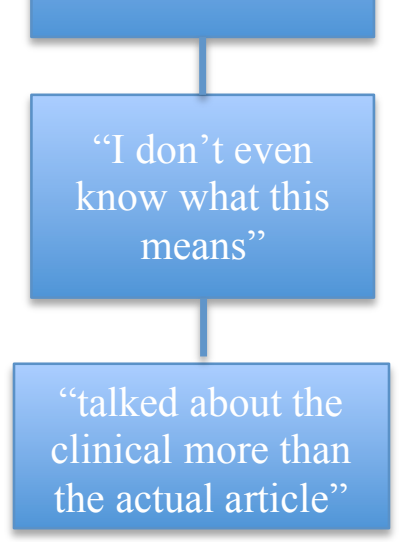




\section{Categories Resulted in 5 Main Themes}

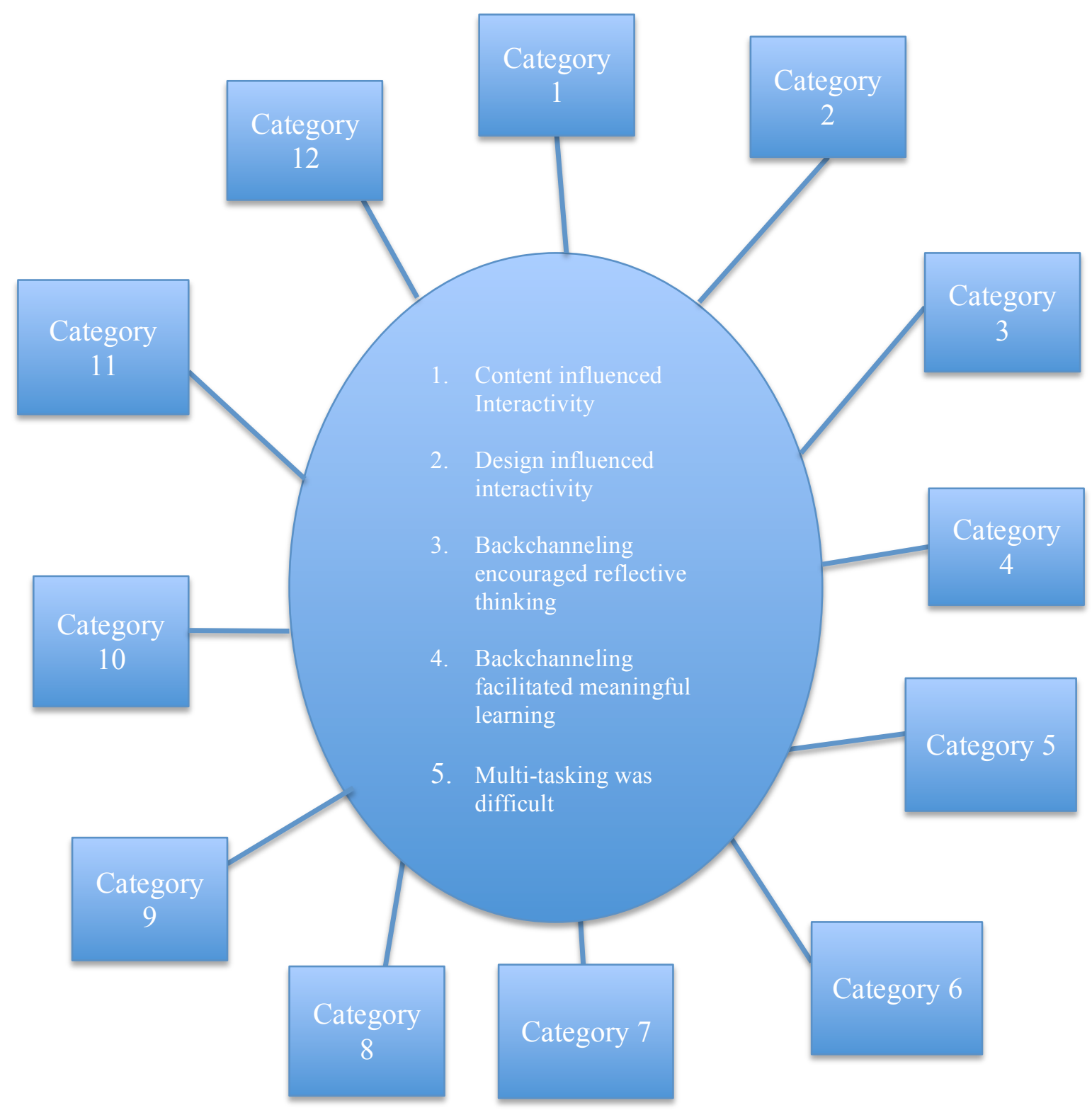

